\title{
The Development of an Insect Succession Model Suitable for Time-Since-Death Statistics
}

Anne E. Perez

Follow this and additional works at: https://researchrepository.wvu.edu/etd

\section{Recommended Citation}

Perez, Anne E., "The Development of an Insect Succession Model Suitable for Time-Since-Death Statistics" (2014). Graduate Theses, Dissertations, and Problem Reports. 7339.

https://researchrepository.wvu.edu/etd/7339

This Dissertation is protected by copyright and/or related rights. It has been brought to you by the The Research Repository @ WVU with permission from the rights-holder(s). You are free to use this Dissertation in any way that is permitted by the copyright and related rights legislation that applies to your use. For other uses you must obtain permission from the rights-holder(s) directly, unless additional rights are indicated by a Creative Commons license in the record and/ or on the work itself. This Dissertation has been accepted for inclusion in WVU Graduate Theses, Dissertations, and Problem Reports collection by an authorized administrator of The Research Repository @ WVU.

For more information, please contact researchrepository@mail.wvu.edu. 


\title{
The Development of an Insect Succession Model Suitable for Time- Since-Death Statistics
}

\author{
Anne E. Perez \\ Dissertation submitted to the Eberly College of Arts and Sciences \\ at West Virginia University \\ in partial fulfillment of the requirements for the degree of \\ Doctor of Philosophy in Biology \\ Jeffrey D. Wells, Ph.D., Chair \\ Rita V. M. Rio, Ph. D., Chair of Record \\ Kevin C. Daly, Ph. D. \\ Lynn R. LaMotte, Ph.D. \\ Keith B. Morris, Ph.D. \\ Department of Biology \\ Morgantown, West Virginia \\ 2014
}

Keywords: forensic entomology, succession interval, postmortem interval, intercarcass distance, accumulated degree hours, statistics

Copyright 2014 Anne E. Perez 
UMI Number: 3618314

All rights reserved

INFORMATION TO ALL USERS

The quality of this reproduction is dependent upon the quality of the copy submitted.

In the unlikely event that the author did not send a complete manuscript and there are missing pages, these will be noted. Also, if material had to be removed, a note will indicate the deletion.

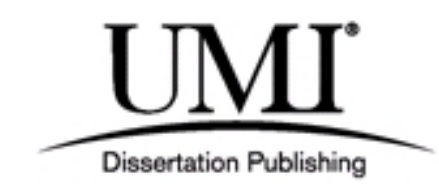

UMI 3618314

Published by ProQuest LLC (2014). Copyright in the Dissertation held by the Author.

Microform Edition () ProQuest LLC.

All rights reserved. This work is protected against unauthorized copying under Title 17, United States Code

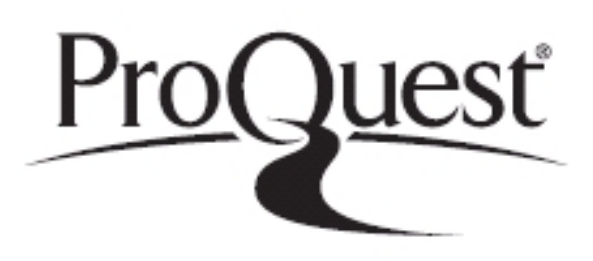

ProQuest LLC.

789 East Eisenhower Parkway

P.O. Box 1346

Ann Arbor, MI 48106 - 1346 


\begin{abstract}
The Development of an Insect Succession Model Suitable for Time-Since-Death Statistics
\end{abstract}

Anne E. Perez

For academic carrion insect succession studies to be applicable to forensic casework, the study must provide statistically defensible postmortem interval (PMI) estimates. Multiple statistical approaches have been used to describe insect succession, but no study to date has been able to determine a confidence interval about a succession based PMI estimate. The ability to reject PMI values, and thereby create a confidence interval is determined by statistical power, of which sample size is a positive correlate. A proposed model established prospective sample sizes for desired levels of statistical power, indicating a target sample size of $\sim 50$ carcasses for estimating PMI based on two carrion insect species (LaMotte and Wells 2000). A surrogate for human decomposition has been identified, the domestic pig, yet studies to date have failed to include more than 5 carcasses in a single treatment group. This lack of replication has lead to strictly observational findings that are unsuitable for forensic use. As replication of carcasses increases, in an attempt to generate a suitable reference insect succession dataset, additional obstacles are encountered. Constraints of time and space, as well as development of an appropriate species list and sampling procedure are of specific concern. Throughout a century of research concerning insect succession on carrion, issues central to development of large datatsets, including the effect of year, fine-scale spatial discrepancies, repeated sampling and intercarcass distance, remain largely unknown.

The use of temperature to describe succession is an additional area of succession research critical to casework application. Because temperature directly affects decomposition rates, insect development rates and insect activity, succession data collected across time and space (potentially experiencing differing temperature histories) may most accurately be described using a physiological time measure as compared to an absolute time measure. Further, succession described in physiological time may be more accurate for application to a case that occurred at a different time and location than the reference dataset. The proposed research aims to create a succession dataset that is suitable for statistical analysis and estimation of time since death by: (1) investigating current sampling methods as well as the assumption that succession is consistent among year and small-scale variation in location, (2) determination of minimum intercarcass distance to ensure independence of carcasses, (3) identifying candidate insect species appropriate for analytical methods prescribed by LaMotte and Wells (2000), and (4) assessing accuracy of PMI estimates using an absolute and physiological time measure. 


\section{Acknowledgements}

I would first like to thank my doctoral advisor, Jeffrey Wells, Ph.D. Leading by example, he inspires true passion and fearless defense of your science.

I would also like to thank my committee members, Rita, Kevin, Keith, and Lynn for their thoughtful comments and support throughout my graduate carreer.

I need to thank two additional mentors Neal Haskell, Ph.D., and Ken Schoenly, Ph.D. Without Neal, a study of this magnitude would not have been possible. He generously offered up his land, home, time and expertise to a very green graduate student. Ken was an extremely gracious resource for semivariogram analyses.

I am grateful to current and former Wells' lab members, Christine, Baneshwar, Lizmery, Miriam and Josh, as well as former fellow graduate students Stephanie, Sarah and John. A positive peerbased souding board is a necessity of graduate student life. Additionally I would like to thank the Biology Department staff: Mickey, Diana, Judy, Pat and Wendy. Each of these people, at one time or another, put a smile on my face and made my life a little easier.

Thanks to my husband Louie for embracing forensic entomology and tolerating the smell. 


\section{Table of Contents}

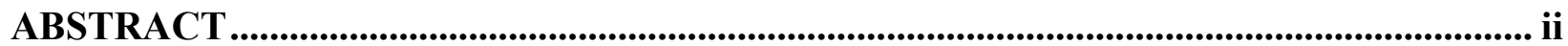

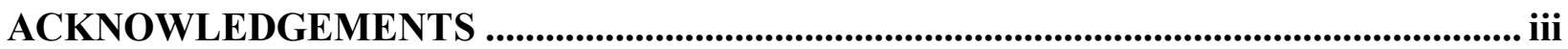

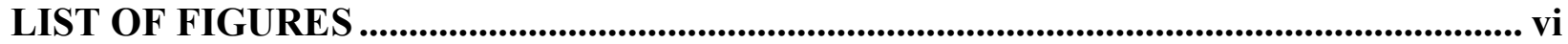

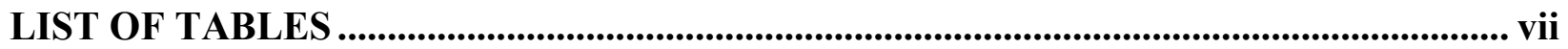

CHAPTER 1: General Introduction ............................................................................................1

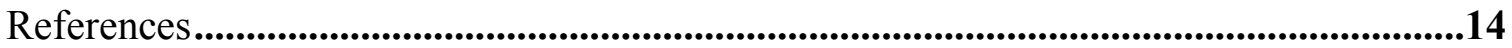

CHAPTER 2: Spatio-temporal and Sampling Effects on Carrion Insect Communities: Considerations for Generating Large Forensic Datasets

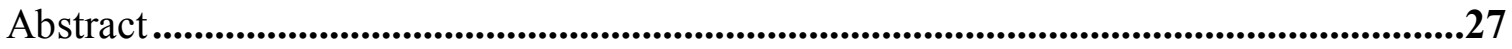

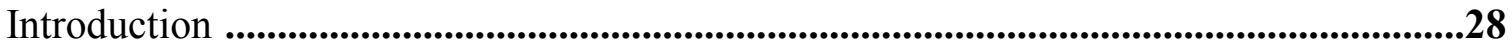

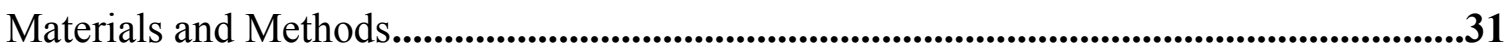

Results and Discussion ...............................................................................................................34

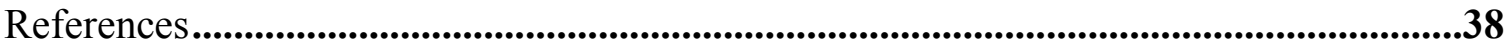

CHAPTER 3: Toward the Determination of Minimum Intercarcass Distance for Forensic Entomology Field Methodologies

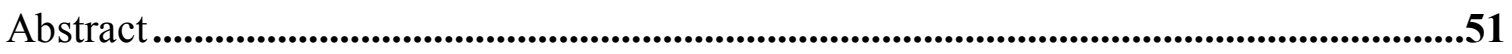

Introduction .........................................................................................................................51

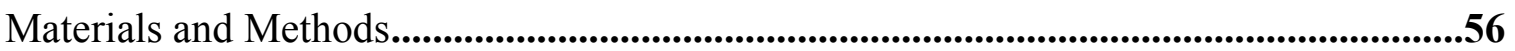

Results and Discussion .............................................................................................................59

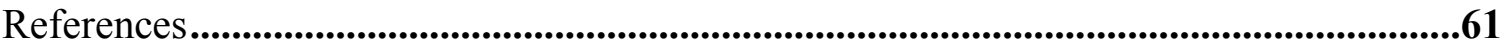

CHAPTER 4: Evaluating the Utility of Hexapod Species for Calculating a Confidence Interval about a Succession Based Postmortem Interval Estimate

Abstract .............................................................................................................................76

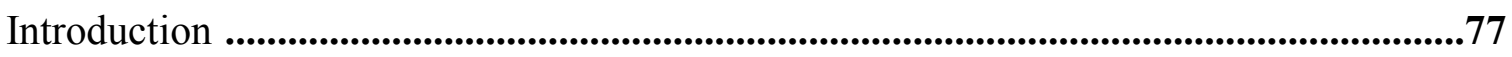

Materials and Methods..................................................................................................................80

Results and Discussion ................................................................................................................81 


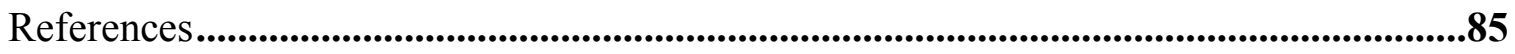

Acknowledgements ...................................................................................................102

Supplemental Table References.................................................................................105

CHAPTER 5: Precision and Accuracy of Succession Based Postmortem Interval Estimates Using a Physiological and an Absolute Time Measure

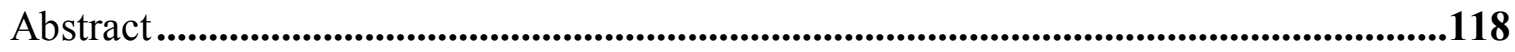

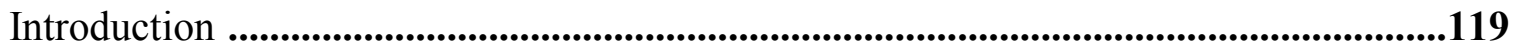

Materials and Methods.....................................................................................123

Results and Discussion ..................................................................................................................128

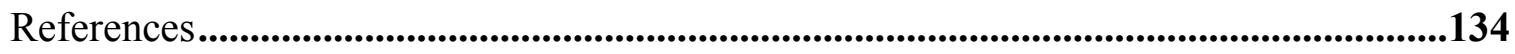

CHAPTER 6: Summary, Conclusions, and Recommendations .........................................152

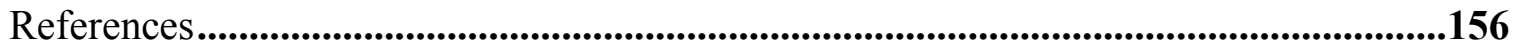




\section{List of Figures}

Figure 1.1: A hypothetical occurrence matrix .........................................................................26

Figure 2.1: Average Jaccard similarity index of within and among year pairwise comparisons 44

Figure 2.2: Average Jaccard similarity index of within and among woodlot pairwise

comparisons

Figure 2.3: Pairwise comparisons of control and experimental, day 7 since exposure, insect collections to days $4-11$..........................................................................................................46

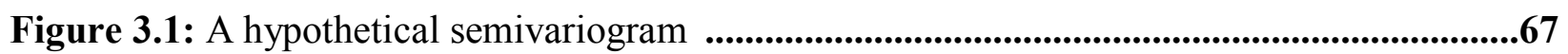

Figure 3.2: Frequency distribution of intercarcass distance ...............................................................68

Figure 3.3: The absence of a relationship between insect community similarity index and distance of pair-wise comparisons of pig carcasses

Figure 3.4: Relationship of $\mathrm{SI}_{\min }$ to distance and batch, as well as $\mathrm{SI}$ width to distance for 8 common and nonreoccuring species

Figure 3.5: Community similarity (measured as either Jaccard similarity index or Morisita's index) semivariograms for two years of data

Figure 3.6: $\mathrm{SI}_{\min }$ semivariograms of two selected forensically important species for two years of data

Figure 5.1: Graphical representations and associated equations of four hypothetical types of occurrence overlap .138

Figure 5.2: Average Daily ADH for exposure periods, each experienced by a different batch of pigs 


\section{List of Tables}

Table 2.S1: Collection time and daily collection order of 53 experimental pigs

Table 3.1 The coefficients of determination, equations and $p$-values of $\mathrm{H}_{0}: \beta_{1}=0$ for community similarity indices vs. pairwise distance

Table 3.2: The coefficients of determination and $p$-values of $\mathrm{H}_{0}: \beta_{1}=0$ for $\mathrm{SI}_{\min }$ vs. distance, $\mathrm{SI}_{\min }$ vs. carcass exposure order (Priming) and SI Width vs. distance.

Table 4.1: Distribution and published forensic utility of carrion insects that were observed on a

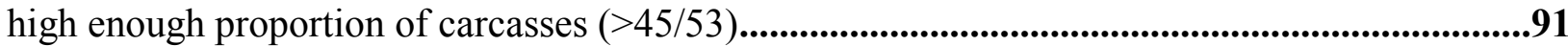

Table 4.2: Contingency tables based on the presence/absence of C. maxillosus $(\mathrm{Cm})$ adults, P.regina larvae $(\mathrm{Pr})$ and L. illustris larvae (Li). .

Table 4.3: Contingency tables based on the presence/absence of all possible two species combinations of C. maxillosus $(\mathrm{Cm})$ adults, P.regina larvae (Pr) and L. illustris larvae (Li).......93 Table 4.S1: List of beetle species collected from 53 pig corpses and reference used for identification.

Table 4.S2: List of fly species collected from 53 pig corpses and reference used for identification

Table 4.S3: List of non-fly and non-beetle species collected from 53 pig corpses and reference used for identification.

Table 4.S4: Reoccurrence frequency for each carrion species that was observed on a high enough proportion of carcasses ( $>45 / 53)$ for placing confidence limits on an estimation of postmortem interval .

Table 5.1: Average occurrence overlap for absolute (hours) and physiological (ADH) time measures

Table 5.2: Average relative presence period for absolute (hrs) and physiological (ADH) time measures.

Table 5.3: Statistically supported PMI widths calculated using one of three time measurement categories as column values in a contingency table; (1) days converted (\# of days contained in PMI width $\mathrm{X}$ average ADH experienced over the entire experimental period), (2) ADH mean 
(average $\mathrm{ADH}$ experienced over the entire experimental period and (3) ADH narrow (shortest $\mathrm{ADH}$ amount experienced in any 24 hour period over the entire experimental period)

Table 5.4: The accuracy of predictions intervals measured by the percentage of instances the PI contains either the entire SI (Entire) or each single observation within a SI (Single) of an experimental pig used for comparison.

Table 5.S1: Contingency tables for all abundant and nonreoccurring insect species, each created with a different column value: (a) 1 day, (b) $428 \mathrm{ADH}$ and (c) $547 \mathrm{ADH}$........................................14 


\section{Chapter 1: General Introduction}

\section{Estimation of Time Since Death and Forensic Entomology}

In criminal investigations, the amount of time elapsed since death, commonly referred to as the postmortem interval (PMI), is critical to establishing death case timelines. The appropriate approach to PMI estimation is context dependent. In the early postmortem interval, within $\sim 24$ hours (Cantenese et al. 2010), there are reliable techniques that utilize physical and physicochemical processes (Henssge and Madea 2007). During the subsequent portion of the postmortem interval, available techniques are less reliable and result in an estimation that widens as PMI increases. Forensic entomology can potentially be used for extended PMI estimations. While forensic entomology includes any intersection of insects and the law, the most common application is the estimation of PMI using the development of dipteran larvae (maggots) (Catts and Goff 1992). Under optimal circumstances, blow flies (Calliphoridae) and flesh flies (Sarcophagidae) will arrive at a corpse within minutes after death (Catts 1991, Catts 1992). Among these flies are gravid females that use the corpse as an oviposition site. Assuming that the deceased was not infested with maggots prior to death (myiasis) or maggots originating from a different oviposition site (e.g. adjacent garbage dumpster), the minimum PMI (PMI $\mathrm{min}_{\text {n }}$ ) can be determined by comparing attributes (i.e. length, weight) of a maggot collected from the corpse to experimentally generated development data for the same maggot species under similar environmental conditions (Williams 1984). 


\section{Forensic Insect Succession}

A second, much less common approach, (Nichols et al. 2011) compares the set of insect species/life stages in the corpse to a model of postmortem insect succession (Wells and LaMotte 2010). Simply stated, succession is a change in community composition over time (Drury and Nisbet 1973). Insect succession on carrion is dominated by two orders, Diptera and Coleoptera that use a corpse as: (1) a source of nutrition, (2) a mating site, (3) an oviposition site and (4) hunting ground (by predators and parasitoids). As the pioneering Calliphoridae and Sarcophagidae larvae decrease in number, larvae of other, less studied, taxa including Piophilidae, Sepsidae, Muscidae, Fannidae, and Sphaeroceridae (Byrd and Castner 2010) are collected. The Coleoptera of noted importance are: Silphidae, Staphylinidae, Nitidulidae, Cleridae, Histeridae, Dermestidae, and Trogidae. Adult silphid beetles arrive comparatively early during decomposition (Sharanowski et al. 2008) because the adult beetles are carrion eaters as well as predatory on maggots (Steele 1927). Similarly, their larvae are scavengers and predators of carrion insects (Ratcliff 1996). Opportunistic predators on carrion insects are present throughout decomposition including staphylinids, clerids, and histerids. In general, the latest arrivers are dermestid and trogid beetles (Anderson and VanLaerhoven 1996, Kocarek 2003) that can utilize parts of the corpse other insects cannot digest (e.g. dried skin, hair, cartilage) (Ratcliffe 1980).

A succession model describes the species and development stages present as a function of the amount of time the corpse has been accessible to insects (or other taxa should they be used for this purpose) at that location (Anderson 2010). For brevity, this time period is called the 
succession interval (SI) and it is equal to the actual PMI if an investigator is confident the remains were not significantly disturbed and the victim died where the remains were discovered. If there is indication that death and remains discovery occurred at disparate locations, the SI can be equal to the minimum PMI $\left(\mathrm{PMI}_{\min }\right)$. Even though the term SI was not used, the modern forensic use of the concept is outlined by Schoenly et al. (1992). Training data or baseline fauna of a specific geographical region is stored in an occurrence matrix (Figure 1). Each column of the occurrence matrix represents a period of time (days) and each row represents a taxon. Each cell of the matrix contains a one or zero, indicating the presence or absence of a taxon on a corpse through time. A collection of corpse fauna is compared to the baseline occurrence matrix and the lower and upper limit of the SI are defined by the first time and last time all corpse fauna are present together in the training data. This approach assumes no random variation of the succession pattern in a given set of experimental conditions, resulting in an estimate without confidence intervals.

\section{Forensic Science and Expert Testimony}

For expert testimony based on forensic entomology research, or any other forensic discipline, to be accepted in the United States federal court system it must be "scientifically valid" and reliable (Daubert v Merrell Dow Pharmaceuticals 1993). These are not legal terms, but when scientists apply them to an analytical method, valid is generally synonymous with accurate, and reliable means that the method gives consistent results (Cole 2006). Furthermore, Daubert outlined four conditions to help define the acceptability of scientific testimony. Expert testimony must be based on science that: (1) has a testable and tested hypothesis, (2) is peer-reviewed/published, (3) 
has known error rates, and (4) is generally accepted in the appropriate scientific community (a condition adopted from a previous decision, Frye v. United States 1923).

Even though nearly 20 years have passed since Daubert, many methods (including many based on forensic entomology) aimed at estimating PMI don't measure accuracy and precision and therefore fail to meet judicial standards (Madea 2005).

\section{Trends in Forensic Insect Succession Literature}

Studies repeatedly affirm that insect succession on carrion is "predictable" because of observed consistency of: (1) the sequence of carrion insect arrival (Anderson and VanLaerhoven 1996, Avila and Goff 1998, Arnaldos et al. 2005, Sharanowski 2008) (2) carrion insect arrival and departure times (Archer 2003), and (3) change in community composition (Catts 1992, Voss et al. 2009) on carrion exposed under similar conditions. Among similar and simultaneously exposed carcasses, observed variation in succession ranges from negligible (Anderson and VanLaerhoven 1996, Hobishack 1997, Leblanc and Strongman 2002) to considerable (Tantawi et al. 1996, Nelder et al. 2009). Minimal replication preventing the development of a forensically applicable succession dataset was noted (Voss et al. 2009) yet inadequate experimental designs persist (Michaud et al. 2012). It is not uncommon to have only one replicate per set of experimental conditions (Horenstein et al. 2010, Anton et al. 2011, Castro et al. 2012). While some authors used a much larger number of carcasses (i.e. 72 (Dillon 1997)), the carcass replicates per set of experimental conditions remained low (i.e. $\leq 5$ carcasses (Dillon 1997, Wang et al. 2008). The within group variance has to be quantified before the variance encountered among groups can be attributed to a studied factor. Another complicating factor is inconsistent presentation of data. Some authors pool data from multiple carcasses into a 
"representative" figure of the observed succession for presentation in publication (Tabor et al. 2004, Eberhardt and Elliot 2008, Wang et al. 2008, Kelly et al. 2009). The literature on carrion arthropod succession reveals a lack of replication within single studies, resulting in purely descriptive and anecdotal knowledge of carrion insect succession that is inappropriate for forensic use.

\section{Approaches to Estimate Time Since Death Using Insect Succession}

In the past decade there has been an increase in studies attempting to describe variability associated with PMI estimates based on SI (Schoenly et al. 1996) or a portion of SI (i.e. preappearance interval (Matuszewski 2011, 2012)). Methods using resampling statistics, specifically jackknifing and bootstrapping, can be used to assign confidence intervals to PMI estimations (Schoenly et al. 1996), but application is limited if the collected data is atypical, an unsubstantiable distinction given universally low replication ( $\leq 5$ carcasses). In addition, the probability of insect occurrence on a corpse can be described using logistic regression (Michaud and Moreau 2009). A possible flaw with these approaches is that they are based on datasets with potentially under-characterized variation because of extremely small sample sizes. Relative error can be used to assess the performance of models describing the pre-appearance interval of coleopteran species (Matuszewski 2011, 2012), but the overall predictive power of the model is not reported.

LaMotte and Wells (2000) proposed a method for attaching a confidence level to a successionbased PMI estimate. Unlike previous applications this model accommodates natural variation in 
insect succession in the same set of experimental conditions. The proposed model is a day-byday contingency table based on the presence/absence of selected categories of species. The model also shows that for a likely level of statistical significance and number of species, an experimental data set must be based on at least 50 carcasses in order to ever be able to exclude a PMI value in casework using the presence/absence combinations of two species. As the number of replicates increases in order to create a dataset suitable for generating a statistically supported estimation of time since death, many challenges arise concerning space and man-hours collecting and identifying specimens. Approaches to overcome these challenges include the determination of a meaningful subset of insect taxa, the effect of pooling data from carrion exposed across time, the effect of repeated sampling on one carcass, the appropriate inter-carcass distance to ensure independence of samples taken from different carcasses placed concurrently, and the appropriate implementation of a time measurement in an insect succession model.

\section{Development of an Insect Succession Dataset}

\section{Surrogate Models of Human Decomposition}

Human corpses for experiments are difficult to obtain, especially in high numbers, and require specific accredited locations for their outdoor exposure (Mann et al. 1990). Because of these barriers, researchers have chosen to use a range of carcass types including (e.g. guinea pigs (Voss et al. 2009), chickens, (Arnaldos et al. 2004a), cats (Early and Goff 1986), dogs (Reed 1958), goats (Wells and Greenberg 1994a), impalas (Ellison 1990) and alligators (Nelder et al. 2009)). Data collected from non-human decomposition models are used in forensic casework 
(Goff and Flynn 1991, Turchetto et al. 2001, Arnaldos et al. 2004b, Olivia and Ravioli 2004), yet relevance of these data is tenuous. For small carcasses $(20-100 \mathrm{~g})$ there is no effect of carcass size on community structure (Kuusela and Hanski 1982). However, studies with a wider range of carrion sizes have suggested otherwise (Denno and Cothran 1975, Braack 1987, Wells \& Greenberg 1994a). There is observed resource partitioning in some carrion fly (Denno and Cothran 1975, Braack 1987) and burying beetle (Scott 1998) species, resulting in preferential colonization of a carcass type. Small carcasses can be dominated by the species that arrives to the corpse first, but as the carcass size increases, the number of species inhabiting the corpse increases (Kneidel 1984, Wells and Greenberg 1994b). Carcass size can effect community composition throughout succession, a species arrival time can be delayed, or duration increased on larger carcass (Wells and Greenberg 1994a).

The animal that has gained the most support as a model for human decomposition is the domestic pig, Sus scrofa. Pig carcasses are very attractive as a decomposition model because they are comparatively cheap and easy to obtain in high numbers (Catts and Goff 1992, Goff 1992). There is not an effect of pig carcass weight on the decomposition or fauna attracted within a limited weight range (Hewadikaram and Goff 1991). A $23 \mathrm{Kg}$ pig is suggested as an ideal weight (Catts and Goff 1992) and in the only study to directly compare human and porcine corpses this size was supported as a model for human decomposition (Haskell et al. 2002). Initial comparisons have demonstrated similarity of arthropod taxa collected from human and pig cadavers, but very few comparisons have been made (Carvalho et al. 2000, Schoenly et al. 2007). While current work supporting the use of the domestic pig as a surrogate model for human 
decomposition is less than conclusive, preliminary studies for the application of succession studies executed with pigs to forensic cases are promising.

\section{Spatial and Temporal Variation}

Investigators often measured the effect of season (Carvalho and Linhares 2001, Centeno et al. 2002, Tabor et al. 2004, Sharanowski et al. 2008, Voss et al. 2009, Matuszewski et al. 2010), geographic location (Anderson 2010), and habitat (Dillon 1997, Richards and Goff 1997, Davis and Goff 2000, Matuszewski et al. 2008, Voss et al. 2009) on succession pattern. Yet year-toyear and fine-scale spatial variation have been largely uninvestigated. The dependence of insect succession on year has important implications for applying baseline data from one year to casework in another. Inferring an effect from published studies is difficult because of insufficient replication (Tabor et al. 2004) and low occurrence resolution due to diffuse sampling schemes (Archer 2003, Voss et al. 2009).

There are observed differences among habitats within the same general geographic location (Davis and Goff 2000, Eberhardt and Elliot 2008, Voss et al. 2009), but it is unclear whether differences in succession arise between distinctly separate, but characteristically similar sites, within the same habitat and geographic location. This is a required area of further study not only due to the space requirements necessary for exposure of $\sim 50$ pigs, but also to justify the application of baseline data generated in disparate sites within a broader geographic area. If there is negligible variation in succession attributable to sites in the same geographical location, carcasses within a reasonably tight proximity could be pooled into the same treatment group, 
allowing ample space for exposure sites. Considerable variation among characteristically similar exposure sites would suggest a need for an increased number of placement site location characterizations to compose a dataset reflective of inter-site variability.

\section{Effect of Repeated Sampling}

Commonly, insect succession studies involve repeated samples of a carcass over time. Destructive sampling, exhaustively characterizing all specimens on carcasses at varying days postmortem, presents major logistical challenges because of the large number of insects involved. Control carcasses, left un-sampled, appear to decay at the same rate and have similar insect activity as sampled carcasses (Anderson and VanLaerhoven 1996, Dillon 1997, Eberhardt and Elliot 2008, Sharanowski et al. 2008, Segura et al. 2009, Segura et al. 2011). Quantitative studies found no effect of repeated sampling on biomass of insect fauna or carcass (De Jong et al. 2011) or overall taxon number in rat carcasses (De Jong and Hoback 2006). However, an a posteriori power analysis of the models used by De Jong and Hoback (2006) revealed inadequate sample sizes to detect significant differences (Michaud and Moreau 2013). Intense repeated sampling of maggots (i.e. $45-55 \%$ reduction of larval masses per day) can slow physical decomposition and differentially affect abundance of adult taxa (Michaud and Moreau 2013). While most field studies do not quantify sampling intensity of "representative" samples (subsamples thought to include at least one individual of all taxa in the carcass) (Davis and Goff 2000, Eberhardt and Elliot 2008, Sharanowski et al. 2008) this sampling scheme seems to oversample in comparison to many succession studies (i.e. 50-100 maggots/sample (Tabor et al. 2004, Wang et al. 2008, Kelly et al. 2009). No effect of sampling on decomposition or selected 
taxon abundance was observed for intentionally modest maggot sampling schemes (i.e. $\geq 5 \%$ reduction of larval masses per day) (Michaud and Moreau 2013), but the effect of repeated sampling of a community, one that includes the collection of adults and immatures, remains uncharacterized.

\section{Effective Intercarcass Distance}

For an investigator, both space and time are optimized as the distance between corpses decreases, but increasing the distance between corpses presumably promotes independence of carrion insect activity. For within site placement, $100 \mathrm{~m}$ between carcasses was suggested (Schoenly et al. 1991) but commonly corpses are placed $\leq 50 \mathrm{~m}$ apart (e.g. Anderson and VanLaerhoven 1996, Avila and Goff 1998, Archer and Elgar 2003, Tabor et al. 2004, Eberhardt and Elliot 2008, Segura et al. 2009, Voss et al. 2009, Michaud and Moreau 2009, and Matuszewski et al. 2010). This distance seems sufficient to prevent cross-contamination by post-feeding larvae (Greenberg 1990, Lewis and Benbow 2011), but given the high mobility of carrion-seeking adult insects (Bishopp and Laake 1921, Gilmour et al. 1946, MacLeod and Donnelly 1963, Mayer and Atzeni 1993, Roslin 2000, Tomlin et al. 2006) a concern is that $>1$ corpse will "compete" for the same insects. The minimum intercorpse distance to ensure independent carcasses is an urgent area of study, as independence of experimental units is a common assumption of many statistical approaches and is yet to be tested (Michaud et al. 2012) 


\section{Determination of Useful Insect Taxa for an Insect Succession Model}

Choosing which insects are the best forensic indicators is an arduous task due to the presence of 100s of species (Payne 1965) and 10,000s to 100,000s of individuals on any one corpse (Schoenly et al. 2007, Braak 1984). There are many ways to narrow datasets, including limiting taxa to those that are: sarcosaprohagous (Shahid et al. 2003), used to estimate postmortem intervals in previous studies (Schoenly et al. 2007), present as immatures, if the adults are not directly dependent on carrion (Kulshresthra and Satpathy 2001, Lefebvre and Gaudry 2009), reared from experimental carcasses (Carvalho et al. 2000), nonreoccurring taxa (Schoenly 1992), taxa with comparatively narrow PMI widths (Matuszewski et al. 2010) or by excluding insects that are thought to be collected simply by chance, i.e. not included if only collected $<2 \mathrm{x}$ (Lefebvre and Gaudry 2009) or from too few carcasses (Archer 2003). For the intended analysis (LaMotte and Wells 2000) the most basic criteria are collection from practically every carcass exposed and nonreoccurrence.

Insect development and activity are temperature dependent. For carrion insects this is determined by ambient temperature, sunlight, and in some cases metabolic heat generated by a mass of larvae. This creates a problem when selecting a succession model if crime scene temperatures do not match the reference experiment, as they seldom do. One possible way to apply reference data to insects with a different temperature history is to measure development or succession as thermal units rather than absolute time. At intermediate temperatures insect developmental rates often approximate a linear function of temperature. Under those conditions a particular number 
of accumulated degree hours (ADH) are required to reach a given developmental stage, and ADH can be calculated from any temperature profile (Higley and Haskell 2010).

\section{Accumulated Degree Hours}

$\mathrm{ADH}$ is used in agriculture to predict phenology of both plants and their insect pests and has been proposed to estimate the time since death for many non-insect related postmortem processes that are temperature dependent, including: accumulation of chemical markers of decomposition (Vass et al. 2002), RNA degradation in tooth pulp (Young et al. 2013), and the physical decomposition process (Megyesi et al. 2005, Simmons et al. 2010, Michaud and Moreau 2011). Seminal work describing temperature dependent development of forensically relevant flies dates back to the 1950's (Kamal 1958) and use of ADH in forensic entomology to estimate time since death in the United States dates back to 1985 (Greenberg 1985). The use of $\mathrm{ADH}$ in estimating time since death from blow fly development is validated by one study (VanLaerhoven 2008) and showed utility in multiple case studies (Greenberg 1985, Lord et al. 1986a, Lord et al. 1986b). There is some support for the use of ADH to predict the occurrence of specific insect species on a corpse (Michaud and Moreau 2009, Matuszewski 2011,2012), but ADH has not been used in place of absolute time in a succession model. While there are many thermal models an investigator could chose, an ADH model is a logical place to begin the assessment of temperature incorporation into a succession model. 
Many avenues of insect succession research are continually investigated, but those areas at the heart of its practical application to forensic work remain largely unstudied. Questions addressed by this work will include (1) the effect of year, fine-scale spatial variation, and repeated sampling on succession, (2) determination of effective intercarcass spacing (3) identification of a manageable and meaningful subset of the carrion insect community and (4) implementation and assessment of ADH performance in an insect succession model. Given all of the above, and the possible impact it may have on future insect succession field studies, I completed a research project that examined insect succession on $>50$ replicate pig carcasses leading to the development of a reference dataset that can be used to estimate a statistically supported PMI. 


\section{References}

Anderson GS and SL VanLaerhoven. 1996. Initial studies on insect succession on carrion in southwestern British Columbia. Journal of Forensic Science 41(4): 617-625.

Anderson GS. 2010. Factors that influence insect succession on carrion, in: Byrd JH and JL Castner eds., Forensic Entomology: The Utility of Arthropods in Legal Investigations, $2^{\text {nd }}$ Edition, CRC Press, Boca Raton, FL pp. 201-250.

Anton E, S Niederegger and RG Beutel. Beetles and flies collected on pig carrion in an experimental setting in Thuringia and their forensic implications. 2011. Medical and Veterinary Entomology 25(4): 353-364.

Archer MS. 2003. Annual variation in arrival and departure times of carrion insects at carcasses: implications for succession studies in forensic entomology. Australian Journal of Zoology 51: 569-576.

Archer MS and MA Elgar. 2003. Yearly activity patterns in southern Victoria (Australia) of seasonally active carrion insects. Forensic Science International 132: 173-176.

Arnaldos MI, E Romera, JJ Presa, A Luna and MD Garcia. 2004a. Studies on seasonal arthropod succession on carrion in the southeastern Iberian Peninsula. International Journal of Legal Medicine 118: 197-205.

Arnaldos MI, F Sanchez, P Alvarez and MD Garcia. 2004b. A forensic entomology case from the southeastern Iberian Peninsula. Aggrawal's Internet Journal of Forensic Medicine and Toxicology 5(1): 22-25.

Arnaldos MI, MD Garcia, E Romera, JJ Presa and A Luna. 2005. Estimation of postmortem interval in real cases based on experimentally obtained entomological evidence. Forensic Science International 149: 57-65. 
Avila FW and ML Goff. 1998. Arthropod succession patterns onto burnt carrion in two contrasting habitats in the Hawaiian Islands. Journal of Forensic Science 43(3): 581-586.

Bishopp FC and LW Laake. 1921. Dispersion of flies by flight. Journal of Agricultural Research 21: 729-766.

Braack LEO. 1984. An ecological investigation of the insects associated with exposed carcasses in the northern Kruger National Park: a study of populations and communities. Ph.D. Thesis. University of Natal Pietermaritzburg, South Africa.

Braack LEO. 1987. Community dynamics of carrion-attendant arthropods in tropical African woodland. Oecolgica 72(3): 402-409.

Byrd JH, and JL Castner. 2010. Insects of forensic importance, in: Byrd JH and JL Castner eds., Forensic Entomology: The Utility of Arthropods in Legal Investigations, $2^{\text {nd }}$ Edition, CRC Press, Boca Raton, pp. 39-126.

Cantenese CA, B Levy and G Cantenese. 2010. Postmortem change and time of death in: Cantenese CA ed., Color Atlas of Forensic Medicine and Pathology. CRC Press, Boca Raton, FL,USA, pp. 111-148.

Carvalho LML, PJ Thyssen, AX Linhares and FAB Palhares. 2000. Checklist of arthropods associated with pig carrion and human corpses in southeastern Brazil. Memórias do Instituto Oswaldo Cruz 95:135-138.

Carvalho LML and AX Linhares. 2001. Seasonality of insect succession and pig carcass decomposition in a natural forest area in southeastern Brazil. Journal of Forensic Science 46(3): 604-608. 
Castro CPe, A Serrano, P Martins de Silva and MD Garcia. 2012. Carrion flies of forensic interest: a study of seasonal community composition and succession in Lisbon, Portugal. Medical and Veterinary Entomology 26(4): 417-431.

Catts EP. 1991. Analyzing entomological data. In Entomology and death: A procedural guide. Catts EP and NH Haskell Eds. Forensic Entomology Partners, Clemson, SC, USA, 182 pp.

Catts EP. 1992. Problems in estimating the postmortem interval in death investigations. Journal of Agricultural Entomology 9(4): 245-255.

Catts EP and ML Goff. 1992. Forensic entomology in criminal investigations. Annual Review of Entomology 37: 253-72.

Centeno N, M Maldonado and A Olivia. 2002. Seasonal patterns of arthropods occurring on sheltered and unsheltered pig carcasses in Buenos Aires Province (Argentina). Forensic Science International 126: 63-70.

Cole SA. 2006. Is fingerprint identification valid? Rhetorics of reliability in fingerprint proponents' discourse. Law and Policy 28(1): 109-135.

Davis JB and ML Goff. 2000. Decomposition patterns in terrestrial and intertidal habitats on Oahu Island and Coconut Island, Hawaii. Journal of Forensic Sciences 45(4): 836-842.

De Jong GD and WW Hoback. 2006. Effect of investigator disturbance in experimental forensic entomology: succession and community composition. Medical and Veterinary Entomology 20: 248-258.

De Jong GD, WW Hoback and LG Higley. 2011. Effect of investigator disturbance in experimental forensic entomology: carcass biomass loss and temperature. Journal of Forensic Sciences 56(1): 143-149. 
Denno RF and WR Cothran. 1975. Niche relationships of a guild of necrophagous flies. Annals of the Entomological Society of America 68(4): 741-754.

Dillon LC. 1997. Insect succession on carrion in three biogeoclimatic zones of British Columbia. Masters' Thesis. Simon Frasier University, Canada.

Drury WH and ICT Nisbet. 1973. Succession. Journal of the Arnold Arboretum 54(3): 331-368.

Early M and ML Goff. 1986. Arthropod succession patterns in exposed carrion on the island of O’ahu, Hawaiian Islands, USA. Journal of Medical Entomology 23(5): 520-531.

Eberhart TL and DL Elliot. 2008. A preliminary investigation of insect colonization and succession on remains in New Zealand. Forensic Science International 176: 217-223.

Ellison GTH. 1990. The effect of scavenger mutilation on insect succession at impala carcasses in southern Africa. Journal of Zoology 220(4): 679-688.

Gilmour D, DF Waterhouse and GA McIntyre. 1946. An account of experiments undertaken to determine the natural population density of the sheep blowfly, Lucilia cuprina Wied. Council for Scientific and Industrial Research Organisation Bulletin 195.

Goff ML. 1992. Problems in estimation of postmortem interval resulting from wrapping of the corpse: a case study from Hawaii. Journal of Agricultural Entomology 9(4): 237-243.

Goff ML and MM Flynn. 1991. Determination of postmortem interval by arthropod succession: a case study from the Hawaiian Islands. Journal of Forensic Sciences 36(2): 607-614.

Greenberg B. 1985. Forensic Entomology: Case Studies. The Bulletin of the Entomological Society of America 31(4): 25-28.

Greenberg B. 1990. Flies as forensic indicators. Journal of Medical Entomology (13): 565-577. 
Haskell NH, KG Schoenly and RD Hall. 2002. Testing reliability of animal models in research and training programs in forensic entomology, part II. Final Report, Grant 97-IJ-CX-0046. U.S. National Institute of Justice, Washington, DC.

Henssege C and B Madea. 2007. Estimation of the time since death. Forensic Science International 165: 182-184.

Hewadikaram KA and ML Goff. 1991. Effect of carcass size on rate of decomposition and arthropod succession patterns. The American Journal of Forensic Medicine and Pathology 12(3): $235-240$.

Higley LG and NH Haskell. 2010. Insect Development and Forensic Entomology in: The Utility of Arthropods in Legal Investigations, $2^{\text {nd }}$ edition. JH Byrd and JL Castner eds. CRC Press, Boca Raton, FL, USA, pp. 389-403.

Hobischak NR. 1997. Freshwater invertebrate succession and decompositional studies on carrion in British Colombia. Master's Thesis. Simon Fraser University.

Horenstein MB, AX Linhares, BR De Ferradas and D Garcia. 2010. Decomposition and dipteran succession in pig carrion in central Argentina: ecological aspects and their importance in forensic science. Medical and Veterinary Entomology 24(1): 16-25.

Kamal AS. 1958. Comparative study of thirteen species of sarcosaprophagous Calliphoridae and Sarcophagidae (Diptera). I. Bionomics. Annals of the Entomological Society of America 51: 261-270.

Kelly JA, TC van der Linde and GS Anderson. 2009. The influence of clothing and wrapping on carcass decomposition and arthropod succession during the warmer seasons in central South Africa. Journal of Forensic Science 54(5): 1105-1112. 
Kneidel KA. 1984. Influence of carcass taxon and size on species composition of carrion breeding-diptera. American Midland Naturalist 111(1): 57-63.

Kocarek P. 2003. Decomposition and Coleoptera succession on exposed carrion of small mammal in Opava, the Czech Republic. European Journal of Soil Biology 39: 31-45.

Kulshresthra P and DK Satpathy. 2001. Use of beetles in forensic entomology. Forensic Science International 120: 15-17.

Kuusela S and I Hanski. 1982. The structure of carrion fly communities: the size and type of carrion. Holartic Ecology 5: 337-348.

LaMotte LR and JD Wells. 2000. $p$-values for postmortem intervals from arthropod succession data. Journal of Agricultural, Biological, and Environmental Statistics 5(1): 58-68.

Leblanc H and D Strongman. 2002. Carrion insects associated with small pig carcasses during fall in Nova Scotia. Canadian Society of Forensic Science Journal 35(3): 145-152.

Lefebvre F and E Gaudry. 2009. Forensic entomology: a new hypothesis for the chronological succession pattern of necrophagous insect on human corpses. Annales de la Société Entomologique de France 45(3): 377-392.

Lewis AJ and ME Benbow. 2011. When entomological evidence crawls away: Phormia regina en masse larval dispersal. Journal of Medical Entomology 48(6): 1112-1119.

Lord WD, EP Catts, DA Scarboro and DB Hadfield. 1986a. The green blowfly, Lucilia illustris as an indicator of human postmortem interval: a case of homicide from Fort Lewis, Washington. Bulletin of the Society of Vector Ecologists 11:271-275. 
Lord WD, RW Johnson and F Johnston. 1986b. The blue bottle fly, Calliphora vicina (=erythrocephala) as an indicator of human post-mortem interval: a case of homicide from suburban Washington, D.C. Bulletin of the Society of Vector Ecologists 11: 276-280.

MacLeod J and J Donnelly. 1963. Dispersal and interspersal of blowfly populations. Journal of Animal Ecology 32(1): 1-32.

Madea B. 2005. Is there recent progress in the estimation of the postmortem interval by means of thanatochemistry? Forensic Science International 151: 139-149.

Mann MA, WM Bass and L Meadows. 1990. Time since death and decomposition of the human body: variables and observations in case and experimental field studies. Journal of Forensic Sciences 35(1): 103-111.

Matuszewski S, D Bajerlein, S Konwerski and K Szpila. 2008. An initial study of insect succession and carrion decomposition in various forest habitats of Central Europe. Forensic Science International 180: 61-69.

Matuszewski S, D Bajerlein, S Konwerski and K Szpila. 2010. Insect succession and carrion decomposition in selected forests of Central Europe. Part 1: Pattern and rate of decomposition. Forensic Science International 194: 85-93.

Matuszewski S. 2011. Estimating the pre-appearance interval from temperature in Necrodes littoralis L. (Coleoptera: Silphidae). Forensic Science International 212: 180-188.

Matuszewski S. 2012. Estimating the pre-appearance interval from temperature in Creophilus maxillosus L. (Coleoptera: Staphylinidae). Journal of Forensic Sciences 57(1): 136-145.

Mayer DG and MG Atzeni. 1993. Estimation of dispersal distances for Cochliomyia hominovorax (Diptera: Calliphoridae). Environmental Entomology 22: 368-374. 
Megyesi MS, SP Nawrocki and NH Haskell. 2005. Using accumulated degree days to estimate the postmortem interval from decomposed human remains. Journal of Forensic Sciences 50(3): 618-626.

Michaud JP and G Moreau. 2009. Predicting the visitation of carcasses by carrion-related insects under different rates of degree-day accumulation. Forensic Science International 185: 78-83.

Michaud JP and G Moreau. 2011. A statistical approach based on accumulated degree-days to predict decomposition-related processes in forensic studies. Journal of Forensic Science 56(1): 229-232.

Michaud JP, KF Schoenly and G Moreau. 2012. Sampling flies or sampling flaws? Experimental design and inference strength in forensic entomology. Journal of Medical Entomology 49(1): 110.

Michaud JP and G Moreau. 2013. Effect of variable rates of daily sampling of fly larvae on decomposition and carrion insect community assembly: implications for forensic entomology field study protocols. Journal of Medical Entomology 30(4): 890-897.

Nelder MP, JW McCreadie and CS Major. 2009. Blow flies visiting decaying alligators: Is succession synchronous or asynchronous? Psyche 2009: doi:10.1155/2009/573362, 7 pp.

Nichols AE, JD Wells and NH Haskell. 2011. Presentation: The Current Use and Research Investigating Succession for Determining the Postmortem Interval. American Academy of Forensic Sciences (AAFS), Chicago, IL.

Olivia A and JA Ravioli. 2004. Conscript Carrasco: a peacetime casualty. Aggrawal's Internet Journal of Forensic Medicine and Toxicology 5(1): 45-49.

Payne JA. 1965. A summer carrion study of the baby pig Sus scrofa Linnaeus. Ecology 46 (5): $592-602$. 
Ratcliffe BC. 1980. A matter of taste or the natural history of carrion beetles. University of Nebraska-Lincoln News 59(31):1-4.

Ratcliffe BC. 1996. The carrion beetles (Coleoptera: Silphidae) of Nebraska. Bulletin of the University of Nebraska State Museum 13: 1-98.

Reed HB, Jr. 1958. A study of dog carcass communities in Tennessee, with special reference to the insects. American Midland Naturalist 59(1): 213-245.

Richards EN and ML Goff. 1997. Arthropod succession on exposed carrion in three contrasting tropical habitats on Hawaii Island, Hawaii. Journal of Medical Entomology 34(3): 328-339.

Roslin T. 2000. Dung beetle movements at two spatial scales. Oikos 91(2): 323-335.

Schoenly KG, K Griest and S Rhine. 1991. An experimental field protocol for investigating the postmortem interval using multidisciplinary indicators. Journal of Forensic Sciences 36(5): 1395-1415.

Schoenly KG. 1992. A statistical analysis of successional patterns in carrion-arthropod assemblages: implications for forensic entomology and determination of the postmortem interval. Journal of Forensic Sciences 37(6): 1489-1513.

Schoenly KG, ML Goff and M Early. 1992. A BASIC algorithm for calculating the postmortem interval from arthropod successional data. Journal of Forensic Sciences 37(3): 808-823.

Schoenly KG, ML Goff, JD Wells and WD Lord. 1996. Quantifying statistical uncertainty in succession-based entomological estimates of the postmortem interval in death scene investigations: a simulation study. American Entomologist 42(20): 106-112. 
Schoenly KG, NH Haskell, RD Hall and JR Gbur. 2007. Comparative performance and complimentarity of four sampling methods and arthropod preference tests from human and porcine remains at the forensic anthropology center in Knoxville, Tennessee. Journal of Medical Entomology 44(5): 881-894.

Scott MP. 1998. The ecology and behavior of burying beetles. Annual Review of Entomology 43: 595-618.

Segura NA, W Usaquén, MC Sánchez, L Chuaire and F Bello. 2009. Succession pattern of cadaverous entomofauna in a semi-rural area of Bogotá, Columbia. Forensic Science International 187: 66-72.

Segura NA, MA Bonilla, W Usaquén, and F Bello. 2011. Entomofauna resource distribution associated with pig cadavers in Bogotá DC. Medical and Veterinary Entomology 25: 46-52.

Shahid SA, K Schonely, NH Haskell, RD Hall and W Zhang. 2003. Carcass enrichment does not alter decay rates or arthropod community structure: a test of the arthropod saturation hypothesis at the anthropological research facility in Knoxville, Tennessee. Journal of Medical Entomology 40(4): 559-569.

Sharanowski BJ, EG Walker and GS Anderson. 2008. Insect succession and decomposition patterns on shaded and sunlight carrion in Saskatchewan in three different seasons. Forensic Science International 179: 219-240.

Simmons T, RE Adlam and C Moffatt. 2010. Debugging decomposition data- comparative taphonomic studies and the influence of insects and carcass size on decomposition rate. Journal of Forensic Sciences 55(1): 8-13.

Steele BF. 1927. Notes on the feeding habits of carrion beetles. Journal of the New York Entomological Society 35(1): 77-81. 
Tabor KL, CC Brewster and RD Fell. 2004. Analysis of the successional patterns of insects on carrion in southwest Virginia. Journal of Medical Entomology 41(4): 785-795.

Tantawi TI, EM El-Kady, B Greenberg and HA El-Ghaffar. 1996. Arthropod succession on exposed rabbit carrion in Alexandria, Egypt. Journal of Medical Entomology 33: 566-80.

Tomlin AD, DGR McLeod, LV Moore, JW Whistlecraft, JJ Miller and JH Toleman. 2006. Dispersal of Aleochata bilineata (Coleoptera: Staphylinidae) following inundative releases in urban gardens. Entomophaga 37(1): 55-63.

Turchetto M, S Lafisca and G Constantini. 2001. Postmortm interval (PMI) determined by study sarcophagous biocenoses: three cases from the province of Venice (Italy). Forensic Science International 120: 28-31.

VanLaerhoven SL. 2008. Blind validation of postmortem interval estimates using developmental rates of blow flies. Forensic Science International 180: 76- 80.

Vass AA, S-A Baishick, G Sega, J Caton, JT Skeen, JC Love and JA Systelien. 2002. Decomposition chemistry of human remains: a new methodology for determining the postmortem interval. Journal of Forensic Science 47(3): 542-553.

Voss SC, H Spafford and IR Dadour. 2009. Annual and seasonal patterns of insect succession on decomposing remains at two locations in Western Australia. Forensic Science International 193: 26-36.

Wang J, Z Li, Y Chin, Q Chin and X Yin. 2008. The succession and development of insects on pig carcasses and their significances in estimating PMI in south China. Forensic Science International 179: 11-18. 
Wells JD and B Greenberg. 1994a. Effect of the red imported fire ant (Hymenoptera:

Formicidae) and carcass type on the daily occurrence of postfeeding carrion-fly larvae (Diptera:

Calliphoridae, Sarcophagidae). Journal of Medical Entomology 31(1): 171-174.

Wells JD and B Greenberg. 1994b. Resource use by an introduced and native carrion flies.

Oecologia 99: 181-187.

Wells JD and LR LaMotte. 2010. Estimating the postmortem interval in: Forensic Entomology:

The Utility of Arthropods in Legal Investigations, $2^{\text {nd }}$ edition. JH Byrd and JL Castner eds. CRC Press, Boca Raton, FL, USA, pp. 367-384

Williams H. 1984. A model for the aging of fly larvae in forensic entomology. Forensic Science International 25(3): 191-199.

Young ST, JD Wells, GR Hobbs and CP Bishop. 2013. Estimating postmortem interval using RNA degradation and morphological changes in tooth pulp. Forensic Science International 229: 163.e1-163.e6.

\section{Cases Cited}

Daubert v. Merrell Dow Pharmaceuticals, 509 US 579 (1993)

Frye v. United States, 54 App. D.C. 46 (1923) 


\begin{tabular}{|c|c|c|c|c|c|c|c|c|}
\hline & & & ost & em & rva & & & \\
\hline & Day & 1 & 2 & 3 & 4 & 5 & 6 & 7 \\
\hline Taxon A & & 0 & 0 & 0 & 0 & 0 & 1 & 1 \\
\hline Taxon B & & 0 & 0 & 1 & 1 & 1 & 1 & 1 \\
\hline Taxon C & & 1 & 1 & 1 & 0 & 0 & 0 & 0 \\
\hline Taxon D & & 0 & 0 & 1 & 1 & 0 & 0 & 0 \\
\hline Taxon E & & 0 & 1 & 1 & 0 & 0 & 0 & 0 \\
\hline Taxon $\mathrm{F}$ & & 0 & 0 & 0 & 1 & 1 & 1 & 0 \\
\hline
\end{tabular}

Figure 1. Hypothetical occurrence matrix (adapted from Schoenly et al. 1992) 


\title{
Chapter 2: Spatio-temporal and Sampling Effects on Carrion Insect Communities: Considerations for Generating a Large Forensic Dataset
}

\begin{abstract}
Frequently published descriptions of carrion insect succession in different geographical areas, habitats and seasons highlight large-scale, spatio-temporal variation in insect succession. Forensic investigators aim to use reference datasets that most closely mirror crime scene conditions, but application to casework lags because associated postmortem interval (PMI) estimates lack statistical support. Almost universally, insect succession studies contain low replication ( $\leq 5$ carcasses/experimental conditions), undoubtedly hindering the use of models capable of attaching probabilities to PMI estimates. Larger datasets can be obtained if data are pooled from the same season of different years exposed in characteristically similar locations. This coupled with the common practice of repeatedly sampling the same carcass aids in overcoming constraints of space, time and carcass availability. Effects of interannual variation, variation among characteristically similar sites and repeated sampling on succession remain largely uncharacterized. A common metric of succession comparison among carcasses, the Jaccard similarity index, was used to compare insect communities of 53 repeatedly sampled pig carcasses, placed over 3 years in 3 characteristically similar sites. This study found significant variation in community similarity across years and sites, as well as a negative effect of repeated sampling on succession rate. This understudied spatio-temporal variation and effect of repeatedly sampling must be incorporated or addressed in reference datasets. Succession data collection for forensic application should span multiple years and sites as well as avoid comprehensive species collection, as crime scenes are not equal to experimental exposure sites in space and time.
\end{abstract}




\section{Introduction}

Most commonly forensic entomologists are employed to estimate time since death or the postmortem interval (PMI) (Catts and Goff 1992). There are two general entomological approaches to make this estimate: (1) development and (2) succession. Both are inferential approaches based on the comparison of collections made at a death scene to experimental data generated under similar conditions. Since the earliest arrivers to a corpse (blow flies and flesh flies) use it as an oviposition/larviposition site, physical aspects of the developing maggots (e.g. weight, length) are compared to species-specific laboratory generated development data to provide an estimate of the minimum amount of time elapsed since death or $\mathrm{PMI}_{\text {min }}$ (Williams 1984). Estimates using succession are based on the comparison of the insect community collected at a crime scene to experimentally generated data of insect community changes on a corpse through time (Wells and LaMotte 2010).

In comparison to development, noted advantages of using succession-based PMI estimations include: (1) encompassing the time elapsed before insect arrival, thereby estimating both a minimum and maximum PMI (given the corpse was not moved) and (2) the previous development of methods to provide statistically supported PMI estimates (LaMotte and Wells 2000). A large difference between development and succession studies, affecting succession study applicability, is the experimental location; developmental data are commonly acquired in a laboratory setting and succession data are obtained in the field. In succession fieldwork there are constraints of time, space, and corpse availability. To deal with these constraints it is common for investigators to: (1) repeatedly sample from the same corpse (De Jong and Hoback 2006, 
Michaud et al. 2012, Michaud and Moreau 2013), (2) use non-human carrion subjects (Catts and Goff 1992), and (3) simultaneously expose a limited number of carcasses. But with each of these field-practical solutions comes analytical considerations.

Destructive sampling, exhaustively characterizing all specimens on carcasses at varying days postmortem, presents major logistical challenges because of the large number of insects involved (1,000s of individuals per carcass (Braack 1984, Schoenly et al. 2007) and 100s of taxa (Payne 1965)). Consequently, investigators commonly make repeated samples of a given carcass over time in order to describe succession. Unsampled control carcasses appear to decay at the same rate and have similar insect activity as repeatedly sampled carcasses (Anderson and VanLaerhoven 1996, Dillon 1997, Eberhardt and Elliot 2008, Sharanowski et al. 2008, Segura et al. 2009, Segura et al. 2011). Recent authors highlight the need for quantitive treatment of repeated sampling and demonstrate preliminary support for the current practice; among smaller carcasses (i.e. rat carcasses) there is no effect of repeated sampling on overall taxon number (De Jong and Hoback 2006) and removing $\leq 5 \%$ of eggs and larvae present does not affect abundance of many carrion insects (Michaud and Moreau 2013). Using a community similarity index, like the Jaccard similarity index (JSI) is a common method of determining the similarity of succession among carcasses (Schoenly and Reid 1987, Schoenly 1992, Tabor et al. 2004, Shi et al. 2009) because it is based on presence/absence data (as opposed to abundance), and is easily calculable by dividing the total number of taxa shared by two corpses by the total number of taxa collected. The effect of sampling on succession rate can be determined from the JSI values of repeatedly sampled corpses compared to previously unsampled control corpses. 
Because human corpses for experiments are difficult to obtain, especially in high numbers, and require specific accredited locations for their outdoor exposure, pig carcasses are commonly used as a decomposition model (Mann et al. 1990). Pig corpses are comparatively cheap, easy to obtain in high numbers, and there is preliminary experimental support for their use as a surrogate for human decomposition (Carvalho et al. 2000, Haskell et al. 2002, and Schoenly et al. 2007). However, the constraints of time, space, and corpse availability have collectively led to low sample sizes among studies using pig carcasses (at most a replication of 5 in an experimental treatment (Dillon 1997, Wang et al. 2008)). This lack of replication has led to only a preliminary understanding of the inherent variation in forensic insect succession.

In the literature, observations of little to no variation among carcasses placed at the same time (Anderson and VanLaerhoven 1996, Hobishack 1997, Leblanc and Strongman 2002), contrast against indications that succession on carcasses in the same conditions can vary widely (Reed 1958, Tantawi et al. 1996). In any analysis the within group variance has to be quantified before the variance encountered among groups can be attributed to a studied factor (e.g. wrappings, sunlight, or location). Variability in succession has not been empirically characterized for pigs exposed to similar conditions leaving many studies purely descriptive and anecdotal, as well as inappropriate for forensic use.

A possible avenue to obtain larger training datasets is to pool data collected from the same or similar locations exposed at similar times (i.e. same season of different years), a practice encouraged by recent authors to increase the inferential power of a succession dataset (Michaud et al. 2013). The effect of geographic location has been widely recognized to affect succession 
patterns (Anderson 2001), but it is unclear whether differences in succession (and to what degree) arise between distinctly separate, but characteristically similar sites, within the same geographic location. This is a required area of further study not only due to the space requirements necessary for exposure of replicate pigs, but also to justify the application of baseline data generated in disparate sites within a broader geographic area. A succession model suitable for time since death statistics should be applicable: (1) to a defined area (e.g. an EPAdefined ecoregion) and (2) across years (given the same season in each year). In other words, carrion insect communities at any chosen, characteristically similar, site within the defined area should not significantly differ, regardless of year of exposure. If there are determined effects, this inter-site and/or inter-annual variation needs to be incorporated into a succession model to make it fit for forensic inference.

The aim of this work is to determine the effect of year, distinct yet similar locations and repeated sampling on succession in order to establish future protocols for the generation and application of datasets suitable for forensic use.

\section{Materials and Methods}

\section{Data Collection}

Daily insect collections from 53 experimental domestic pig carcasses were made during the summer months (June-August) of three consecutive years (2008-2010) in three mature oak woodlots ( $\mathrm{n}=9,36$, and 8 for woodlots 1,2 , and 3 , respectively). The order of daily collections was not randomized, but was purposely varied to avoid an effect of time of day on collection 
composition (Appendix 1). See Chapter 4 Materials and Methods for additional details concerning the study site and methods of collection and identification.

\section{Effect of Year}

An occurrence matrix was created, for each exposed pig, with species as columns, days as rows and each cell containing either a zero (absence) or one (presence). Columns were summed and any species total greater than zero was scored as a one. The resultant row represents the presence/absence of all species collected during the entire 14-day exposure period and was used to calculate the JSI (see introduction) for all pair-wise comparisons of the 53 carcasses exposed. A JSI score ranges from zero to one; the closer the score is to one the more similar the insect communities. A Welch's one-way analysis of variance (ANOVA) $(p<0.05)$ was used to examine the average JSI of pair-wise comparisons of pigs exposed in the same year as compared to the average JSI of pair-wise comparisons of pigs exposed in different years. A Welch's ANOVA was used to test for equal means because this analysis is robust to heterogeneity of variance and unequal sample sizes. All analyses were performed using the statistical package JMP version 11.0.0 (SAS Institute Inc, Cary, North Carolina).

\section{Effect of Placement Site}

Pig placement sites were chosen in three woodlots, all within the same $\sim 800$ acre farm. The same JSI calculations described to test the effect of year were used to test the effect of woodlot. A oneway ANOVA was used to examine the average JSI of pair-wise comparisons of pigs exposed in 
the same woodlot as compared to the average JSI of pair-wise comparisons of pigs exposed in different woodlots. JSI scores were arcsine transformed prior to analysis.

\section{Effect of Repeated Sampling}

In order to determine the effect of repeated sampling on succession, four control pigs (two in 2009 and two in 2010) were exposed during the same exposure periods and in the same manner as the 53 other experimental carcasses, but each control pig was sampled only on day seven. Mean JSI was calculated for each of multiple sets of pair-wise comparisons, including; (1) each control pig collection to all day four through eleven collections from experimental pigs, and (2) each experimental pig, day seven collection to all day four through eleven collections from experimental pigs. A range of experimental pig collections from days four through eleven was used for comparison to control pigs to elucidate any possible patterns that would indicate a decrease or increase in succession rate. Within pig comparisons (e.g. pig 1 day 7 collection versus pig 1 day 8 collection) were omitted from the analysis. A separate one-way ANOVA was used to determine the relationship of the average JSI of control comparisons and experimental comparisons. Box-Cox power transformations were necessary for multiple sets of data to meet the assumption of normality. In addition, whenever the assumption of homogeneity of variance was violated a Welch's ANOVA was used. In an attempt to control the family-wise error rate for these eight comparisons the critical $p$-value was lowered to $p<0.00625(0.05 / 8)$. 


\title{
Results and Discussion
}

\author{
Effect of Year
}

Jaccard similarity indices are significantly higher for pairwise comparisons of carrion insect communities in pig carcasses exposed in the same year than pairwise comparisons of carrion insect communities in pig carcasses exposed in different years $(\mathrm{F}=266.6373, p<0.0001)$ (Figure 1). The effect of year on community composition is likely the result of annual variation in abundance of carrion frequenting species with lower species abundance resulting in lower occurrence/collection. Annual variation in occurrence was observed for at least one forensically important species (case work examples include Greenberg 1985, Oliveira-Costa and Antunes de Mello-Patiu 2004, Huntington et al. 2007), Cochliomyia macellaria; in 2009 C. macellaria larvae were collected from $65 \%$ of exposed carcasses, in contrast to collection form $100 \%$ of exposed carcasses in 2010. Data collected solely over one year (2009 or 2010) would have lead to opposite conclusions concerning the relative utility of $C$. macellaria for use in succession casework.

Because it is only the very common species that are suitable for PMI estimation, it may be that species showing annual fluctuations would not directly affect casework analysis. It may be, though, that a fluctuating species could affect occurrence patterns of forensically important species. From this dataset, variation in occurrence rate of incidental species examples included: (1) the scarab beetle, Dialytes truncatus, was not collected in 2009 , but was collected from $42 \%$ of exposed carcasses in 2010 (2) the tenebrionid beetle, Uloma punctulata was collected from 
$30 \%$ of carcasses exposed in 2009 but was not collected in 2010. In the absence of exhaustively characterizing how fluctuations in carrion insect abundance and interactions affect successionbased PMI estimations future succession studies should aim to span multiple years to incorporate more variation than single year studies, as suggested by previous authors (Michaud et al. 2012). In addition, succession data collected solely over one year could be inappropriate for extrapolation to casework from a different year. These data also stress the need to continually add to existing succession datasets and repeat field validation tests of succession datasets through time.

\section{Effect of Placement Site}

Jaccard similarity indices are also significantly higher for pairwise comparisons of carrion insect communities in pig carcasses exposed in the same woodlot than to pairwise comparisons of carrion insect communities in pig carcasses exposed in different woodlots $(\mathrm{F}=76.1681, p<0.001)$ (Figure 2). This variation occurs among pig placement sites in extremely close proximity (all located on the same $\sim 800$ acre farm), most likely closer than the distance between an experimental site used to generate a succession dataset and a crime scene. The effect of woodlot on community similarity is likely a result of spatial variation in abundance of carrion frequenting species. These differences could be a result of woodlot size and edge effects (Diaz et al. 2010), or the patchy distributions of insects that utilize ephemeral resources (Hanski 1987, Blackith and Blackith 1990), local variation in species visiting carrion is not always easily explained (Hanksi 1987). A noted difference across woodlots included consistently higher occurrences of multiple rove beetle species in woodlot 1 (Ontholestes cingulatus (100\%), Philonthus varians (100\%), 
and Atheta sp. (100\%)) as compared to woodlot $2(O$. cingulatus $(100 \%), P$. varians $(67 \%)$ and, Atheta sp. (66.6\%)) and $3($ O. cingulatus (57\%), P. varians (52\%) and, Atheta sp. (52\%)). To ensure that adequate variation is encompassed, forensic insect succession datasets need to include data collected over multiple characteristically similar sites spanning the entire area of desired forensic application.

\section{Effect of Repeated Sampling}

On day seven since exposure, repeatedly sampled carrion pairwise community comparisons (experimental) are not significantly more similar to each other, than they are to previously unsampled carrion pairwise community comparisons (control) $(\mathrm{F}=6.9075, p=0.0087)$ (Figure 3).While the comparison of day seven experimental and control collections does not indicate an effect of sampling, day seven experimental and control collection comparisons to preceding and subsequent days, do indicate an effect of sampling on succession. Jaccard similarities are not significantly different but are higher for control insect communities than experimental communities when compared to subsequent experimental day collections (days eight through eleven). Day seven experimental insect communities are significantly more similar to days prior to collection (days four through six) as compared to control insect communities (Figure 3). Contrary to previous observations (Anderson and VanLaerhoven 1996, Dillon 1997, Eberhardt and Elliot 2008, Sharanowski et al. 2008, Segura et al. 2009, Segura et al. 2011) this study suggests that repeated sampling retards succession. 
During sampling, an effort was made to collect as few adult insects as possible, as well as minor subsets of immature insect species. The percentage of immature individuals removed was not quantified and it is possible that the same effect of sampling would not be observed with a sampling scheme that collected fewer immatures (Michaud and Moreau 2013). A potential caveat of smaller collections, could be an increase in false negative observations. For the collection of adults, an effect of sampling could be avoided if a small subset of forensically important insects is collected instead of all species present. Further, easily identified species could be recorded instead of collected (Michaud and Moreau 2009). A possible avenue of future research could be the development of a time scale correction factor to adjust for repeated sampling.

This study represents the largest examination of the effect of small-scale spatial variation, interannual variation and repeated sampling, on insect succession. Because crime scene locations are unequal in space and time, to experimental sites, the observed effect of all studied factors suggests that development of forensically relevant reference datasets should include data collected from multiple years, multiple characteristically similar sites, and from carcasses that are minimally sampled. 


\section{References}

Anderson GS and SL VanLaerhoven. 1996. Initial studies on insect succession on carrion in southwestern British Columbia. Journal of Forensic Science 41(4): 617-625.

Anderson GS. 2001. Insect succession on carrion and its relationship to determining time of death pp 143-169. In Forensic Entomology: The Utility of Arthropods in Legal Investigations. JH Byrd and JL Castner Eds. CRC Press, Boca Raton, FL, USA, 440 pp.

Blackith RE and RM Blackith. 1990. Insect infestations of small corpses. Journal of Natural History 24: 699-709.

Braack LEO. 1984. An ecological investigation of the insects associated with exposed carcasses in the northern Kruger National Park: a study of populations and communities. Ph.D. Thesis. University of Natal Pietermaritzburg, South Africa.

Catts EP and ML Goff. 1992. Forensic entomology in criminal investigations. Annual Review of Entomology 37: 253-72.

Carvalho LML, PJ Thyssen, AX Linhares and FAB Palhares. 2000. Checklist of arthropods associated with pig carrion and human corpses in southeastern Brazil. Memórias do Instituto Oswaldo Cruz 95:135-138.

De Jong GD and WW Hoback. 2006. Effect of investigator disturbance in experimental forensic entomology: succession and community composition. Medical and Veterinary Entomology 20: 248-258. 
Diaz A, E Galante and ME Favila. 2010. The effect of the landscape matrix on the distribution of dung and carrion beetles in a fragmented tropical rainforest. The Journal of Insect Science 10(81): 1-16.

Dillon LC. 1997. Insect succession on carrion in three biogeoclimatic zones of British Columbia. Masters' Thesis. Simon Frasier University, Canada.

Eberhart TL and DL Elliot. 2008. A preliminary investigation of insect colonization and succession on remains in New Zealand. Forensic Science International 176: 217-223.

Greenberg B. 1985. Forensic entomology: case studies. Bulletin of the American Society of Entomology 31(4): 25-28.

Hanksi I. 1987. Carrion fly community dynamics: patchiness, seasonality and coexistence. Ecological Entomology 12: 257-66.

Haskell NH, KG Schoenly and RD Hall. 2002. Testing reliability of animal models in research and training programs in forensic entomology, part II. Final Report, Grant 97-IJ-CX-0046. U.S. National Institute of Justice, Washington, DC.

Hobischak NR. 1997. Freshwater invertebrate succession and decompositional studies on carrion in British Colombia. Master's Thesis. Simon Fraser University

Huntington TE, LG Higley and FP Baxendale. 2007. Maggot development during morgue storage and its effect on estimating the post-mortem interval. Journal of Forensic Sciences 52(2): 453-458.

LaMotte LR and JD Wells. 2000. $p$-values for postmortem intervals from arthropod succession data. Journal of Agricultural, Biological, and Environmental Statistics 5(1): 58-68. 
Leblanc H and D Strongman. 2002. Carrion insects associated with small pig carcasses during fall in Nova Scotia. Canadian Society of Forensic Science Journal 35(3): 145-152.

Mann MA, WM Bass and L Meadows. 1990. Time since death and decomposition of the human body: variables and observations in case and experimental field studies. Journal of Forensic Sciences 35(1): 103-111.

Michaud JP and G Moreau. 2009. Predicting the visitation of carcasses by carrion-related insects under different rates of degree-day accumulation. Forensic Science International 185: 78-83.

Michaud JP, KG Schoenly and G Moreau. 2012. Sampling flies or sampling flaws? Experimental design and inference strength in forensic entomology. Journal of Medical Entomology 49(1): 110 .

Michaud JP and G Moreau. 2013. Effect of variable rates of daily sampling of fly larvae on decomposition and carrion insect community assembly: implications for forensic entomology field study protocols. Journal of Medical Entomology 50(4): 890-897.

Oliveira-Costa J and C Antunes de Mello-Patiu. 2004. Application of forensic entomology to estimate the postmortem interval (PMI) in homicide investigation by the Rio de Janeiro Police Department in Brazil. Aggrawal's Internet Journal of Forensic Medicine and Toxicology 5(1): 40-44.

Payne JA. 1965. A summer carrion study of the baby pig Sus scrofa Linnaeus. Ecology 46 (5): $592-602$.

Reed HB, Jr. 1958. A study of dog carcass communities in Tennessee, with special reference to the insects. American Midland Naturalist 59(1): 213-245.

Schoenly KG and W Reid. 1987. Dynamics of hetertrophic succession in carrion arthropod assemblages: discrete series or a continuum of change? Oecologia 17: 192-202. 
Schoenly KG. 1992. A statistical analysis of successional patterns in carrion-arthropod assemblages: implications for forensic entomology and determination of the postmortem interval. Journal of Forensic Sciences 37(6): 1489-513.

Schoenly KG, NH Haskell, RD Hall and JR Gbur. 2007. Comparative performance and complimentarity of four sampling methods and arthropod preference tests from human and porcine remains at the forensic anthropology center in Knoxville, Tennessee. Journal of Medical Entomology 44(5): 881-894.

Segura NA, W Usaquén, MC Sánchez, L Chuaire and F Bello. 2009. Succession pattern of cadaverous entomofauna in a semi-rural area of Bogotá, Columbia. Forensic Science International 187: 66-72.

Segura NA, MA Bonilla, W Usaquén and F Bello. 2011. Entomofauna resource distribution associated with pig cadavers in Bogotá DC. Medical and Veterinary Entomology 25: 46-52.

Sharanowski BJ, EG Walker and GS Anderson. 2008. Insect succession and decomposition patterns on shaded and sunlight carrion in Saskatchewan in three different seasons. Forensic Science International 179: 219-240.

Shi Y-W, X-S Liu, H-Y Wang and R-J Zhang. 2009. Seasonality of insect succession on exposed rabbit carrion in Ghuangzhou, China. Insect Science 16: 425-439.

Tabor KL, CC Brewster and RD Fell. 2004. Analysis of the successional patterns of insects on carrion in southwest Virginia. Journal of Medical Entomology 41(4): 785-795.

Tantawi TI, EM El-Kady, B Greenberg and HA El-Ghaffar. 1996. Arthropod succession on exposed rabbit carrion in Alexandria, Egypt. Journal of Medical Entomology 33: 566-80. 
Wang J, Z Li, Y Chin, Q Chin and X Yin. 2008. The succession and development of insects on pig carcasses and their significances in estimating PMI in south China. Forensic Science International 179: 11-18.

Wells JD and LR LaMotte. 2010. Estimating the postmortem interval in: Forensic Entomology: The Utility of Arthropods in Legal Investigations, $2^{\text {nd }}$ edition. JH Byrd and JL Castner eds. CRC Press, Boca Raton, FL, USA, pp. 367-384.

Williams H. 1984. A model for the aging of fly larvae in forensic entomology. Forensic Science International 25(3): 191-199. 


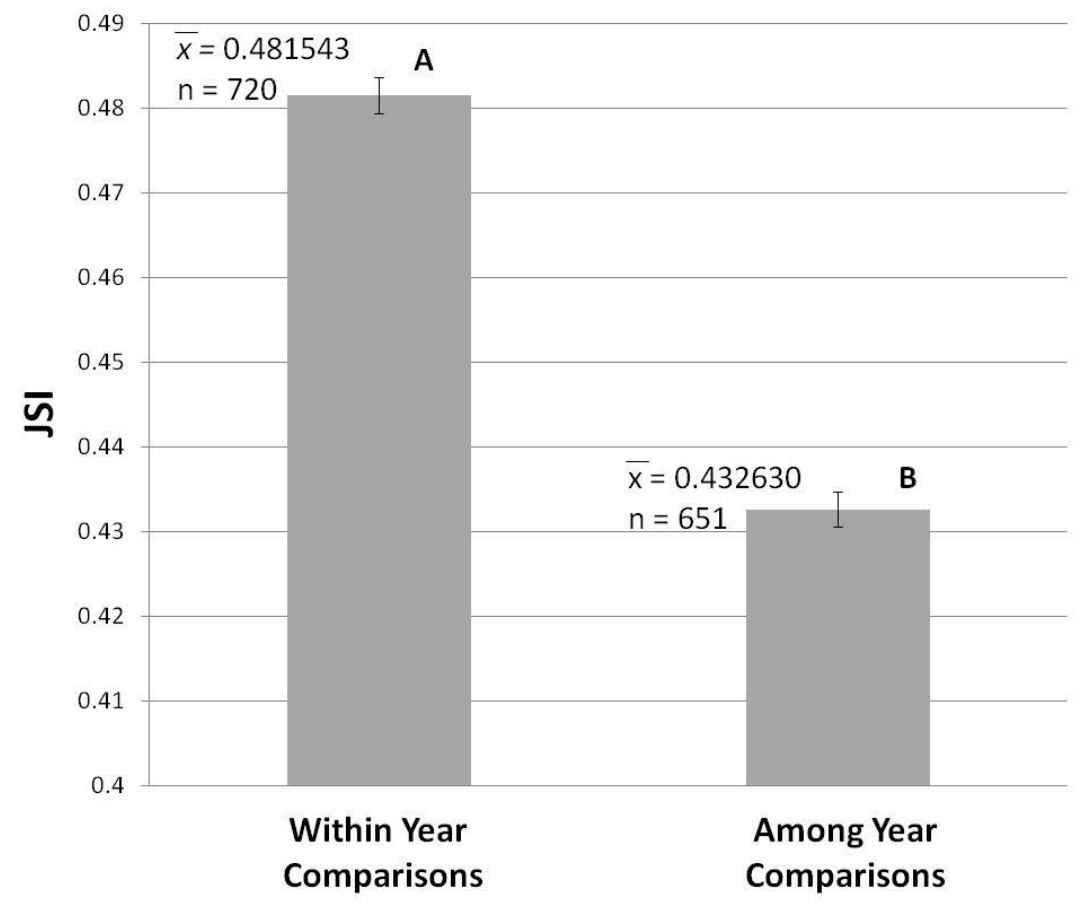

Figure 1. Average Jaccard similarity index of within and among year pairwise comparisons 


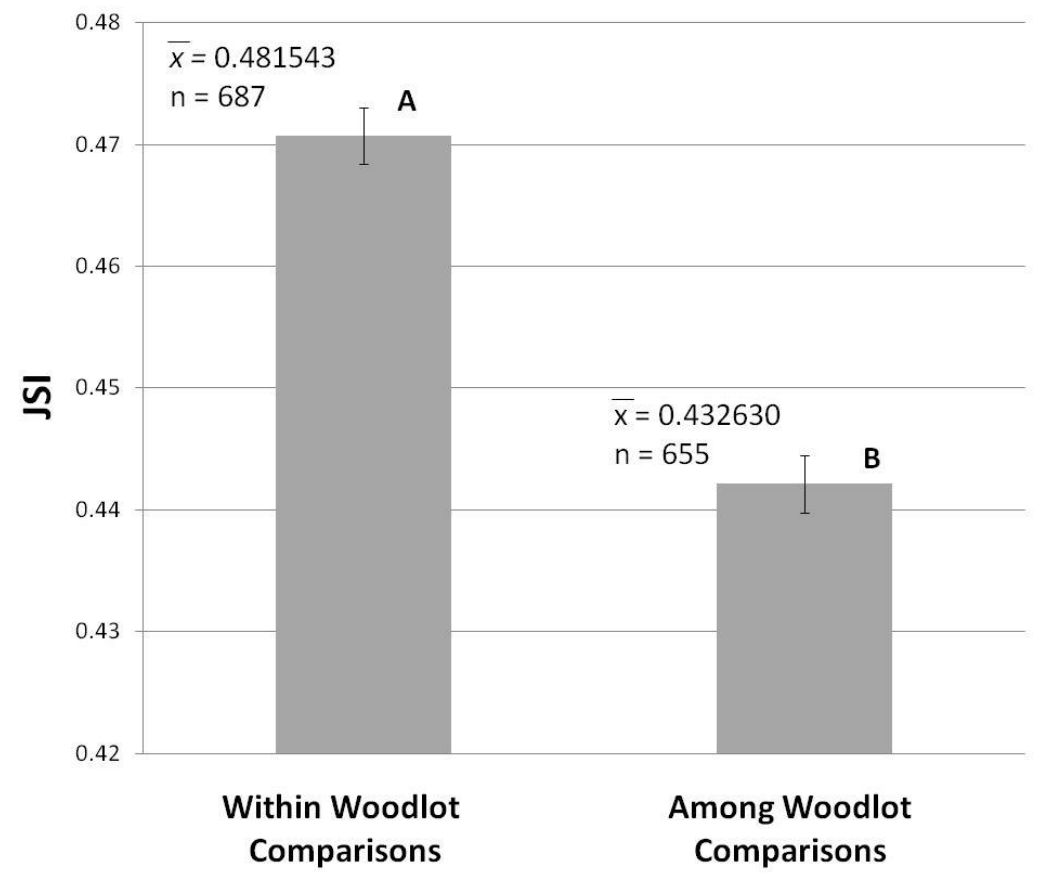

Figure 2. Average Jaccard similarity index of within and among woodlot pairwise comparisons 


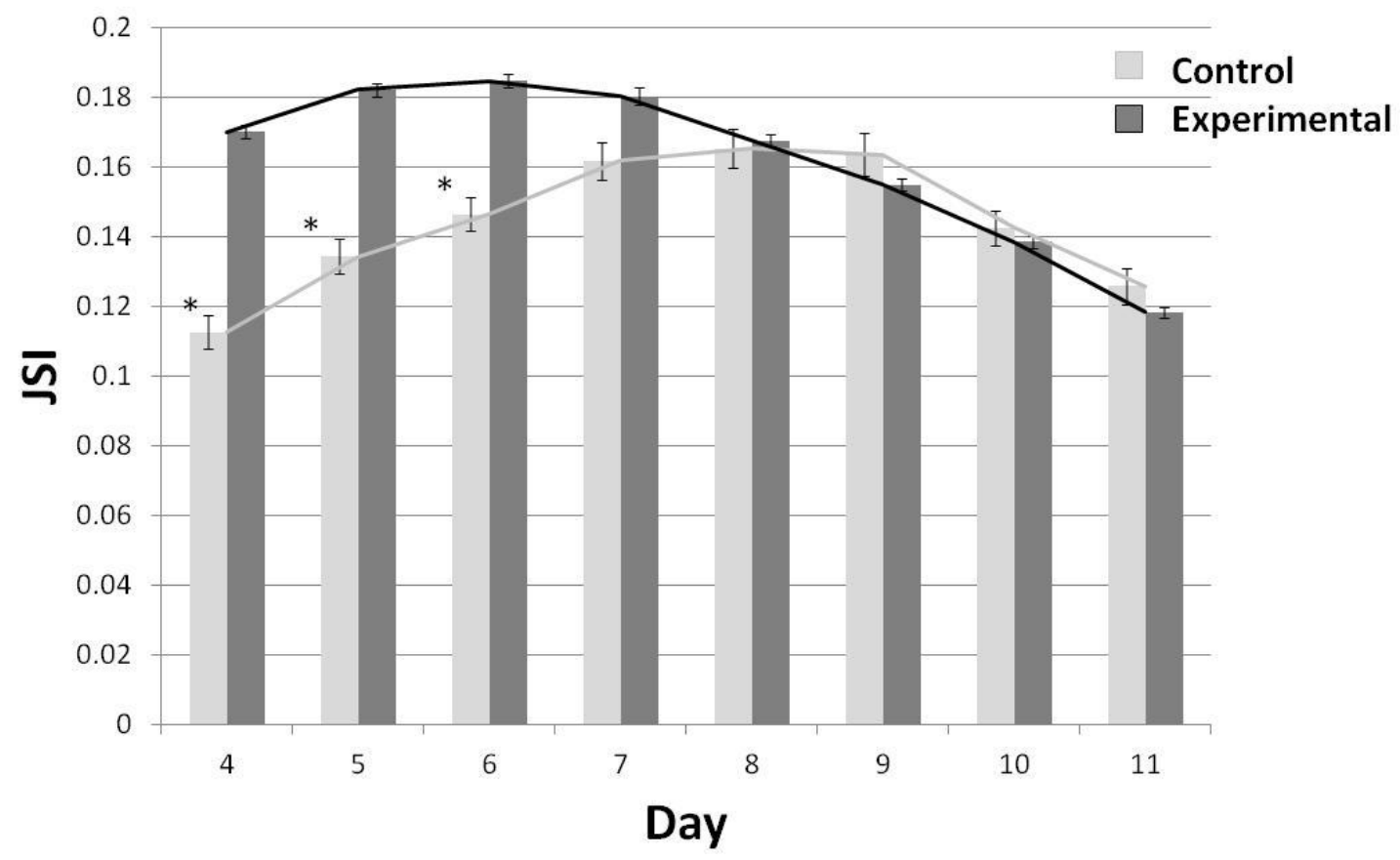

Figure 3. Pairwise comparisons of control and experimental, day 7 since exposure, insect collections to days 4-11. The control bars represent the average JSI for pairwise comparisons of the four control pigs to all repeatedly sampled pigs on days 4-11. The experimental bars represent the average JSI for pairwise comparisons of all day 7 collections from repeatedly sampled pigs, as well as all pairwise comparisons of the day 7 collections from repeatedly sampled pigs to collections from repeatedly sampled pigs on days 4-6 and 8-11. 
Table S1. Collection time and (daily collection order) of 53 experimental pigs

2008

2009

\begin{tabular}{|c|c|c|c|c|c|c|c|c|c|c|c|c|}
\hline Date Pig & 1 & 2 & 3 & 4 & 5 & 6 & 7 & 8 & 9 & 10 & 11 & 12 \\
\hline 2-Jul & & & & & & & & & & & & \\
\hline 3-Jul & & & & & & & & & & & & \\
\hline 4-Jul & & & & & & & & & & & & \\
\hline 5-Jul & & & & & & & & & & & & \\
\hline 6-Jul & & & & & & & & & & & & \\
\hline 7-Jul & & & & & & & & & & & & \\
\hline 8-Jul & & & & & & & & & & & & \\
\hline 9-Jul & & & & & & & & & & & & \\
\hline 10-Jul & & & & & & & & & & & & \\
\hline $11-J u l$ & $16: 20(1)$ & & $12: 26(5)$ & & $11: 14(1)$ & $13: 00(7)$ & $11: 27(2)$ & $11: 51(3)$ & $12: 20(4)$ & $12: 39(6)$ & & \\
\hline 12-Jul & $16: 00(2)$ & $12: 30(1)$ & $9: 30(1)$ & & $11: 12(3)$ & $11: 21(4)$ & $10: 30(2)$ & $12: 00(5)$ & $14: 31(7)$ & $12: 16(6)$ & & \\
\hline 13-Jul & $16: 30(2)$ & $12: 30(1)$ & $9: 30(1)$ & & $13: 07(7)$ & $10: 26(3)$ & $12: 42(6)$ & $11: 34(5)$ & $9: 50(2)$ & $10: 57(4)$ & & \\
\hline 14-Jul & $16: 30(2)$ & $12: 10(1)$ & 9:35 (1) & & $12: 34(6)$ & $10: 34(3)$ & 13:07 (7) & $11: 26(5)$ & $10: 05(2)$ & $10: 58(4)$ & & \\
\hline 15-Jul & $16: 40(2)$ & $12: 00(1)$ & 9:53 (1) & & $12: 39(7)$ & $10: 58(3)$ & $11: 02(4)$ & $12: 10(6)$ & $10: 26(2)$ & $11: 41(5)$ & & \\
\hline 16-Jul & $12: 00(1)$ & $16: 00(2)$ & $9: 21(1)$ & & $11: 37(6)$ & $10: 09(3)$ & $11: 55(7)$ & $10: 56(5)$ & $9: 45(2)$ & $10: 27(4)$ & & \\
\hline 17-Jul & $11: 20(1)$ & $12: 20(2)$ & $11: 00(1)$ & & $13: 03(7)$ & $11: 43(3)$ & $12: 40(6)$ & $12: 21(5)$ & $11: 26(2)$ & $12: 06(4)$ & & \\
\hline 18-Jul & $13: 30(2)$ & $13: 00(1)$ & $9: 02(2)$ & $10: 38(7)$ & $13: 32(15)$ & $9: 46(4)$ & $13: 43(16)$ & $13: 21(14)$ & $9: 26(3)$ & $12: 17(10)$ & 14:06 (17) & $12: 31(11)$ \\
\hline 19-Jul & $13: 00(1)$ & $13: 30(2)$ & 9:01 (2) & $10: 32(7)$ & $12: 21(13)$ & $9: 35(4)$ & $13: 35(16)$ & $13: 09(15)$ & $9: 19(3)$ & $11: 12(10)$ & $14: 53(17)$ & $11: 37$ (11) \\
\hline 20-Jul & $14: 00(1)$ & $14: 40(2)$ & $9: 10(2)$ & $10: 27(7)$ & $13: 51(15)$ & $9: 42(4)$ & $14: 05(16)$ & $13: 37(14)$ & $9: 24(3)$ & $12: 55(12)$ & $14: 17$ (17) & $13: 19$ (13) \\
\hline 21-Jul & $11: 40(2)$ & $11: 00(1)$ & $10: 57(2)$ & $12: 32(7)$ & $15: 09$ (15) & $11: 36(4)$ & $15: 21(16)$ & $14: 51(14)$ & $11: 12(3)$ & $14: 23(12)$ & $15: 47$ (17) & $14: 39$ (13) \\
\hline 22-Jul & $12: 00(1)$ & $12: 30(2)$ & $11: 08(2)$ & $13: 14(7)$ & $16: 17$ (15) & $11: 45(4)$ & $16: 30(16)$ & $16: 03(14)$ & $11: 21(3)$ & $14: 52(10)$ & $16: 55(17)$ & $15: 09$ (11) \\
\hline 23-Jul & $14: 30(2)$ & $14: 00(1)$ & $10: 45(2)$ & $12: 18(7)$ & $14: 45(15)$ & $11: 20(4)$ & $15: 06(16)$ & $14: 17(14)$ & $10: 55(3)$ & $13: 17(10)$ & $15: 33(17)$ & $13: 25$ (11) \\
\hline 24-Jul & $11: 20(1)$ & $12: 00(2)$ & $11: 39(2)$ & $12: 51(6)$ & $17: 10(17)$ & $15: 35(14)$ & $16: 19(16)$ & $12: 12(4)$ & 11:57 (3) & $14: 28$ (10) & $15: 50(15)$ & $14: 40$ (11) \\
\hline 25-Jul & & $12: 30(1)$ & & $13: 36(8)$ & & & & & & & $11: 43(3)$ & $15: 27$ (13) \\
\hline 26-Jul & & & & $15: 29(8)$ & & & & & & & $16: 48(12)$ & $14: 46(6)$ \\
\hline 27-Jul & & & & $13: 28(6)$ & & & & & & & $12: 01(4)$ & $15: 22(11)$ \\
\hline 28-Jul & & & & $12: 08(5)$ & & & & & & & $11: 55(4)$ & $15: 00(12)$ \\
\hline 29-Jul & & & & $9: 07(5)$ & & & & & & & $8: 52(4)$ & $11: 36(12)$ \\
\hline 30-Jul & & & & $17: 00(3)$ & & & & & & & $16: 46(2)$ & $18: 20(11)$ \\
\hline 31-Jul & & & & $16: 00(12)$ & & & & & & & $16: 15$ (13) & $13: 49(7)$ \\
\hline 1-Aug & & & & & & & & & & & & \\
\hline 2-Aug & & & & & & & & & & & & \\
\hline 3-Aug & & & & & & & & & & & & \\
\hline 4-Aug & & & & & & & & & & & & \\
\hline 5-Aug & & & & & & & & & & & & \\
\hline 6-Aug & & & & & & & & & & & & \\
\hline 7-Aug & & & & & & & & & & & & \\
\hline 8-Aug & & & & & & & & & & & & \\
\hline 9-Aug & & & & & & & & & & & & \\
\hline 10-Aug & & & & & & & & & & & & \\
\hline
\end{tabular}


Table S1. Continued

\begin{tabular}{|c|c|c|c|c|c|c|c|c|c|c|c|c|}
\hline \multirow{2}{*}{ Date Pig } & \multicolumn{8}{|l|}{2009} & & & \multicolumn{2}{|l|}{2010} \\
\hline & 13 & 14 & 15 & 16 & 17 & 18 & 19 & 20 & 21 & 22 & 23 & 24 \\
\hline 2-Jul & & & & & & & & & & & $14: 16(1)$ & \\
\hline 3-Jul & & & & & & & & & & & $11: 21(1)$ & \\
\hline 4-Jul & & & & & & & & & & & $9: 27$ (1) & \\
\hline 5-Jul & & & & & & & & & & & $12: 10(1)$ & \\
\hline 6-Jul & & & & & & & & & & & $13: 57(1)$ & \\
\hline 7-Jul & & & & & & & & & & & $15: 41(4)$ & $15: 09(3)$ \\
\hline 8-Jul & & & & & & & & & & & $11: 14(1)$ & $12: 15$ (3) \\
\hline 9-Jul & & & & & & & & & & & $14: 33(9)$ & $12: 08(4)$ \\
\hline 10-Jul & & & & & & & & & & & $11: 45(5)$ & $13: 07(8)$ \\
\hline 11-Jul & & & & & & & & & & & $14: 10(8)$ & $12: 22(4)$ \\
\hline 12-Jul & & & & & & & & & & & $14: 45(10)$ & $10: 57(4)$ \\
\hline 13-Jul & & & & & & & & & & & $15: 47(8)$ & $16: 37(10)$ \\
\hline 14-Jul & & & & & & & & & & & $15: 50(16)$ & $10: 09(3)$ \\
\hline 15-Jul & & & & & & & & & & & $10: 56(3)$ & $15: 53(12)$ \\
\hline 16-Jul & & & & & & & & & & & & $10: 43(4)$ \\
\hline 17-Jul & & & & & & & & & & & & $11: 16(6)$ \\
\hline 18-Jul & $11: 51(8)$ & $13: 05$ (13) & $10: 20(6)$ & $8: 47$ (1) & $10: 04(5)$ & $12: 00(9)$ & $12: 50(12)$ & & & & & $15: 40(20)$ \\
\hline 19-Jul & $10: 42(8)$ & $12: 30(14)$ & $10: 12(6)$ & $8: 47$ (1) & $9: 55(5)$ & $10: 54(9)$ & $12: 06(12)$ & & & & & $10: 09(4)$ \\
\hline 20-Jul & $11: 42(8)$ & $12: 21(10)$ & $10: 14(6)$ & $8: 50$ (1) & $10: 01(5)$ & $12: 37$ (11) & $11: 55(9)$ & & & & & $10: 28(6)$ \\
\hline 21-Jul & $12: 51(8)$ & $13: 37(10)$ & $12: 12(6)$ & $10: 34(1)$ & $11: 52(5)$ & $14: 01(11)$ & $13: 08(9)$ & & & & & \\
\hline 22-Jul & $14: 19(8)$ & $15: 46(13)$ & $12: 24(6)$ & $10: 47(1)$ & $12: 00(5)$ & $14: 38(9)$ & $15: 31(12)$ & & & & & \\
\hline 23-Jul & $12: 42(8)$ & $14: 03(13)$ & $11: 56(6)$ & $10: 21(1)$ & $11: 37(5)$ & $12: 53(9)$ & $13: 42(12)$ & & & & & \\
\hline 24-Jul & $12: 27(5)$ & $13: 48(8)$ & $14: 59(12)$ & $11: 20(1)$ & $15: 20(13)$ & $14: 09(9)$ & $13: 27(7)$ & & & & & \\
\hline 25-Jul & $13: 58(9)$ & $14: 45(11)$ & $12: 22(5)$ & $10: 31(1)$ & $12: 43(6)$ & $15: 09(12)$ & $14: 25(10)$ & $10: 54(2)$ & $12: 18(4)$ & $13: 10(7)$ & & \\
\hline 26-Jul & $15: 09(7)$ & $13: 03(4)$ & $15: 50(9)$ & $11: 26(1)$ & $16: 05(10)$ & $14: 20(5)$ & $12: 32(3)$ & $12: 00(2)$ & $17: 10(13)$ & $16: 30(11)$ & & \\
\hline 27-Jul & $12: 20(5)$ & $16: 33(13)$ & $13: 58(7)$ & $10: 30(1)$ & $14: 19$ (3) & $15: 05(10)$ & $16: 02(12)$ & $10: 56(2)$ & $11: 30(3)$ & $14: 42(9)$ & & \\
\hline 28-Jul & $14: 40(9)$ & $15: 30(11)$ & $12: 21(6)$ & $10: 24(1)$ & $12: 42(7)$ & $14: 50(10)$ & $15: 20(13)$ & $11: 00(2)$ & $11: 40(3)$ & $13: 09(8)$ & & \\
\hline 29-Jul & $10: 11(9)$ & $10: 26(10)$ & $9: 59(8)$ & $8: 06(1)$ & $9: 39(7)$ & $11: 52(13)$ & $10: 41(11)$ & $8: 27$ (2) & $8: 47$ (3) & $9: 27(6)$ & & \\
\hline 30-Jul & $17: 26(7)$ & $17: 42(9)$ & $17: 05(4)$ & $18: 37(12)$ & $17: 15(5)$ & $17: 53(10)$ & $17: 33(8)$ & $18: 49$ (13) & $16: 30(1)$ & $17: 21(6)$ & & \\
\hline 31-Jul & $14: 35$ (9) & 13:01 (5) & $12: 05(3)$ & 11:04 (1) & $15: 42(11)$ & $14: 10(8)$ & $13: 25(6)$ & $11: 28(2)$ & $12: 40(4)$ & $15: 05(10)$ & & \\
\hline 1-Aug & & & & & & & & $15: 17(3)$ & $14: 53(2)$ & $14: 30(1)$ & & \\
\hline 2-Aug & & & & & & & & $12: 04(1)$ & $12: 30(2)$ & $12: 54(3)$ & & \\
\hline 3-Aug & & & & & & & & $13: 30(1)$ & $14: 20(3)$ & $13: 55(2)$ & & \\
\hline 4-Aug & & & & & & & & $15: 30(1)$ & $16: 15(3)$ & $15: 50(2)$ & & \\
\hline 5-Aug & & & & & & & & $16: 00(1)$ & $16: 26(2)$ & $16: 50(3)$ & & \\
\hline 6-Aug & & & & & & & & $17: 08(1)$ & $17: 31(2)$ & $17: 54(3)$ & & \\
\hline 7-Aug & & & & & & & & $10: 55(2)$ & 10:23 (1) & $11: 22(3)$ & & \\
\hline 8-Aug & & & & & & & & & & & & \\
\hline 9-Aug & & & & & & & & & & & & \\
\hline 10-Aug & & & & & & & & & & & & \\
\hline
\end{tabular}


Table S1. Continued

\begin{tabular}{|c|c|c|c|c|c|c|c|c|c|c|c|c|}
\hline \multicolumn{12}{|l|}{ Pig } & 36 \\
\hline \multicolumn{13}{|l|}{ 2-Jul } \\
\hline \multicolumn{13}{|l|}{ 3-Jul } \\
\hline \multicolumn{13}{|l|}{$4-\mathrm{Jul}$} \\
\hline \multicolumn{13}{|l|}{ 5-Jul } \\
\hline \multicolumn{13}{|l|}{ 6-Jul } \\
\hline 7-Jul & $14: 40(2)$ & $14: 02(1)$ & & & & & & & & & & \\
\hline 8-Jul & $11: 47(2)$ & $15: 04(4)$ & & & & & & & & & & \\
\hline 9-Jul & $11: 45(3)$ & $11: 04(2)$ & $14: 05$ (8) & $10: 35$ (1) & $14: 55(10)$ & $13: 11(6)$ & $12: 39(5)$ & $13: 38(7)$ & & & & \\
\hline 10-Jul & $12: 42(7)$ & $13: 57(10)$ & $10: 52(3)$ & 13:33 (9) & $11: 22(4)$ & 10:01 (1) & $12: 09(6)$ & $10: 28(2)$ & & & & \\
\hline 11-Jul & $11: 55(3)$ & $11: 14(2)$ & $13: 45(7)$ & $10: 44(1)$ & $14: 30(9)$ & $14: 55(10)$ & $12: 48(5)$ & $13: 20(6)$ & & & & \\
\hline 12-Jul & $10: 30(3)$ & $9: 47$ (2) & $13: 58(8)$ & $9: 14(1)$ & $14: 23(9)$ & $11: 50(6)$ & $11: 19(5)$ & $13: 28(7)$ & & & & \\
\hline 13-Jul & $16: 16(9)$ & $10: 35(2)$ & $15: 02(6)$ & $10: 05(1)$ & $15: 26(7)$ & $14: 16(4)$ & $13: 45(3)$ & $14: 38(5)$ & & & & \\
\hline 14-Jul & $10: 30(4)$ & $9: 39(2)$ & $13: 57$ (12) & $9: 17$ (1) & $15: 26(15)$ & $12: 17(8)$ & $11: 18(6)$ & $13: 29(11)$ & $11: 47(7)$ & $10: 54(5)$ & $14: 18(13)$ & $15: 00(14)$ \\
\hline 15-Jul & $16: 25(13)$ & $17: 47(16)$ & $12: 06(6)$ & $17: 27$ (15) & $10: 15(2)$ & $9: 42(1)$ & $15: 25$ (11) & $12: 26(7)$ & $15: 03(10)$ & $16: 47$ (14) & $11: 46(5)$ & $11: 18(4)$ \\
\hline 16-Jul & $10: 22(3)$ & $17: 24(21)$ & $14: 42(14)$ & $17: 44(22)$ & $16: 06(18)$ & $13: 10(10)$ & $11: 07(5)$ & $14: 16(13)$ & $11: 29(6)$ & $9: 34$ (1) & $15: 02(15)$ & $16: 26(19)$ \\
\hline 17-Jul & $10: 53(5)$ & $9: 40(2)$ & $14: 05$ (13) & $9: 22(1)$ & $11: 43(7)$ & $16: 10(19)$ & $17: 19(22)$ & $14: 28(14)$ & $16: 56(21)$ & $10: 05(3)$ & $13: 44(12)$ & $12: 10(8)$ \\
\hline 18-Jul & $15: 20$ (19) & $16: 30(22)$ & $11: 24$ (8) & $16: 12(21)$ & 13:32 (14) & $8: 48(1)$ & $14: 15$ (16) & $11: 00(7)$ & $13: 52(15)$ & $14: 37$ (17) & $12: 26(11)$ & 13:11 (13) \\
\hline 19-Jul & 9:46 (3) & $11: 41(8)$ & $14: 39(16)$ & $11: 24(7)$ & $16: 48(22)$ & $12: 15(9)$ & $10: 30(5)$ & $14: 20(15)$ & $10: 52(6)$ & 9:03 (1) & $15: 38$ (19) & $16: 22(21)$ \\
\hline 20-Jul & $10: 05(5)$ & $9: 04(2)$ & $16: 36$ (19) & $8: 47$ (1) & $11: 23(9)$ & $14: 32(15)$ & $10: 41(7)$ & $16: 19(18)$ & $10: 57$ (8) & $9: 27$ (3) & $16: 51(20)$ & $11: 43(10)$ \\
\hline 21-Jul & & & $12: 42(10)$ & $17: 40(22)$ & $9: 15(1)$ & $15: 11(17)$ & $16: 00$ (19) & $13: 10(11)$ & $15: 36(18)$ & $16: 17(20)$ & $11: 36(7)$ & $9: 56(3)$ \\
\hline 22-Jul & & & $14: 17$ (13) & 9:00 (1) & $17: 00(21)$ & $12: 47$ (9) & $10: 35(4)$ & $13: 43(12)$ & $10: 55(5)$ & $9: 22(2)$ & $15: 17(16)$ & $16: 42(20)$ \\
\hline 23-Jul & & & & & & & & & $10: 49(3)$ & $9: 40(1)$ & $13: 26(9)$ & $11: 55(5)$ \\
\hline 24-Jul & & & & & & & & & $16: 09$ (14) & $16: 31(15)$ & $13: 36(8)$ & $11: 10(2)$ \\
\hline 25-Jul & & & & & & & & & 10:05 (3) & $9: 10(1)$ & $12: 25(9)$ & $14: 38(15)$ \\
\hline 26-Jul & & & & & & & & & 10:08 (3) & 9:11 (1) & $13: 28(12)$ & $12: 49(10)$ \\
\hline 27-Jul & & & & & & & & & $10: 38(3)$ & $9: 35(1)$ & $15: 03(11)$ & $16: 40(16)$ \\
\hline 28-Jul & & & & & & & & & & & & \\
\hline 29-Jul & & & & & & & & & & & & \\
\hline 30-Jul & & & & & & & & & & & & \\
\hline 31-Jul & & & & & & & & & & & & \\
\hline 1-Aug & & & & & & & & & & & & \\
\hline 2-Aug & & & & & & & & & & & & \\
\hline 3-Aug & & & & & & & & & & & & \\
\hline 4-Aug & & & & & & & & & & & & \\
\hline 5-Aug & & & & & & & & & & & & \\
\hline 6-Aug & & & & & & & & & & & & \\
\hline 7-Aug & & & & & & & & & & & & \\
\hline 8-Aug & & & & & & & & & & & & \\
\hline 9-Aug & & & & & & & & & & & & \\
\hline 10-Aug & & & & & & & & & & & & \\
\hline
\end{tabular}


Table S1. Continued

2010

\begin{tabular}{|c|c|c|c|c|c|c|c|c|c|c|c|c|}
\hline Date Pig & 37 & 38 & 39 & 40 & 41 & 42 & 43 & 44 & 45 & 46 & 47 & 48 \\
\hline 2-Jul & & & & & & & & & & & & \\
\hline 3-Jul & & & & & & & & & & & & \\
\hline 4-Jul & & & & & & & & & & & & \\
\hline 5-Jul & & & & & & & & & & & & \\
\hline 6-Jul & & & & & & & & & & & & \\
\hline 7-Jul & & & & & & & & & & & & \\
\hline 8-Jul & & & & & & & & & & & & \\
\hline 9-Jul & & & & & & & & & & & & \\
\hline 10-Jul & & & & & & & & & & & & \\
\hline 11-Jul & & & & & & & & & & & & \\
\hline 12-Jul & & & & & & & & & & & & \\
\hline 13-Jul & & & & & & & & & & & & \\
\hline 14-Jul & $12: 45(9)$ & 13:07 (10) & & & & & & & & & & \\
\hline 15-Jul & $14: 36(9)$ & $14: 15(8)$ & & & & & & & & & & \\
\hline 16-Jul & $13: 33(11)$ & $13: 56(12)$ & $12: 20(8)$ & $15: 46(17)$ & $10: 01(2)$ & $12: 45(9)$ & $15: 24(16)$ & $16: 47(20)$ & $11: 57(7)$ & & & \\
\hline 17-Jul & $15: 08(16)$ & $14: 48(15)$ & $15: 29(17)$ & $13: 02(10)$ & $10: 29(4)$ & $15: 49(18)$ & $13: 23(11)$ & $12: 38(9)$ & $16: 31(20)$ & & & \\
\hline 18-Jul & $10: 16(5)$ & $10: 38(6)$ & $9: 30(3)$ & $11: 44(9)$ & $14: 59$ (18) & $9: 08(2)$ & 12:04 (10) & $12: 50(12)$ & $9: 52(4)$ & & & \\
\hline 19-Jul & $13: 37$ (13) & 13:58(14) & $12: 56(11)$ & $14: 58(17)$ & $9: 23(2)$ & $12: 36(10)$ & $15: 17(18)$ & $16: 02(20)$ & $13: 18(12)$ & & & \\
\hline 20-Jul & $14: 51(16)$ & $15: 07$ (17) & $13: 55(13)$ & $17: 27(22)$ & $9: 48(4)$ & $14: 12(14)$ & $17: 08(21)$ & $12: 00(11)$ & $13: 05(12)$ & & & \\
\hline 21-Jul & 13:47 (13) & $13: 27(12)$ & $14: 29(15)$ & $12: 16(9)$ & $16: 56(21)$ & $14: 51(16)$ & $11: 56(8)$ & $10: 38(5)$ & $14: 09(14)$ & $9: 33(2)$ & $10: 17(4)$ & $11: 00(6)$ \\
\hline 22-Jul & 13:06 (10) & $13: 25(11)$ & $12: 05(7)$ & $14: 36(14)$ & $9: 44(3)$ & $12: 27(8)$ & 14:57 (15) & $16: 20$ (19) & $11: 40(6)$ & $17: 16(22)$ & $15: 58(18)$ & $15: 37(17)$ \\
\hline 23-Jul & $15: 00(13)$ & $14: 32(12)$ & $15: 40(15)$ & $14: 10$ (11) & $10: 15(2)$ & $16: 00(16)$ & $13: 49(10)$ & $12: 41(7)$ & $15: 21(14)$ & $11: 32(4)$ & $12: 17(6)$ & $13: 02(8)$ \\
\hline 24-Jul & $14: 36(10)$ & 14:15 (9) & $15: 19(12)$ & $12: 50(6)$ & $16: 47(16)$ & $15: 40$ (13) & $13: 14(7)$ & $11: 57(4)$ & $14: 58$ (11) & $10: 45(1)$ & $11: 32(3)$ & $12: 18(5)$ \\
\hline 25-Jul & $11: 34(7)$ & $11: 53(8)$ & $10: 48(5)$ & $13: 10$ (11) & $9: 40(2)$ & $11: 11(6)$ & $12: 45(10)$ & $13: 58(13)$ & $10: 27(4)$ & $15: 02(16)$ & $13: 32(12)$ & $14: 18(14)$ \\
\hline 26-Jul & $14: 53(16)$ & $14: 33(15)$ & $10: 29(4)$ & $14: 08(14)$ & $9: 30(2)$ & $10: 53(5)$ & $13: 48(13)$ & $12: 05(8)$ & $11: 13(6)$ & 13:08 (11) & $12: 25$ (9) & $11: 35(7)$ \\
\hline 27-Jul & $12: 09(7)$ & $12: 38(8)$ & $11: 11(4)$ & $13: 40(9)$ & $9: 55(2)$ & $11: 30(5)$ & $15: 18(12)$ & $16: 09(14)$ & $11: 50(6)$ & $16: 24(15)$ & $14: 33(10)$ & $15: 32(13)$ \\
\hline 28-Jul & & & $16: 08(13)$ & 15:04 (8) & $10: 48(2)$ & $16: 19(14)$ & $15: 14(9)$ & $11: 46(5)$ & $15: 56(12)$ & $11: 13(3)$ & $11: 30(4)$ & $12: 00(6)$ \\
\hline 29-Jul & & & $11: 09(5)$ & $12: 19(10)$ & $10: 24(2)$ & $11: 20(6)$ & $12: 08(9)$ & $13: 12(14)$ & $10: 57(4)$ & $12: 46(12)$ & $12: 57(13)$ & $13: 22(15)$ \\
\hline 30-Jul & & & & & & & & & & $11: 59(7)$ & $12: 11(8)$ & $11: 47(6)$ \\
\hline 31-Jul & & & & & & & & & & $17: 15(6)$ & $17: 26(7)$ & $17: 38(8)$ \\
\hline 1-Aug & & & & & & & & & & $14: 51(7)$ & 15:07 (8) & $14: 35(6)$ \\
\hline 2-Aug & & & & & & & & & & $13: 43(8)$ & $13: 26(7)$ & $13: 00(6)$ \\
\hline 3-Aug & & & & & & & & & & $16: 35(8)$ & $16: 18(7)$ & $16: 02(6)$ \\
\hline 4-Aug & & & & & & & & & & & & \\
\hline 5-Aug & & & & & & & & & & & & \\
\hline 6-Aug & & & & & & & & & & & & \\
\hline 7-Aug & & & & & & & & & & & & \\
\hline 8-Aug & & & & & & & & & & & & \\
\hline 9-Aug & & & & & & & & & & & & \\
\hline 10-Aug & & & & & & & & & & & & \\
\hline
\end{tabular}


Table S1. Continued

\begin{tabular}{|c|c|c|c|c|c|}
\hline Date Pig & 49 & 50 & 51 & 52 & 53 \\
\hline 2-Jul & & & & & \\
\hline 3-Jul & & & & & \\
\hline 4-Jul & & & & & \\
\hline 5-Jul & & & & & \\
\hline 6-Jul & & & & & \\
\hline 7-Jul & & & & & \\
\hline 8-Jul & & & & & \\
\hline 9-Jul & & & & & \\
\hline 10-Jul & & & & & \\
\hline 11-Jul & & & & & \\
\hline 12-Jul & & & & & \\
\hline 13-Jul & & & & & \\
\hline 14-Jul & & & & & \\
\hline 15-Jul & & & & & \\
\hline 16-Jul & & & & & \\
\hline 17-Jul & & & & & \\
\hline 18-Jul & & & & & \\
\hline 19-Jul & & & & & \\
\hline 20-Jul & & & & & \\
\hline 21-Jul & & & & & \\
\hline 22-Jul & & & & & \\
\hline 23-Jul & & & & & \\
\hline 24-Jul & & & & & \\
\hline 25-Jul & & & & & \\
\hline 26-Jul & & & & & \\
\hline 27-Jul & & & & & \\
\hline 28-Jul & $16: 32(15)$ & $15: 26(10)$ & $10: 28(1)$ & $14: 49(7)$ & $15: 43(11)$ \\
\hline 29-Jul & $10: 39(3)$ & $11: 51(8)$ & $10: 05$ & $12: 30(11)$ & $11: 34(7)$ \\
\hline 30-Jul & $10: 40(2)$ & $11: 11(4)$ & $10: 16(1)$ & $11: 30(5)$ & 10:55 (3) \\
\hline 31-Jul & $16: 15(2)$ & $16: 46(4)$ & $15: 55$ (1) & $17: 01(5)$ & $16: 31(3)$ \\
\hline 1-Aug & 13:19 (2) & $13: 58(4)$ & 12:54 (1) & $14: 17$ (5) & 13:39 (3) \\
\hline 2-Aug & $11: 38(2)$ & $12: 22(4)$ & $11: 14(1)$ & $12: 42(5)$ & 12:01 (3) \\
\hline 3-Aug & $14: 40(2)$ & $15: 24(4)$ & $14: 19$ (1) & $15: 43(5)$ & 15:04 (3) \\
\hline 4-Aug & $15: 39(4)$ & $14: 52(2)$ & $16: 05$ (5) & $15: 16(3)$ & $14: 25(1)$ \\
\hline 5-Aug & 12:58 (2) & $13: 55(5)$ & $12: 28(1)$ & $13: 30(4)$ & 13:16 (3) \\
\hline 6-Aug & 9:57 (2) & $10: 51(4)$ & $9: 28(1)$ & $10: 27(3)$ & $11: 14(5)$ \\
\hline 7-Aug & $9: 41(2)$ & $10: 39(4)$ & $9: 18(1)$ & 11:05 (5) & 10:11 (3) \\
\hline 8-Aug & $15: 38(2)$ & $16: 14(4)$ & $15: 14(1)$ & $16: 37$ (5) & 15:56 (3) \\
\hline 9-Aug & 11:37 (4) & $10: 54(2)$ & $12: 00(5)$ & 10:21 (1) & 11:16 (3) \\
\hline 10-Aug & $11: 30(2)$ & $12: 37(5)$ & 11:14 (1) & $12: 06(4)$ & 11:52 (3) \\
\hline
\end{tabular}




\title{
Chapter 3: Toward the Determination of Minimum Intercarcass Distance for Forensic Entomology Field Methodologies
}

\begin{abstract}
Forensic entomology field researchers commonly place experimental corpses $\leq 50 \mathrm{~m}$ apart. Experimental observations indicate that this intercarcass distance sufficiently prevents cross contamination by crawling larvae, but seems insufficient for highly mobile adult insects. Minimum intercarcass distance should ensure independence of corpses, an assumption of common statistical analyses. For 32 domestic pig carcasses exposed over two years (at a minimum intercarcass distance of $30 \mathrm{~m}$ ), possible relationships between: (1) average distance to another carcass and aspects of the succession interval of forensically important species and (2) intercarcass distance and community similarity indices were determined with regression analyses. In addition, minimum intercarcass distance was investigated through semivariogram analyses of aspects of the succession interval as well as community similarity indices. Minimum succession interval was the only variable that displayed a consistent, and negative, relationship to distance. Semivariogram analysis suggests that commonly used intercarcass distances are satisfactory to ensure independence of carcasses.
\end{abstract}

\section{Introduction}

Insect succession on carrion can be used to estimate the postmortem interval (PMI) (Catts 1992). Forensic insect succession models describe the insect species and life stages present on a corpse over time as a function of multiple ecological factors (Anderson 2010). This period of exposure 
to insects, termed the succession interval (SI) accounts for the time elapsed prior to presence and can therefore be used to estimate the minimum and maximum $\mathrm{SI}\left(\mathrm{SI}_{\min }\right.$ and $\left.\mathrm{SI}_{\max }\right)$. Forensic statistical methods should allow for probabilities to be associated with PMI estimations (National Research Council 2009). The only statistical method available for analyzing occurrence data from replicate carcasses (LaMotte and Wells 2000) suggests that $\approx \geq 20$ replicate corpses are necessary to be able to reject an SI value and thereby place a confidence interval about an SI estimate. Generating large succession datasets using human corpses is difficult because there are limited locations authorized for their outdoor exposure (Mann et al. 1990) as well as paucity in availability. As a result, succession researchers have most often used the domestic pig, Sus scrofa, as a surrogate for human corpses (Matuszewski et al. 2008, Sharanowski et al. 2008, Horenstein et al. 2010, Anton et al. 2011, Ortloff et al. 2012, Pastula and Merritt 2013), with initial support from the few studies to directly compare insect fauna and decomposition of pig ( 23 kg) and human corpses (Carvalho et al. 2000, Schoenly et al. 2007).

Even when based on pig carcasses, generation of large succession datasets characterizing ecologically distinct regions presents tremendous practical difficulties (Matuszewski 2011, 2012) due to time and space constraints. For an investigator, both space and time are optimized as the distance between corpses decreases. But analytically, the spacing should ensure independence of corpses, the basis of true replication for statistical analysis. For within site placement, $100 \mathrm{~m}$ between carcasses is suggested (Schoenly et al. 1991) but commonly corpses are placed $\sim 50 \mathrm{~m}$ apart (e.g. Anderson and VanLaerhoven 1996, Avila and Goff 1998, Archer and Elgar 2003, Tabor et al. 2004, Eberhardt and Elliot 2008, Segura et al. 2009, Voss et al. 2009, Michaud and Moreau 2009, and Matuszewski et al. 2010). This distance seems sufficient to avoid cross- 
contamination by crawling larvae (Greenberg 1990, Lewis and Benbow 2011), but given the high mobility of carrion-seeking adult insects (Bishopp and Laake 1921, Gilmour et al. 1946, MacLeod and Donnelly 1963, and Mayer and Atzeni 1993, Roslin 2000, Tomlin et al. 2006) a concern is that $>1$ corpse will "compete" for the same insects.

Michaud et al. (2012) suggested possible analytical approaches to determine minimum intercarcass distance for such experiments. These included the use of a geostatistical analysis, with a history of ecological use (Carroll and Pearson 1998, Crist 1998, King et al. 2010). The semivariogram tests for spatial autocorrelation of carcasses separated by varying distances. Generally, the observation that a variable measured at two distances are more, or less, similar than would be expected from a random pair of samples indicates positive, or negative, spatial autocorrelation, respectively (Legendre 1993). A semivariogram depicts spatial autocorrelation by fitting a model to a plot of the average variance of the measured variable as a function of pairwise distance (Figure 1). Each data point represents the variance of data in a specified lag class. Lag classes define the distance intervals in which pairs of observations are grouped. The range of the semivariogram is the distance where variance peaks or flattens and represents the minimum distance for which two observations are not spatially autocorrelated (Figure 1).

Presumably, if there is an effect of intercarcass distance it might be detected in terms of $\mathrm{SI}_{\min }$, SI width, and community similarity indices. However, the aspects of carrion insect biology that might cause non-independence of carcasses suggest potential contradictory effects of intercarcass distance. Two corpses might "compete" for the same adult insects (Shahid et al. 2003), a process that would presumably retard succession, causing an increase in $\mathrm{SI}_{\min }$ and/or width when 
intercarcass distance is reduced. The nearby presence of a carcass installed earlier might "prime" the carrion insect population (Conley 1982), that is, increase the local pool of colonizing insects. This would result in a decreased $\mathrm{SI}_{\min }$ for latter-placed carcasses. Another plausible mechanism for non-independence could be simply very local differences in carrion insect activity rather than any "interaction" of carcasses. This mechanism might produce a negative relationship between intercarcass distance and an index of community similarity of forensically important species.

The Jaccard similarity index (JSI) is commonly used in forensically focused studies to measure carrion insect community similarity across carcasses (e.g. Schoenly and Reid 1987, Schoenly 1992, Tabor et al. 2004, 2005, De Jong and Hoback 2006, Shi et al. 2009, Bunchu et al. 2012) and is attractive for use because it is based on presence/absence data, is easily calculable by dividing the total number of taxa shared by two corpses by the total number of taxa collected, and is suggested for use in comparison to other occurrence-based approaches (Janson and Vegelius 1981). The JSI ranges from zero to one, representing no species in common to complete overlap of species from pairwise carcasses. Less often, forensic entomology studies use abundance-based similarity indices, like Morisita's metric (Schoenly and Hall 2002), likely because abundance measures are not always possible given common sampling schemes. An abundance based similarity index could identify differences/similarities not able to be detected with occurrence-based approaches (Chao et al. 2008). Morisita's metric is advocated in comparison to other abundance-based indices because of demonstrated attractive statistical qualities (i.e. robust to effects of sample size and diversity (Wolda 1981)). Morista's metric $\left(C_{D}\right)$ (Morisita 1959) is : 


$$
C_{D}=\frac{2 \sum_{i=1}^{s} x_{i} y_{i}}{\left(D_{x}+D y\right) X Y}
$$

where $x_{i}$ and $y_{i}$ are the number of times a species $i$ occurs in the total sample $\mathrm{X}$ and $\mathrm{Y}$, respectively. The product of $x_{i}$ and $y_{i}$ are summed for each species (total S) in either of the two samples. Simpson's diversity index (Simpson 1949) for each of sample $D_{x x}$ and $D y$ is calculated with the formula below.

$$
D_{x}=\frac{\sum_{i=1}^{s} x_{i}\left(x_{i}-1\right)}{X(X-1)}
$$

The Simpson's diversity index gives the probability that two random individuals drawn from the same sample belong to the same species ranging from zero to one. The closer the value is to one, the lower the species diversity. Morisita's metric ranges from zero to slightly over one: a zero value represents no species overlap, a value of $\sim 1$ indicates complete overlap of species occurring in the same proportions.

This study aims to estimate the minimum effective distance to ensure independent carcasses for forensic insect succession studies. Because intercarcass distance plausibly affects aspects of both carrion insect population and community dynamics, four variables ( $\mathrm{SI}_{\min }$, $\mathrm{SI}$ length, and two community similarity indices) were utilized to: (1) test for a relationship to intercarcass distance through regression analysis and (2) determine minimum effect distance through semivariogram analysis. These relationships and distances were investigated for the same season of two different years with the expectation of similar trends/values across years. 


\section{Material and Methods}

\section{Data Collection}

A total of 51 pigs were each exposed for a 14-day period during the summer months (July and August) of two consecutive years (20 pigs exposed in 2009, 31 pigs exposed in 2010) in Rensselear, Indiana, USA. Because of limited pig availability, few of the pigs shared exactly the same exposure period. Those pigs sharing the exact same exposure period were considered to be in the same batch. Only pigs with similar distances across years were included in further analyses, resulting in 16 replicates per year (Figure 2). The placement site of each pig was located in the full shade of mature oak woodlots fragmented across corn and soybean fields. No two pigs shared the exact same pig placement site (across years) and each pig placement site within year was separated by at least 30 meters. Placement sites and the distance between placement sites were determined and recorded with an eTrex Summit HC handheld GPS receiver (Garmin Ltd, Olathe, Kansas). Pairwise distance was determined by plotting pig placement sites on a Cartesian coordinate system and calculating the Euclidean distance separating each pair of points.

Each pig weighed $16 \mathrm{~kg} \pm 2.5 \mathrm{~kg}$ and was protected from large vertebrate scavengers by a hardware cloth cage staked to the ground. Daily collections, for each of the 14 days consisted of a sweep net sample (eight rapid passes of a net directly over the body) and three handpicked samples; (1) maggots preserved on site, (2) maggots reared to adulthood for ease of identification, and (3) all other adult and immature insects in the immediate vicinity of the 
corpse. To ensure consistent sampling across pig carcasses, all handpicked samples were collected in exactly 20 minutes. Handpicked and sweepnet samples have been documented to yield the highest percentage of forensically important insects (Schoenly et al. 2007).

\section{Similarity Indices}

An occurrence matrix was created, for each exposed pig, with species as columns, days as rows and each cell containing either a zero (absence) or one (presence). Columns were summed and any species total greater than zero was scored as a one. The resultant row represents the presence/absence of all species collected during the entire 14-day exposure period and was used to calculate the JSI (see Introduction) for all pair-wise comparisons of the 16 carcasses exposed in each year. Daily abundance counts for only adult dipteran species collected by sweepnet were summed for the entire exposure period and used to calculate Morisita's metric (see Introduction) for all pair-wise comparisons of the 16 carcasses exposed in each year.

\section{Regression Analyses}

To visualize the relationship between intercarcass distance and community similarity, four regression analyses and t-tests of zero slope were performed for each year of placement and both similarity indices. For each of eight species, previously determined to be abundant and nonreoccurring (Necrodes surinamensis (adult),Necrophila americana (larva), Creophilus maxillosus (adult), Necrobia ruficollis (adult), Fannia scalaris (larva), Cochliomyia macellaria (larva), Phormia regina (larvae), and Lucillia illustris (larva)) (Chapter 4), three separate 
regression analyses and t-tests of slope were performed to determine the relationship of intercarcass distance (recorded for each pig carcass as average distance away from any other carcass placed in the same year) to $\mathrm{SI}_{\min }$, $\mathrm{SI}$ width. In the same manner, a possible effect of priming was explored by determining the relationship of $\mathrm{SI}_{\min }$ to order of carcass exposure (relation to first batch). For the 16 pigs per year determined to have similar placement site distances, in 2009, there were three different batches and in 2010 there were five different batches (recorded as 1-5). Because of the similarity of time elapsed between placements, the three batches of 2009 were recorded as one, three, and five. All regression analyses and t-tests of regression line slope were preformed in Excel 2007 (Microsoft Corporation, Redmond, Washington). In an attempt to control the family-wise error rate the critical $p$ - value was lowered to $p<0.0021(0.05 / 24)$.

\section{Semivariogram Analyses}

Jaccard and Morisita's metric as well as the $\mathrm{SI}_{\min }$ of $P$. regina and L. illustris were analyzed as Zvalues for each of the two years. The $\mathrm{SI}_{\min }$ semivariograms were restricted to two species, $P$. regina and L.illustris, because they were present on all carcasses included in the study resulting in the use of the same lag classes and number of lag classes. All metrics were log transformed prior to analysis. Isotropic semivariogram analyses were performed using the geostatistics software, GS+ Version 9 (Gamma Design Software, LLC, Plainwell, Michigan). Model type (linear, spherical, Gaussian, or exponential) varied by analysis and was determined by the GS+ software according to best fit. Custom lag classes were used for each year so that each lag class represented at least 30 pairs of points (Journal and Huijbregts 1987), resulting in a total of 6 lag classes. The active lag distance was set to the largest distance between any two exposed pigs in 
order to include all measured comparisons. Semivariogram models can deteriorate when maximum distances are included because of fewer observations, but this was not observed as the active lag distance was manipulated between $80 \%$ (GS + default setting) and $100 \%$ of the largest distance.

\section{Results and Discussion}

\section{Regression Analyses}

All four regression analyses, resulting from two years of data and two different community similarity indices, failed to detect a relationship of community similarity and intercarcass distance (Figure 3, Table 1). There was no consistent effect (positive or negative) of average distance to other carcasses on SI width or of batch on $\mathrm{SI}_{\min }$ (Figure 4). However, a negative relationship between average distance to other carcasses and $\mathrm{SI}_{\min }$ was observed for all 8 species analyzed (Figure 4, Table 2). Although, this relationship was not statistically significant, the consistent effect of distance on $\mathrm{SI}_{\min }$ would be an intriguing avenue of future research in investigations of minimum effective distance.

From an ecological perspective, dependence of community or population characteristics (e.g. abundance (Michaud et al. 2012) or similarity indices) on intercarcass distance can serve as an indication of community and metacommunity dynamics. From a purely forensic standpoint, an effect on community is of interest because of the potential influence on aspects of the SI of forensically important insect species, which can be measured directly. Average distance to other carcasses potentially results in training data underestimating $\mathrm{PMI}_{\min }$. Given the large sample 
sizes necessary to execute the previously proposed methodological approaches (Michaud et al. 2012) ( $\geq 16$ carcasses) less labor intensive data collection and variable calculation are valuable conditions for future investigators. Practically, the focus of forensic investigators should be independence of a metric (like $\mathrm{SI}_{\min }$ ) that directly affects PMI estimates and is the likely variable subject to statistical analysis.

\section{Semivariogram Analyses}

Many semivariogram analyses were best described by horizontal, linear best fit lines, indicating the independence of distance and the measured variable at sampling intervals $\geq 30 \mathrm{~m}$, resulting in uninformative range values ( $\mathrm{SI}_{\min }$ of L. illustris both years and Morisita Index 2010) (Figures 5 and 6). Although half of the semivariograms were best described by spherical and exponential models (resembling "textbook" semivariograms (Figure 1) and providing ranges spanning 25.5 to $75.8 \mathrm{~m}$ ), $\mathrm{r}^{2}$ values were extremely low (Figures 5 and 6 ). In addition, these variograms contained no discernible correlation between distance and dissimilarity at low lag values (Figures 5 and 6). In sum, the semivariogram analyses suggest commonly used experimental distances are sufficient to ensure independence of measurements taken from experimentally exposed carcasses. 


\section{References}

Anderson GS. 2010. Factors that influence insect succession on carrion. in: JH Byrd and JL Castner eds., Forensic Entomology: The Utility of Arthropods in Legal Investigations, $2^{\text {nd }}$ Edition, CRC Press, Boca Raton, FL. pp. 201-250.

Anderson GS and SL VanLaerhoven. 1996. Initial studies on insect succession on carrion in southwestern British Columbia. Journal of Forensic Sciences 41(4): 617-625.

Anton E, S Niederegger and RG Beutel. 2011 Beetles and flies collected on pig carrion in an experimental setting in Thuringia and their forensic implications. Medical and Veterinary Entomology 25(4): 353-364.

Archer MS and MA Elgar. 2003. Early activity patterns in southern Victoria (Australia) of seasonally active carrion insects. Forensic Science International 132: 173-176.

Avila FW and ML Goff. 1998. Arthropod succession patterns onto burnt carrion in two contrasting habitats in the Hawaiian Islands. Journal of Forensic Sciences 43(3): 581-586.

Bishopp FC and LW Laake. 1921. Dispersion of flies by flight. Journal of Agricultural Research 21: 729-766.

Bunchu N, K Sukontason, S Sanit, P Chidburee, H Kurahashi and K Sukontason. 2012.

Occurrence of blow fly species (Diptera: Calliphoridae) in Phitsanulok Province, Northern Thailand. Tropical Biomedicine 29(4): 532-543.

Carroll SS and DL Pearson. 1998. The effects of scale and sample size on the accuracy of spatial predictions of tiger beetles (Cicindelidae) species richness. Ecography 21: 401-414.

Carvalho LML, PJ Thyssen, AX Linhares and FAB Palhares. 2000. Checklist of arthropods associated with pig carrion and human corpses in southeastern Brazil. Memórias do Instituto Oswaldo Cruz 95:135-138. 
Catts EP. 1992. Problems in estimating the postmortem interval in death investigations. Journal of Agricultural Entomology 9(4): 245-255.

Chao A, L Jost, SC Chiang, Y-H Jiang and RL Chazdon. 2008. A two-stage probabilistic approach to multiple-community similiarity indices. Biometrics 64: 1178-1186.

Conley MR. 1982. Carrion locating efficiency in burying beetles, Nicrophorus carolinus (L.) (Silphidae). The Southwestern Naturalist 27(1): 11-15.

Crist TO. 1998. The spatial distribution of termites in shortgrass steppe: a geostatistical approach. Oecologia 114(3): 410-416.

De Jong GD and WW Hoback. 2006. Effect of investigator disturbance in experimental forensic entomology: succession and community composition. Medical and Veterinary Entomology 20: 248-258.

Eberhardt TL and DA Elliot. 2008. A preliminary investigation of insect colonization and succession on remains in New Zealand. Forensic Science International 176: 217-223.

Gilmour D, DF Waterhouse and GA McIntyre. 1946. An account of experiments undertaken to determine the natural population density of the sheep blowfly, Lucilia cuprina Wied. Council for Scientific and Industrial Research Organisation Bulletin 195. 39 pp.

Greenberg B. 1990. Behavior of postfeeding larvae of some Calliphoridae and a muscid (Diptera). Annals of the Entomological Society of America 83: 1210-1214.

Horenstein MB, AX Linhares, BR De Ferradas and MD Garcia. 2010. Decomposition and dipteran succession in pig carrion in Central Argentina: ecological aspects and their importance in forensic science. Medical and Veterinary Entomology 24(1): 16-25. 
Janson S and J Vegelius. 1981. Measures of ecological association. Oecologia 49(3): 371-376.

Journal AG and CJ Huijbregts. 1978. Mining Geostatistics. Academic Press. London, England. $600 \mathrm{pp}$.

Karl JW and BA Maurer. 2010. Spatial dependence of predictions from image segmentation. A semivariogram-based method to determine appropriate scales for producing land-management information. Ecological Informatics 5: 194-202.

King AJ, KR Freeman, KF McCormick, RC Lynch, C Lozupone, R Knight and SK Schmidt. 2010. Biogeography and habitat modeling of high alpine bacteria. Nature Communications. DOI: $10.10381 /$ ncomms 1055 .

LaMotte LR and JD Wells. 2000. $p$-values for postmortem intervals from arthropod succession data. Journal of Agricultural, Biological, and Environmental Statistics 5(1): 58-68.

Legendre P. 1993. Spatial autocorrelation: trouble or new paradigm? Ecology 74: 1659-1673.

Lewis AJ and ME Benbow. 2011. When entomological evidence crawls away: Phormia regina en masse larval dispersal. Journal of Medical Entomology 48(6): 1112-1119.

MacLeod J and J Donnelly. 1963. Dispersal and interspersal of blowfly populations. Journal of Animal Ecology 32(1): 1-32.

Mann MA, WM Bass and L Meadows. 1990. Time since death and decomposition of the human body: variables and observations in case and experimental field studies. Journal of Forensic Sciences 35(1): 103-111.

Matuszewski S. 2011. Estimating the pre-appearance interval from temperature in Necrodes littoralis L. (Coleoptera: Silphidae). Forensic Science International 212: 180-188. 
Matuszewski S. 2012. Estimating the preappearance interval from temperature in Creophilus maxillosus L. (Coleoptera: Silphidae). Journal of Forensic Sciences 57(1): 136-145.

Matuszewski S, D Bajerlein, S Konwerski and K Szpila. 2008. An initial study of insect succession and carrion decomposition in various forest habitats of Central Europe. Forensic Science International 180: 61-69.

Matuszewski S, D Bajerlein, S Konwerski and K Szpila. 2010. Insect succession and carrion decomposition in selected forests of Central Europe Part 1: Pattern and rate of decomposition. Forensic Science International 194: 85-93.

Mayer DG and MG Atzeni. 1993. Estimation of dispersal distances for Cochliomyia hominovorax (Diptera: Calliphoridae). Environmental Entomology 22: 368-374.

Michaud JP and G Moreau. 2009. Predicting the visitation of carcasses by carrion-related insects under different rates of degree-day accumulation. Forensic Science International 185: 78-83.

Michaud JP, KG Schoenly and G Moreau. 2012. Sampling flies or sampling flaws? Experimental design and inference strength in forensic entomology. Journal of Medical Entomology 49(1): 1 10 .

Morisita M. 1959. Measuring of interspecific association and similarity between communities. Memoirs of the Faculty of Science, Kyushu University Series E (Biology) 3(1): 65-80.

National Resource Council. 2009. Strengthening forensic science in the United States: a path forward. National Academies Press, Washington, DC, 352 pp.

Ortloff A, P Pena and M Riquelme. 2012. Preliminary study of the succession pattern of necrobiont insects, colonizing species and larvae on pig carcasses in Temuco (Chile) for forensic applications. Forensic Science International 222(1): e36-e41. 
Pastula EC and RW Merritt. 2013. Insects arrival pattern and succession on buried carrion in Michigan. Journal of Medical Entomology 50(2): 432-439.

Roslin T. 2000. Dung beetle movements at two spatial scales. Oikos 91(2): 323-335.

Schoenly KG. 1992. A statistical analysis of successional patterns in carrion-arthropod assemblages: implications for forensic entomology and determination of the postmortem interval. Journal of Forensic Sciences 37(6): 1489-1513.

Schoenly KG and W Reid. 1987. Dynamics of hetertrophic succession in carrion arthropod assemblages: discrete series or a continuum of change? Oecologia 17: 192-202.

Schoenly KG, K Griest and S Rhine. 1991. An experimental field protocol for investigating the postmortem interval using multidisciplinary indicators. Journal of Forensic Sciences 36(5): 1395-1415.

Schoenly KG and RD Hall. 2002. Testing reliability of animal models in research and training programs in forensic entomology, part II, final report. Document No. 192281.

Schoenly KG, NH Haskell, RD Hall and JR Gbur. 2007. Comparative performance and complimentarity of four sampling methods and arthropod preference tests from human and porcine remains at the forensic anthropology center in Knoxville, Tennessee. Journal of Medical Entomology 44(5): 881-894.

Segura NA, W Usaquen, MC Sanchez, L Chuaire and F Bello. 2009. Succession pattern of cadaverous entomofauna in a semi-rural area of Bogota, Colombia. Forensic Science International 187: 66-72. 
Shahid SA, K Schonely, NH Haskell, RD Hall and W Zhang. 2003. Carcass enrichment does not alter decay rates or arthropod community structure: a test of the arthropod saturation hypothesis at the anthropological research facility in Knoxville, Tennessee. Journal of Medical Entomology 40(4): 559-569.

Sharanowski BJ, EG Walker and GS Anderson. 2008. Insect succession and decomposition patterns on shaded and sunlight carrion in Saskatchewan in three different seasons. Forensic Science International 179: 219-240.

Shi Y-W, X-S Liu, H-Y Wang and R-J Zhang. 2009. Seasonality of insect succession on exposed rabbit carrion in Ghuangzhou, China. Insect Science 16: 425-439.

Simpson EH. 1949. Measurement of diversity. Nature 163: 688.

Tabor KL, CC Brewster and RD Fell. 2004. Analysis of the successional patterns of insects on carrion in southwest Virginia. Journal of Medical Entomology 41(4): 785-795.

Tabor KL, RD Fell, CC Brewster, K Pelzer and GS Behonick. 2005. Effects of antemortem ingestion of ethanol on insect successional patterns and development of Phormia regina (Diptera: Calliphoridae). Journal of Medical Entomology 42(3): 481-489.

Tomlin AD, DGR McLeod, LV Moore, JW Whistlecraft, JJ Miller and JH Toleman. 2006. Dispersal of Aleochata bilineata (Coleoptera: Staphylinidae) following inundative releases in urban gardens. Entomophaga 37(1): 55-63.

Voss SC, H Spafford and IR Dadour. 2009. Annual and seasonal patterns of insect succession on decomposing remains at two locations in Western Australia. Forensic Science International 193: 26-36.

Wolda H. 1981. Similarity indices, sample size and diversity. Oecologia 50: 296-302. 


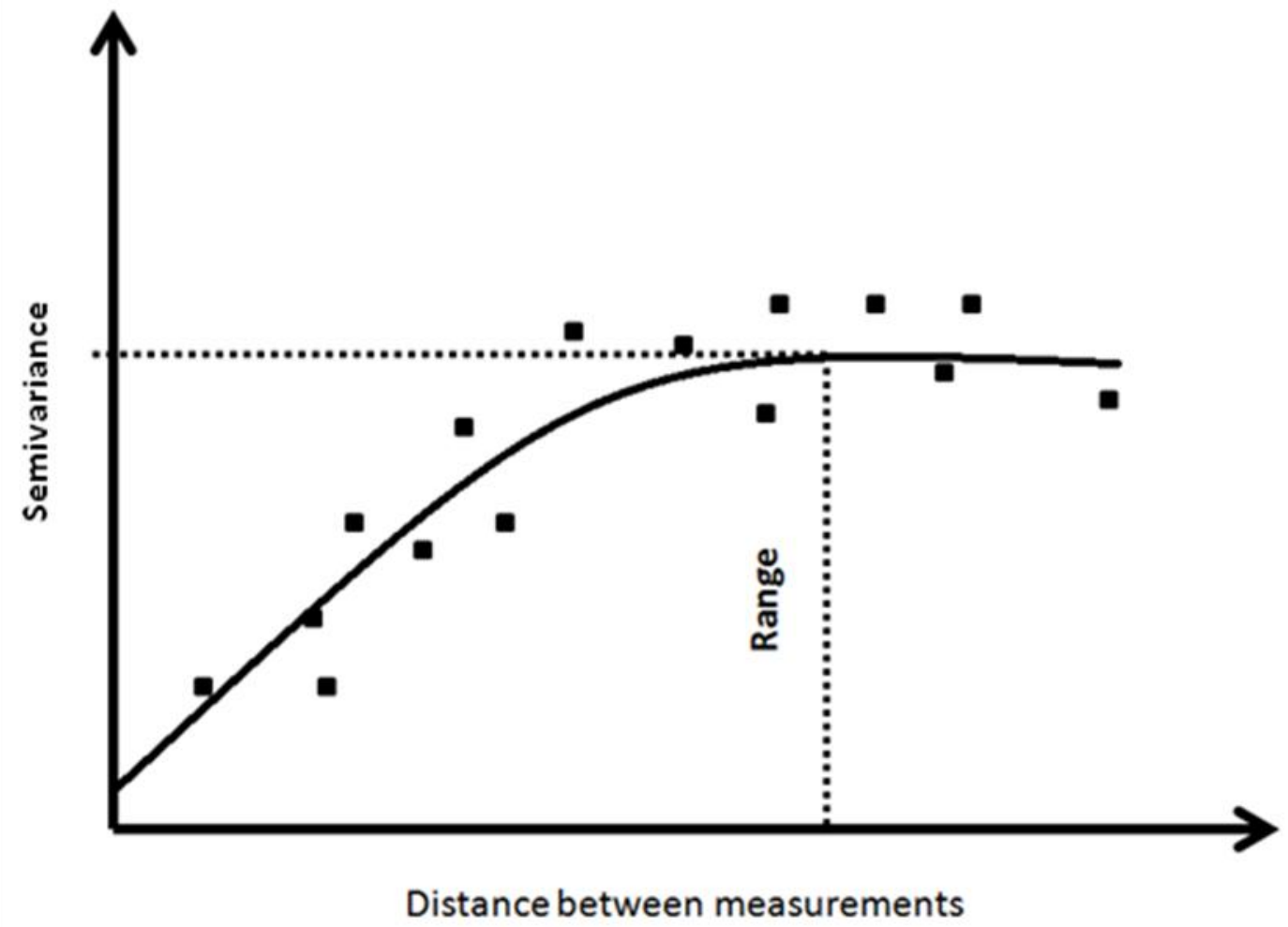

Figure 1. A hypothetical semivariogram (modified from figure 2 of Karl and Maurer 2010) 

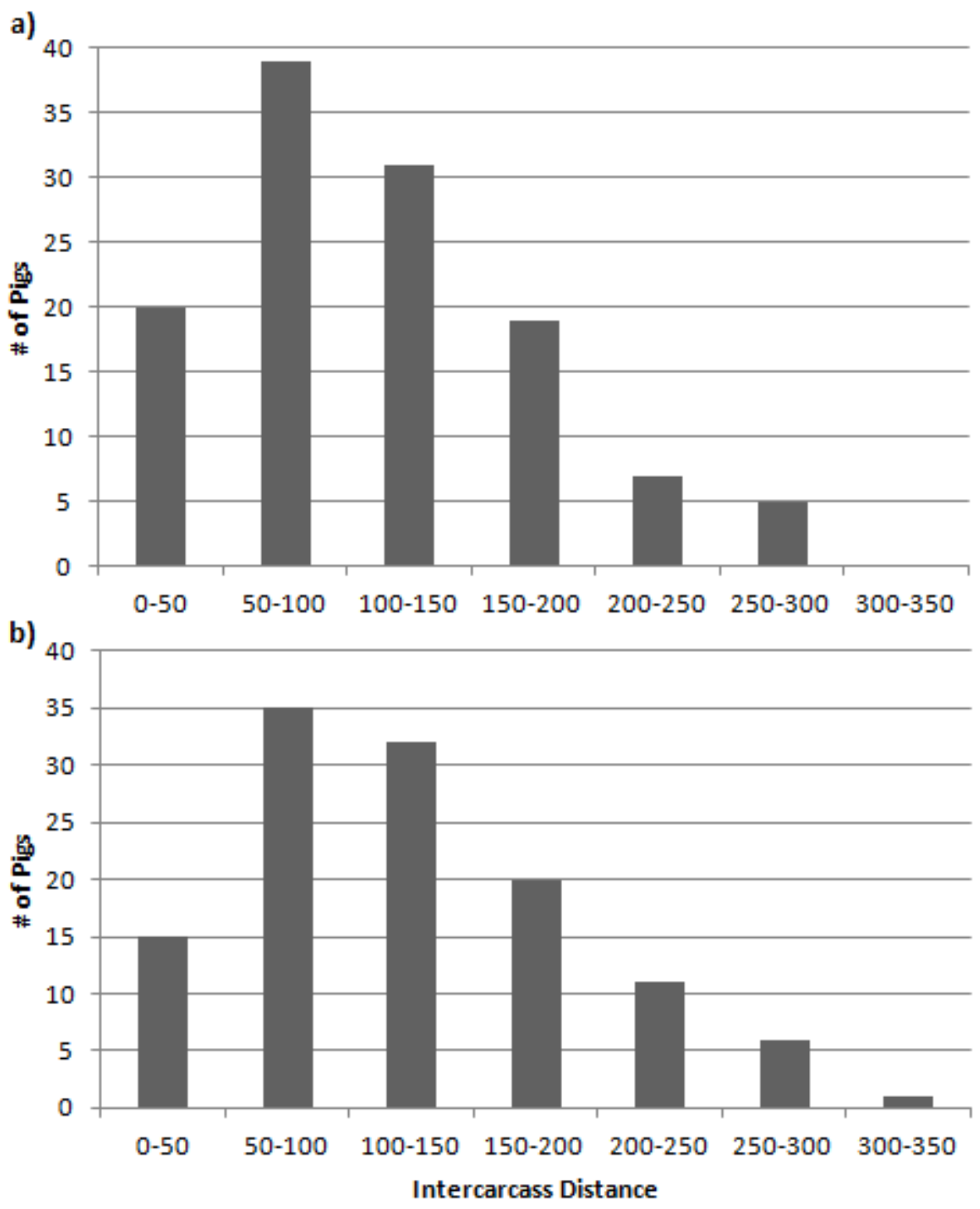

Figure 2. Frequency distribution of intercarass distance for years a) 2009 and b) 2010 

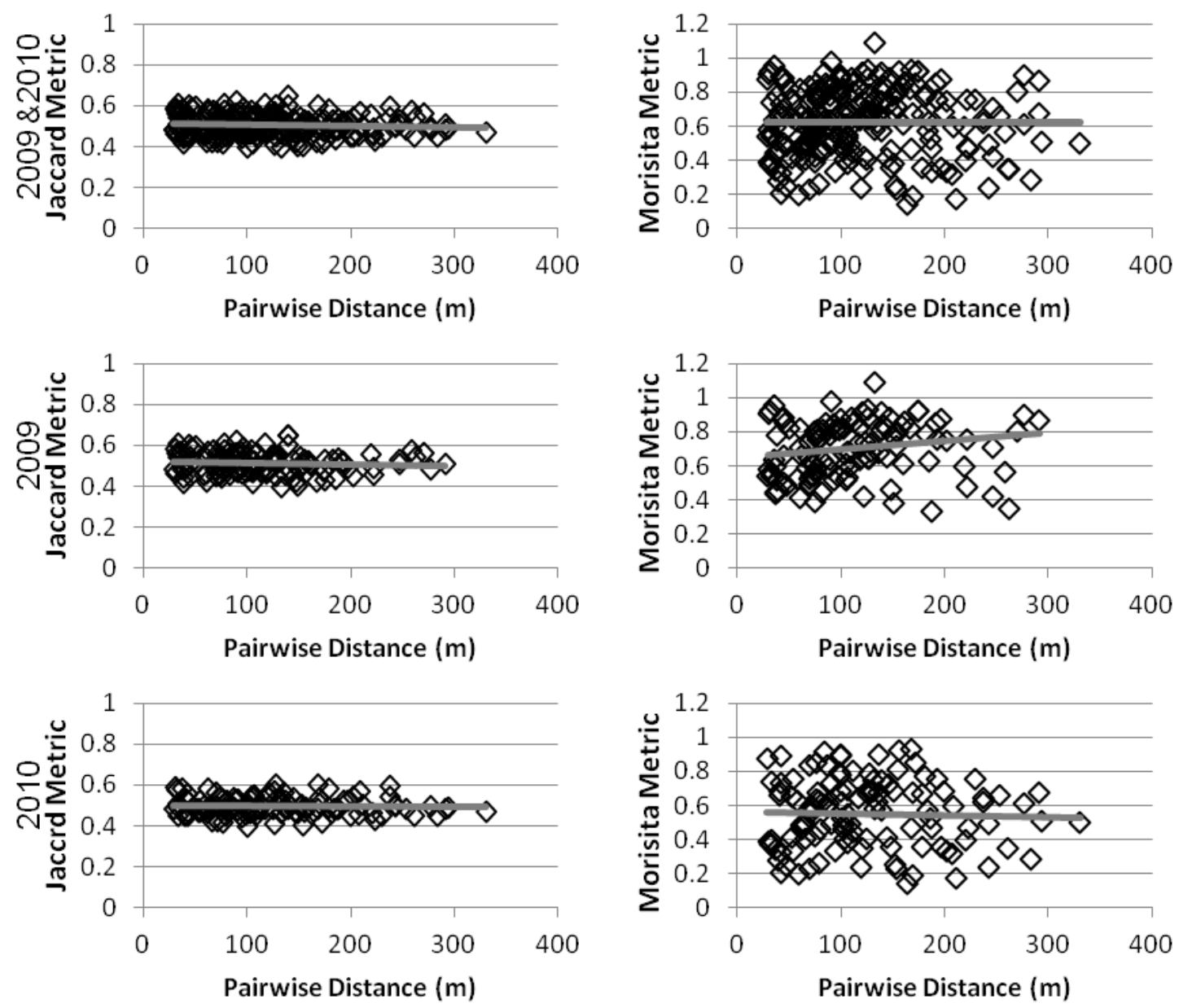

Figure 3. The absence of a relationship between insect community similarity index and distance of pair-wise comparisons of pig carcasses. See Table 1 for associated $\mathrm{r}^{2}$, linear equations, and $p$ values. 

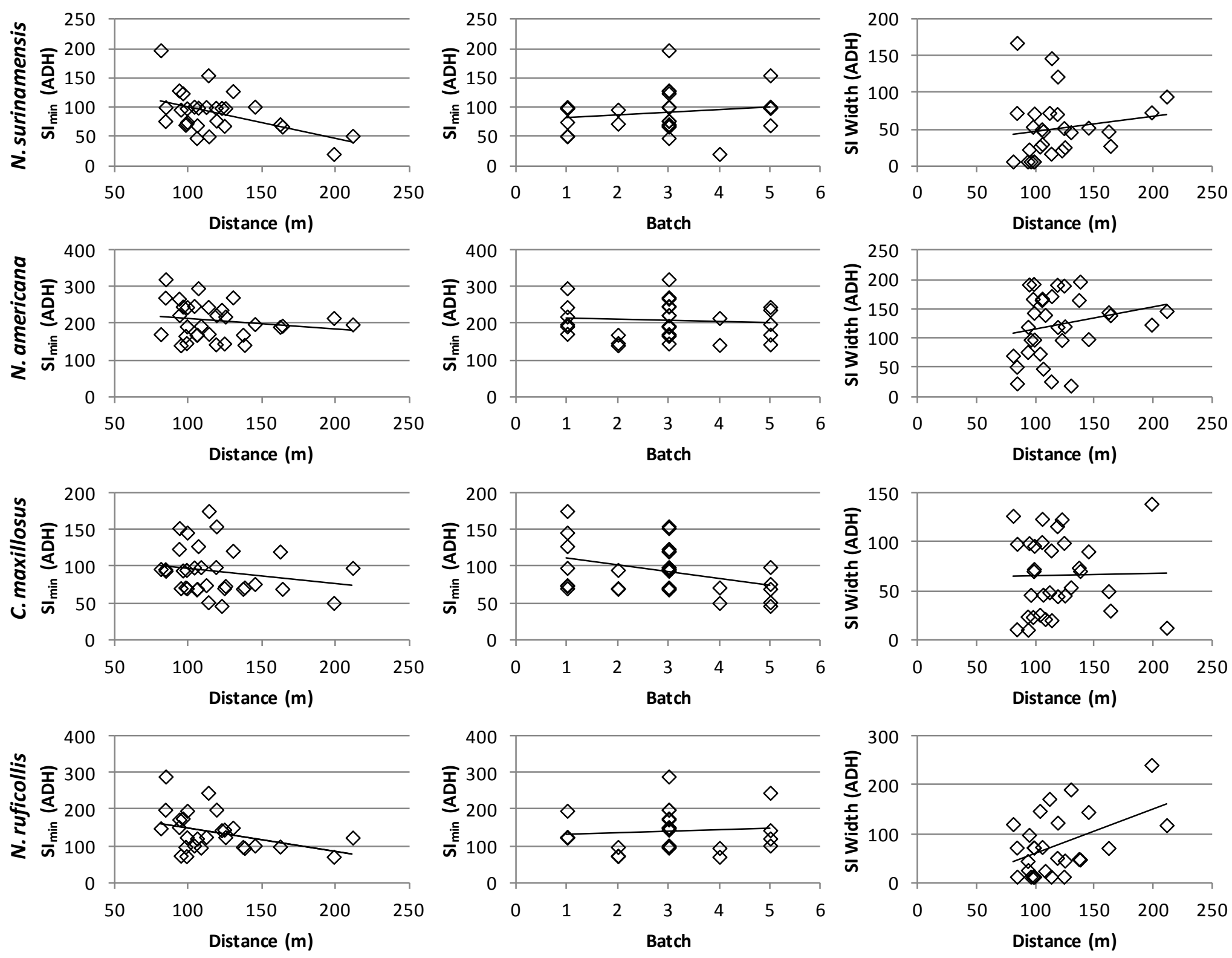

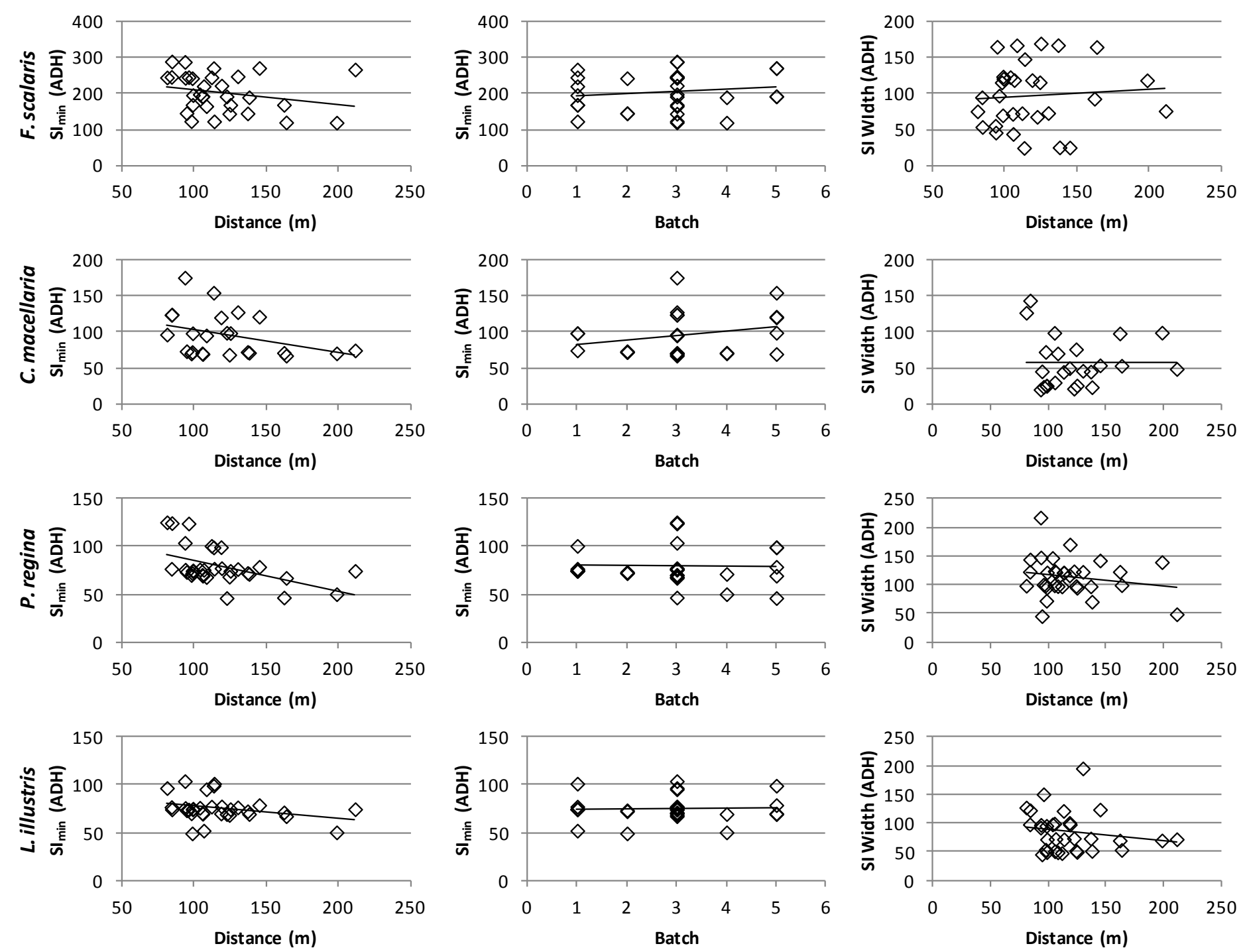

Figure 4. Relationship of $\mathrm{SI}_{\min }$ to distance and batch, as well as $\mathrm{SI}$ width to distance for 8 common and nonreoccuring species. See Table 2 for associated $\mathrm{r}^{2}$, linear equations, and $p$-values. 

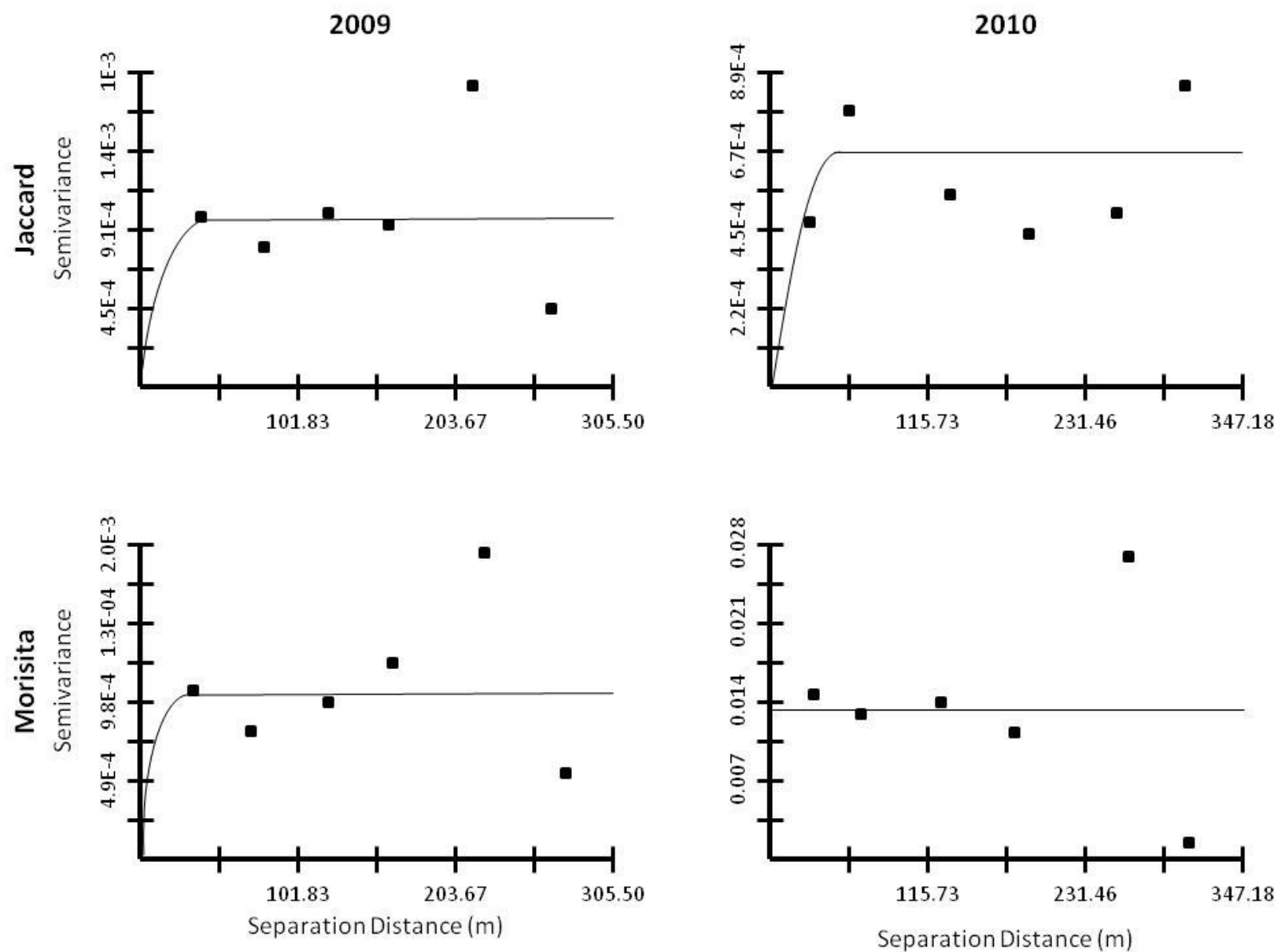

Figure 5. Community similarity (measured as either a Jaccard similarity index or a Morisita's index) semivariograms for two years of data. Range distance and $\mathrm{r}^{2}$ for each semivariogram: Jaccard 2009, $\mathrm{r}^{2}=0.000$, range $=41.1 ;$ Jaccard 2010, $\mathrm{r}^{2}=0.105$, range $=74.3$; Morisita 2009, $r^{2}=0.000$, range $=25.5$; Morisita 2010, $\mathrm{r}^{2}=0.008$, range $=292.4$. 

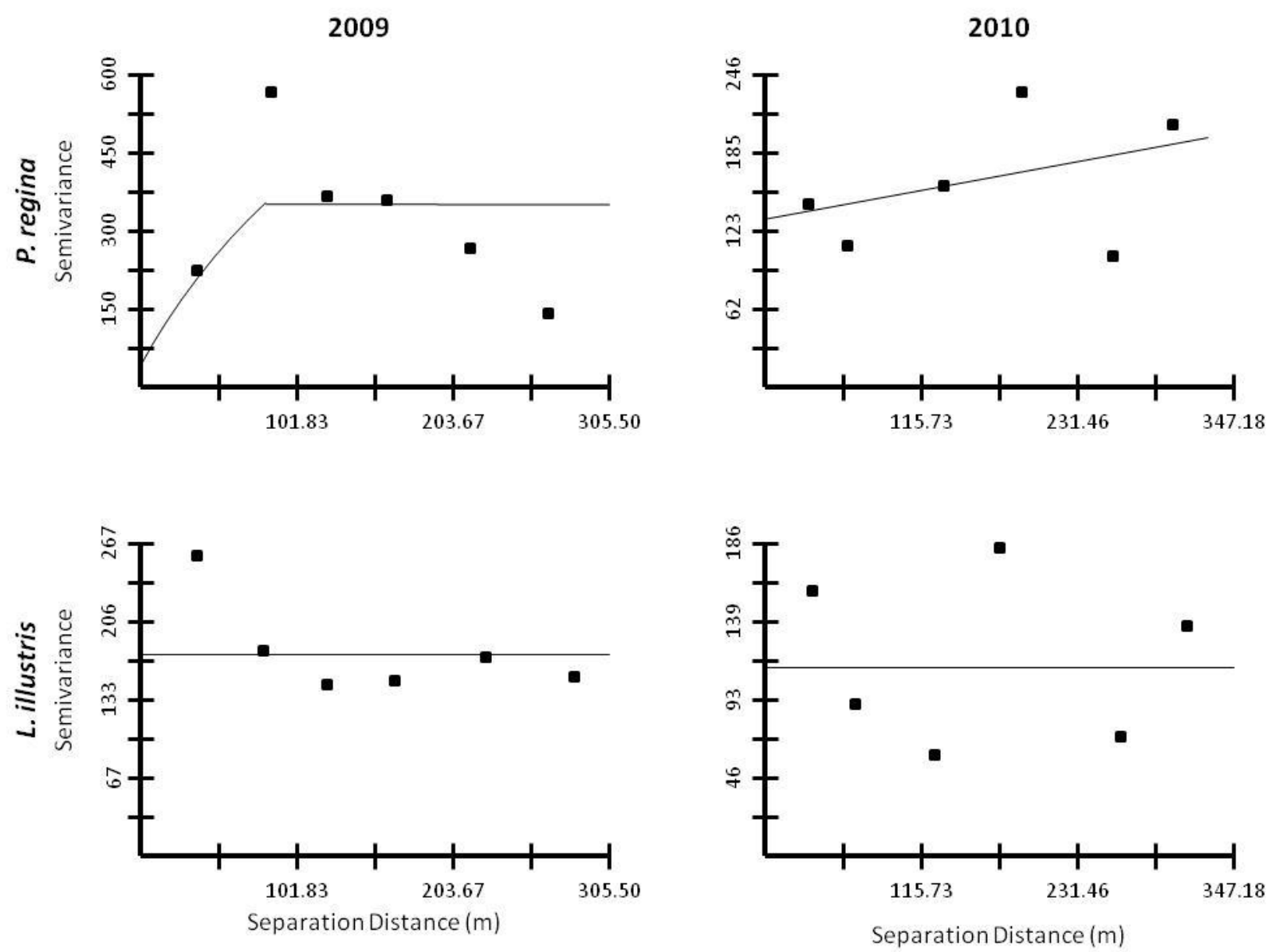

Figure 6. $\mathrm{SI}_{\min }$ semivariograms for two selected forensically important species for two years of data. Range distance and $\mathrm{r}^{2}$ for each semivariogram: $P$. regina $2009 \mathrm{r}^{2}=0.076$, range $=75.8$, P.regina $2010 \mathrm{r}^{2}=0.112$, range $=305.04$; L. illustris $2009 \mathrm{r}^{2}=0.445$, range $=264.23$ L. illustris $2010 \mathrm{r}^{2}=0.000$, range $=305.0$. 
Table 1. The coefficients of determination, equations and $p$-values of $\mathrm{H}_{0}: \beta_{1}=0$ for community similarity indices vs. average pairwise distance

\begin{tabular}{ccccccc}
\cline { 2 - 6 } & \multicolumn{2}{c}{ Total } & \multicolumn{2}{c}{2009} & \multicolumn{2}{c}{2010} \\
\cline { 2 - 7 } & Jaccard & Morisita & Jaccard & Morisita & Jaccard & Morisita \\
\hline $\mathrm{r}^{2}$ & 0.0066 & 0.0000001 & 0.0056 & 0.0264 & 0.0026 & 0.0013 \\
$p$-value & 0.2113 & 0.9851 & 0.4068 & 0.0714 & 0.5793 & 0.6968 \\
\hline
\end{tabular}


Table 2. The coefficients of determination and $p$-values of $\mathrm{H}_{0}: \beta_{1}=0$ for $\mathrm{SI}_{\min }$ vs. distance, $\mathrm{SI}_{\min }$ Vs. carcass exposure order (Priming) and SI width vs. distance

\begin{tabular}{cccccccccc}
\hline & & N. surinamensis & N. americana & C. maxillosus & N. ruficollis & F. scalaris & C. macellaria & P. regina & L. illustris \\
\hline SI $_{\min }$ & $\mathrm{r}^{2}$ & 0.2389 & 0.0315 & 0.0435 & 0.1471 & 0.0630 & 0.1246 & 0.2381 \\
& $p$ & 0.0083 & 0.3391 & 0.2519 & 0.0483 & 0.1731 & 0.0906 & 0.0046 & 0.0984 \\
\hline \multirow{2}{*}{ Priming } & $\mathrm{r}^{2}$ & 0.0039 & 0.0052 & 0.1434 & 0.0101 & 0.0025 & 0.0048 & 0.0068 \\
& $p$ & 0.7530 & 0.7007 & 0.0326 & 0.6187 & 0.7881 & 0.7488 & 0.6538 & 0.0059 \\
\hline \multirow{2}{*}{ SI Width } & $\mathrm{r}^{2}$ & 0.0247 & 0.0470 & 0.0003 & 0.2163 & 0.0051 & 0.0001 & 0.0348 & 0.0305 \\
& $p$ & 0.4242 & 0.2412 & 0.9344 & 0.0145 & 0.7036 & 0.9914 & 0.3068 \\
\hline
\end{tabular}




\title{
Chapter 4: Evaluating the utility of hexapod species for calculating a confidence interval about a succession based postmortem interval estimate*
}

\begin{abstract}
Carrion insect succession patterns have long been used to estimate the postmortem interval (PMI) during a death investigation. However, no published carrion succession study included sufficient replication to calculate a confidence interval about a PMI estimate based on occurrence data. We exposed 53 pig carcasses $(16 \pm 2.5 \mathrm{~kg})$, near the likely minimum needed for such statistical analysis for two taxa, at a site in northcentral Indiana, USA, over three consecutive summer seasons. Insects and Collembola were sampled daily from each carcass for a total of 14 days, by which time each was skeletonized. A life stage of a given species was judged to be potentially useful for succession-based PMI estimation if it was 1) nonreoccurring (one period of presence on a corpse), and 2) found in a sufficiently large proportion of carcasses to support a PMI confidence interval. For this dataset that proportion threshold is $45 / 53$.
\end{abstract}

Of the 266 species collected and identified, the larval forms of Necrophila americana, Fannia scalaris, Cochliomyia macellaria, Phormia regina, and Lucilia illustris satisfied these two criteria. Adults of Creophilus maxillosus, Necrobia ruficollis, and Necrodes surinamensis were common and showed only a few, single day gaps in occurrence. C. maxillosus adults, P. regina, and L. illustris (both as larvae) displayed exceptional forensic utility in that they were observed

\footnotetext{
*Reprinted from the submission: Perez AE, NH Haskell and JD Wells. 2014. Evaluating the utility of hexapod species for calculating a confidence interval about a succession based postmortem interval estimate. Forensic Science International. FSI-D-13-00632R1.
} 
on every carcass. Analyses of occurrence matrices for each of these species alone or in twospecies combinations suggest that a failure to record a taxon is a less reliable observation (i.e. by producing a false negative) than is a record of presence. Also, inverse prediction of the duration of insect succession, which we term the succession interval (SI), was more precise when based on two species rather than one species.

\section{Introduction}

The succession of insect species on a corpse is a biological clock that can be used to predict some portion of the time since death [1]. Specifically, a succession model describes the species and development stages present as a function of the amount of time the corpse has been accessible to insects (or other taxa should they be used for this purpose) at that location [2]. For brevity we designate this time period the succession interval (SI). If an investigator is confident the victim died where the remains were discovered and was not subsequently disturbed in a way that altered succession, the SI equals the actual postmortem interval (PMI). If death occurred elsewhere, as is often the case [3], it may be better to think of SI as a minimum postmortem interval $\left(\mathrm{PMI}_{\min }\right)$.

Carrion insect succession has been investigated for many years [4-8] and the biology of carrion frequenting insects has been characterized in habitats across the world [2]. However, many published studies had a descriptive ecological rather than forensic focus and common data presentation methods, such as an aggregated general succession pattern rather than what occurred in any individual corpse, are not very useful for SI estimation in casework [9]. 
Another common practice of dubious forensic entomological utility has been the division of corpse decomposition into discrete categorical stages characterized by general appearance (e.g. fresh, bloat, etc.). Although these stages reflect real phenomena, such as the bloating of a corpse, they are subjectively defined and incorrectly thought to correspond to shifts in the insect fauna [10].

Schoenly et al. [11] proposed an explicit analytical framework for SI estimation and developed software for data storage and analysis. Their succession model is "baseline" data recorded as an occurrence matrix showing presence or absence (indicated by a 1 or a 0 , respectively) of species/stages for each known SI value. Faced with a corpse of unknown SI, the set of insects on the corpse is compared to a model considered to be appropriate for the death scene. Model SI values with the same set of species as observed on the corpse are considered plausible for that particular case (see Fig. 1 of Schoenly et al. [12]).

Schoenly et al. [11] stated that taxa that "leave and reappear" during the course of succession can "distort" a PMI estimate, and recently this property of a taxon has been used to empirically assess the utility of insect species for this application [13]. It seems to us that the real problem with such a reoccurring taxon [14] is not the fact that it could yield an SI estimate that is not a continuous interval per se. Instead, gaps in occurrence may be a sign of unpredictability, either in actual occurrence or because individuals on a corpse are more likely to be missed by the collector compared to other taxa. The possibility of a false negative observation highlights the fact that specimen collection protocol is as much an experimental condition as are the environmental setting, SI, etc, for any carrion insect occurrence reference data [14-16]. 
LaMotte and Wells [17] developed statistical methods for inverse prediction of SI from categorical (e.g. occurrence) data. As with Schoenly et al. [11] the succession model of LaMotte and Wells [17] is an occurrence matrix with column values for each observed SI, but a cell contains a count of the number of training corpses observed to have a particular set of species rather than showing the presence or absence of a single species. A p-value is calculated for each possible SI for a corpse in a death investigation, and those SI values that are not rejected define a confidence interval. This requires "training" data from replicated experimental corpses. Without sufficient replication when producing training data the statistical test cannot reject any potential SI value and the casework situation is, in practical terms, as if every carrion insect species were present at all times during decomposition.

Probably more than 50 experimental corpses for a given set of conditions are needed for an investigator to ever be able to reject a possible SI value at typical levels of statistical significance when using $\geq 2$ taxa (see Table 3 in LaMotte and Wells [17]). Furthermore, for such an SI estimation the species used would have to be quite common, i.e. observed at one time or another on almost all of the training corpses (see Discussion). Some forensic entomology researchers have exposed many more than 50 pig carcasses, for example one of us (NHH) has employed more than 600 for experiments and workshops (unpublished). However, despite sometimes including a high total over long periods, published succession datasets were based on carcasses installed $<50$ at a time and under a variety of environmental conditions (e.g. Dillon [18]), and therefore they do not represent sufficient replication for the statistical methods of LaMotte and Wells [17]. 
One obstacle to the generation of sufficient replication in succession datasets is that such research can be very labor intensive. A single roughly human-size carcass can yield $>100$ species $[16,19]$ and 10,000 s of individuals $[16,20]$. If an investigator were to target only a small subset of the carrion insect fauna, one composed of the species and life stages most valuable for SI estimation, then the smaller amount of time spent per carcass should allow much greater replication in succession experiments. The purpose of this study was to identify carrion insect species that are useful for SI estimation according to the criteria of nonreoccurrence and commonness, and within the context of a training dataset large enough for the methods of LaMotte and Wells [17]. The training data were obtained from domestic pig carcasses, a typical experimental surrogate for a human corpse $[16,21,22]$.

\section{Materials and Methods}

A total of 53 pigs $(16 \pm 2.5 \mathrm{~kg})$ were exposed during the summer months (June-August) of three consecutive years (2 during 2008, 20 during 2009, 31 during 2010) in mature oak woodlots (approximately $56,200 \mathrm{~m}^{2}, 30,000 \mathrm{~m}^{2}$, and $27,000 \mathrm{~m}^{2}$ in area) within an approximately $3.34 \mathrm{~km}^{2}$ corn and soybean farm in Rensselaer, Indiana, USA. Each experimental pig was to be discarded from a local pig industry rearing facility, because it was either growing too slowly for commercial purposes or because it displayed behavior suggesting an infectious disease, and died as a result of cardiac arrest stunning no more than 12 hours prior to exposure. Pigs (obtained in sets of 1-10 at a time) were placed immediately upon receipt after a visual inspection to ensure no previous insect colonization, under an open-bottomed weld mesh cage, secured to the ground 
with stakes. Placement sites were in shade and at least 30 meters from the nearest pig. Daily insect collections were made from each pig over 14 consecutive days. All collections occurred between 0730 and $1830 \mathrm{hrs}$. The time of collection for each pig was not randomized, but was purposely varied from one day to the next to avoid a consistent effect of time of day on collection composition. Each collection included a series of 4 samples: a sweep net sample ( 8 rapid passes of the net directly above the carcass), a hand-picked sample of maggots preserved upon sampling, a hand-picked sample of maggots reared to adulthood, and a hand-picked sample of any other adult and immature insects on or immediately surrounding $(<30 \mathrm{~cm})$ the carcass. Each collection spanned 20 minutes per carcass to ensure consistent sampling across carcasses.

All individuals collected were identified using the help of taxonomic experts and/or published dichotomous keys (indicated for each species in supplemental material). An occurrence matrix was generated for each pig. Each column, representing a taxon, was summed for each pig and any value over 0 was scored a 1 . Column totals were summed across pigs, and any score over 45 (see Discussion) was analyzed for reoccurrence.

\section{Results and Discussion}

For our sample size of 53, a taxon/stage must be observed on at least 45 of the experimental carcasses in order to potentially support a $90 \%$ confidence interval on PMI when using $\geq 2$ taxa [17]. Of the 266 insect species we observed (see supplemental material), 17 were collected from 45 or more of the 53 carcasses exposed (Table 1). 
Every common insect species displayed at least one occurrence gap in the collection data from at least one carcass. However, as stated in the Introduction, a gap could be a false negative. Eight of the 17 common species (Necrodes surinamensis adults, Necrophila americana larvae, Creophilus maxillosus adults, Necrobia ruficollis adults, Fannia scalaris larvae, Cochliomyia macellaria larvae, Phormia regina larvae, and Lucilia illustris larvae) showed a gap(s) of not larger than one sample day on an individual carcass. For the larvae we can be sure that each of those gaps is a false negative. C. maxillosus adults, which showed gaps on four carcasses, were visually observed on two of those carcasses on a day when no specimen was collected. Given that our sample effort was deliberately less for adults (i.e. avoided taking multiple individuals of a morphospecies to avoid depleting adult populations that were less abundant compared to larvae), our sampling strategy may also have been biased toward easily distinguishable species. More cryptic species may have been under sampled due to the co-occurrence of multiple species that lack macroscopic morphologically distinguishing characteristics (e.g. Histeridae), potentially creating spurious gaps in presence.

Three kinds of carrion insect, C. maxillosus adults, P. regina larvae, and L. illustris larvae, displayed exceptional forensic utility in that they were observed on every carcass and only two one-day gaps in C. maxillosus occurrence were not known to be a false negative. Further research on these species would be especially likely to be of practical value for death investigation, and concentrating on only these species and stages would be a logical way to manage the task of developing greater statistical power for SI estimation. Although training data from $>120$ experimental corpses are probably needed to place confidence limits on an SI estimate using three insect species [17], based on our experience a succession experiment of that 
size targeting only those three species/stages would probably require less effort than the present study.

Sixteen of the 17 abundant species have previously been identified as forensically important (see Table 1 for citations). The exception is the chloropid, Liohippelates bishoppi, a common human and livestock pest (eye gnats and yaw flies) [23] that to our knowledge has not previously been classified as a forensic indicator. Because soil samples were not collected certain taxa or life stages, e.g. nicrophorine larvae, were probably excluded from the data.

Although beetles are certainly used to estimate PMI (e.g. [24-26]), most forensic entomology casework is based on maggots of the families Calliphoridae and Sarcophagidae (e.g. [21, 2729]). These results show that, at least for our study site, beetles have potential forensic utility roughly comparable to that of Diptera.

Even though carrion insect occurrence depends on many environmental factors, (e.g. geographic location and season) we believe these results are relevant to investigators in many locations. The species identified as useful have wide ranging distributions (Table 1), with multiple being cosmopolitan (i.e. C. maxillosus, N. ruficollis, and F. scalaris) and/or listed in case studies in countries outside of the United States (i.e. Stearibia nigriceps in Spain [30]).

$95 \%$ confidence intervals about SI based on either single species or pairwise combinations of $C$. maxillosus adults, $P$. regina third instar larvae, and L. illustris third instar larvae (Tables 2 and 3) suggest that an analysis based on a taxon not being observed is more likely to produce a 
discontinuous SI prediction compared to a prediction based on all species (one or two, depending on the succession model being used) being observed. We suspect that this reflects the relatively lower reliability of not observing a species/life stage compared to observing one when the carcass is not exhaustively sampled.

It also appears that using combinations of two taxa observed to be present produces a more precise SI prediction compared to an analysis based on a single species present. Single species prediction intervals were 4923, 4376, and $3829 \mathrm{ADH}_{10}$ in width (Table 2), while pairwise combination prediction intervals were all $3829 \mathrm{ADH}_{10}$ in width (Table 3).

Finally, we note that although one purpose of this paper is to promote the use of multiple species and increased experimental replication for PMI estimation, the statistical analysis of LaMotte and Wells [17] can be applied to data for a single species, for which fewer training replicates are needed compared to multiple species. Furthermore, although the inverse prediction methods we developed for placing statistical confidence limits on a PMI estimate based on continuous, quantitative or categorical data were illustrated using insect data, they are equally suitable for any type of postmortem measurement variable such as the level of a volatile organic compound [31], amount of bone weathering [32], or tissue color and degree of RNA degradation [33]. 


\section{References}

[1] J.D. Wells, L.R. LaMotte, Estimating the postmortem interval, in: J.H. Byrd, J.L. Castner (Eds.), Forensic Entomology: The Utility of Arthropods in Legal Investigations, $2^{\text {nd }}$ Edition, CRC Press, Boca Raton, FL, 2010, pp. 367-384.

[2] G.S. Anderson, Factors that influence insect succession on carrion, in: J.H. Byrd, J.L. Castner (Eds.), Forensic Entomology: The Utility of Arthropods in Legal Investigations, $2^{\text {nd }}$ Edition, CRC Press, Boca Raton, FL, 2010, pp. 201-250.

[3] B.A.J. Fisher, Techniques of Crime Scene Investigation, 6th edition, CRC Press, Boca Raton, FL, 2000, $584 \mathrm{pp}$.

[4] G.M. Motter, A contribution to the study of the fauna of the grave. A study of one hundred and fifty disinterments, with some additional experimental observations, J. N. Y. Entomol. Soc. 6 (1898) 201-231.

[5] M.E. Fuller, The insect inhabitants of carrion: a study in animal ecology, Coun. Sci. Industr. Res. Aust. Bull. 82 (1934) 5-62.

[6] G.F. Bornemissza, An analysis of arthropod succession in carrion and the effect of its decomposition on the soil fauna, Aust. J. Zool. 5 (1957) 1-12.

[7] H.B. Reed Jr., A study of dog carcass communities in Tennessee, with special reference to the insects, Am. Midl. Nat. 59 (1958) 213-245.

[8] J.A. Payne, A summer carrion study of the baby pig Sus scrofa Linnaeus, Ecology 46 (1965) 592-602.

[9] J.P. Michaud, K.G. Schoenly, G. Moreau, Sampling flies or sampling flaws? Experimental design and inference strength in forensic entomology, J. Med. Entomol. 49 (2012) 1-10. 
[10] K.G. Schoenly, W. Reid, Dynamics of heterotrophic succession in carrion arthropod assemblages: discrete series or a continuum of change? Oecologia 17 (1987) 192-202.

[11] K.G. Schoenly, M.L. Goff, M. Early, A BASIC algorithm for calculating the postmortem interval from arthropod successional data, J. Forensic Sci. 37 (1992) 808-823.

[12] K.G. Schoenly, M.L. Goff, J.D. Wells, W.D. Lord, Quantifying statistical uncertainty in succession-based entomological estimates of the postmortem interval in death scene investigations: a simulation study, Am. Entomol. 42 (1996) 106-112.

[13] S. Matuszewski, D. Bajerlein, S. Konwerski, K. Szpila, Insect succession and carrion decomposition in selected forests of Central Europe. Part 2: composition and residency patterns of carrion fauna, Forensic Sci. Int. 195 (2010) 42-51.

[14] K.G. Schoenly, A statistical analysis of successional patterns in carrion-arthropod assemblages: implications for forensic entomology and determination of the postmortem interval, J. Forensic Sci. 37 (1992) 1489-1513.

[15] K.G. Schoenly, N.H. Haskell, R.D. Hall, J.R. Gbur, Comparative performance and complementarity of four sampling methods and arthropod preference tests from human and porcine remains at the Forensic Anthropology Center in Knoxville, Tennessee, J. Med. Entomol. 44 (2007) 881-894.

[16] J.P. Michaud, G. Moreau, Effect of variable rates of daily sampling of fly larvae on decomposition and carrion insect community assembly: implications for forensic entomology field study protocols, J. Med. Entomol. 50 (2013) 890-897.

[17] L.R. LaMotte, J.D. Wells, $p$-values for postmortem intervals from arthropod succession data, J. Agric. Biol. Envir. S. 5 (2000) 58-68. 
[18] L.C. Dillon, Insect succession on carrion in three biogeoclimatic zones of British Columbia, Simon Frasier University, Canada, 1997, MSc thesis.

[19] L.E.O. Braack, Community dynamics of carrion-attendant arthropods in tropical African woodland, Oecologica 72 (1987) 402-409.

[20] L.E.O Braack, An ecological investigation of the insects associated with exposed carcasses in the northern Kruger National Park: a study of populations and communities, University of Natal Pietermaritzburg, South Africa, 1984, PhD thesis.

[21] E.P. Catts, M.L. Goff, Forensic entomology in criminal investigations, Annu. Rev. Entomol. 37 (1992) 253-272.

[22] L.M.L. Carvalho, P.J. Thyssen, A.X. Linhares, F.A.B. Palhares, A checklist of arthropods associated with pig carrion and human corpses in southeastern Brazil, Mem. Inst. Oswaldo Cruz 95 (2000) 135-138.

[23] C.W. Sabrosky, The Hippelates flies or eye gnats: preliminary notes, Can. Entomol. 73 (1941) 23-27.

[24] M.L. Goff, M.M. Flynn, Determination of postmortem interval by arthropod succession: a case study from the Hawaiian Islands, J. Forensic Sci. 36 (1991) 607-614.

[25] M.I. Arnaldos, M.D. Garcia, E. Romera, J.J. Presa, A. Luna, Estimation of postmortem interval in real cases based on experimentally obtained entomological evidence, Forensic Sci. Int. 149 (2005) 57-65.

[26] W.D. Lord, M.L. Goff, T.R. Adkins, The black soldier fly, Hermetia illucens (Diptera: Stratiomyidae) as a potential measure of human postmortem interval: observations and case histories, J. Forensic Sci. 39 (1994) 215-222. 
[27] B. Greenberg, Forensic entomology: case studies, Bull. Entomol. Soc. Am. 31 (1985) 25-28.

[28] E.P. Catts, Problems in estimating the postmortem interval in death investigations, J. Agr. Entomol. 9 (1992) 245-255.

[29] R.H.L. Disney, J.D. Manlove, First occurrences of the phorid, Megaselia abdita, in forensic cases in Britain, Med. Vet. Entomol. 19 (2005) 489-491.

[30] M.I. Salona, M.L. Moraza, M. Carles-Tolra,V. Iraola, P. Bahillo, T. Yelamos, R. Outerelo, R. Alcaraz, Searching the soil: forensic importance of edaphic fauna after the removal of a corpse, J. Forensic Sci. 55 (2010) 1652-1655.

[31] M. Statheropoulos, C. Spiliopolou, A. Agapiou, A study of volatile organic compounds evolved from the decaying body, Forensic Sci. Int. 153 (2005) 147-55.

[32] A.M. Christensen, S.W. Myers, Macroscopic observations of the effects of varying fresh water pH on bone, J. Forensic Sci. 56 (2011) 475-9.

[33] S.T. Young, J.D. Wells, G.R. Hobbs, C.P. Bishop, Estimation of postmortem interval using RNA degradation and morphological changes in tooth pulp, Forensic Sci. Int. 229 (2013) 163e1e6.

[34] Y. Bousquet, S. Laplante, The Insects and Arachnids of Canada Part 24. Coleoptera Histeridae, NRC Research Press, Ottawa, Ontario, 2006, 485 pp.

[35] B.C. Ratcliffe, The natural history of Necrodes surinamensis (Fabr.) (Coleoptera: Silphidae), Trans. Am. Entomol. Soc. 98 (1972) 359-410.

[36] R.S. Anderson, S.B. Peck, The Insects and Arachnids of Canada Part 13. The Carrion Beetles of Canada and Alaska (Coleoptera: Silphidae and Agyrtidae), Agriculture Canada, Ottawa, Ontario, publ 1778, 1985, 121 pp. 
[37] C.G. Majka, J. Klimaszewski, R.F. Lauff, The coastal rove beetles (Coleoptera, Staphylinidae) of Atlantic Canada: a survey and new records, ZooKeys 2 (2008) 115-150.

[38] A. Smetana, Rove beetles of the subtribe Philonthina of America north of Mexico (Coleoptera: Staphylinidae) classification, phylogeny and taxonomic revision, Associated Publishers, Gainesville, FL, 1995, 946 pp.

[39] M.R. Chani-Posse, Eight Argentinean species of dung-inhabiting Philonthus Stephens (Coleoptera: Staphylinidae), Stud. Neotrop. Fauna E. 39 (2004) 217-232.

[40] J. Kim, B.H. Jung, Taxonomic review of the Cleridae (Coleoptera) in Korea (Part 3): Korynetinae, Tarsosteninae and Tillinae, Entomol. Res. 36 (2006) 245-252.

[41] N.M. Downie, R.H. Arnett Jr., The Beetles of Northeastern North America Volumes 1 and 2, Sandhill Crane Press, Gainesville, FL, 1996, 1721 pp.

[42] A.L. Melander, A. Spuler, The dipterous families Sepsidae and Piophilidae, Wash. Agr. Expt. Sta. Bul. 143 (1917) 1-97.

[43] J.F. McAlpine, Piophilidae, in: J.F. McAlpine, B.V. Peterson, G.E. Shewell, H.J. Teskey, J.R. Vockeroth, D.M. Wood (Eds.), Manual of Nearctic Diptera Volume 2, Agriculture Canada Monograph 28, 1987, 845-852.

[44] G.C. Steyskal, Sepsidae, in: J.F. McAlpine, B.V. Peterson, G.E. Shewell, H.J. Teskey, J.R. Vockeroth, D.M. Wood (Eds.), Manual of Nearctic Diptera Volume 2, Agriculture Canada Monograph 28, 1987, 945-950.

[45] A.L. Ozerov, World catalogue of the family Sepsidae (Insecta: Diptera), Zool. Zh, 8 (2005) $1-74$. 
[46] C.W. Sabrosky, New genera and new combinations in Nearctic Chloropidae (Diptera), Proc. Entomol. Soc. Wash. 82 (1980) 412-429.

[47] J.G. Chillcott, A revision of the Nearctic species of Fanniinae (Diptera: Muscidae), Mem. Entomol. Soc. Can. 92.S14 (1960) 5-295.

[48] D.G. Hall, The Blowflies of North America, Thomas Say Foundation Monographs Volume 4, Baltimore, MD, 1948, 477 pp.

[49] E.J. Watson, C.E. Carleton, Spring succession of necrophilous insects on wildlife carcasses in Louisiana, J. Med. Entomol. 40 (2003) 338-347.

[50] J.H. Byrd, J.L. Castner, Insects of forensic importance, in: J. H. Byrd, J.L. Castner (Eds.), Forensic Entomology: The Utility of Arthropods in Legal Investigations, $2^{\text {nd }}$ Edition, CRC Press, Boca Raton, FL, 2010, pp. 39-126.

[51] J.P. Michaud, C.G. Majka, J.P. Prive, G. Moreau, Natural and anthropogenic changes in the insect fauna associated with carcasses in the North American Maritime lowlands, Forensic Sci. Int. 202 (2010) 64-70.

[52] K.L. Tabor, R.D. Fell, C.C. Brewster, Insect fauna visiting carrion in southwest Virginia, Forensic Sci. Int. 150 (2005) 73-80.

[53] M.L. Goff, M. Early, C.B. Odom, K. Tullis, A preliminary checklist of arthropods associated with exposed carrion in the Hawaiian Islands, Proc. Hawaii. Entomol. Soc. 26 (1986) 53-57. 
Table 1. Distribution and published forensic utility of carrion insects that were observed on a high enough proportion of carcasses $(>45 / 53)$ for placing confidence limits on an estimation of postmortem interval.

\begin{tabular}{|c|c|c|c|c|c|c|}
\hline Order & Family & Species & $\begin{array}{l}\text { Life } \\
\text { Stage }\end{array}$ & \# of Pigs & Distribution & Forensic Importance \\
\hline \multirow[t]{10}{*}{ Coleoptera } & Histeridae & Euspilotus assimilis $^{\mathrm{a}}$ & Adult & 53 & Nearctic [34] & Watson and Carlton [49] \\
\hline & Silphidae & Necrodes surinamensis & Adult & 45 & Nearctic [35] & Byrd and Castner [50] \\
\hline & & Necrophila americana & Adult & 49 & Nearctic [36] & Byrd and Castner [50] \\
\hline & & Necrophila americana & Larva & 48 & Nearctic [36] & Byrd and Castner [50] \\
\hline & Staphylinidae & Creophilus maxillosus $^{\mathrm{b}}$ & Adult & 53 & Cosmopolitan [37] & Byrd and Castner [50] \\
\hline & & Creophilus maxillosus & Larva & 50 & Cosmopolitan [37] & Byrd and Castner [50] \\
\hline & & Philonthus politus ${ }^{\mathrm{b}}$ & Adult & 48 & Holarctic [38] & Michaud et al [51] \\
\hline & & Philonthus sericans ${ }^{\mathrm{b}}$ & Adult & 49 & Nearctic and Neotropical [39] & Tabor et al [52] \\
\hline & Cleridae & Necrobia ruficollis & Adult & 45 & Cosmopolitan [40] & Goff et al [53] \\
\hline & Nitidulidae & Omosita colon & Adult & 52 & Holarctic [41] & Byrd and Castner [50] \\
\hline \multirow[t]{12}{*}{ Diptera } & Piophilidae & Prochyliza xanthostoma & Adult & 53 & Nearctic [42] & Byrd and Castner [50] \\
\hline & & Stearibia nigriceps & Adult & 50 & Holarctic [43] & Salona et al [30] \\
\hline & Sepsidae & Meroplius stercorarius & Adult & 53 & Holarctic [44] & Michaud et al [51] \\
\hline & & Sepsis punctum & Adult & 46 & Holarctic, Neotropical, Oriental [45] & Byrd and Castner [50] \\
\hline & Chloropidae & Liohippelates bishoppi ${ }^{\mathrm{c}}$ & Adult & 52 & Nearctic [46] & Not previously \\
\hline & Fanniidae & Fannia scalaris & Adult & 53 & Cosmopolitan [47] & Byrd and Castner [50] \\
\hline & & Fannia scalaris & Larva & 51 & Cosmopolitan [47] & Byrd and Castner [50] \\
\hline & Calliphoridae & Cochliomyia macellaria & Adult & 50 & Nearctic and Neotropical [48] & Byrd and Castner [50] \\
\hline & & Cochliomyia macellaria & Larva & 46 & Nearctic and Neotropical [48] & Byrd and Castner [50] \\
\hline & & Phormia regina & Adult & 53 & Holarctic [48] & Byrd and Castner [50] \\
\hline & & Phormia regina & Larva & 53 & Holarctic [48] & Byrd and Castner [50] \\
\hline & & Lucilia illustris & Larva & 53 & Holarctic [48] & Byrd and Castner [50] \\
\hline
\end{tabular}


Table 2. Contingency tables based on the presence/absence of C. maxillosus $(\mathrm{Cm})$ adults, P.regina larvae (Pr) and L. illustris larvae (Li). The absence of a species in a given category is indicated with an apostrophe following the species name abbreviation (ex. Pr' $=$ $P$. regina not observed). Column values are the start of each time interval as measured in accumulated degree hours above $0^{\circ} \mathrm{C}$. The grey, bracketed area is the confidence interval about a PMI estimation, at the $95 \%$ confidence level for each scenario of presence/absence.

\begin{tabular}{|c|c|c|c|c|c|c|c|c|c|c|c|c|c|c|c|c|c|c|}
\hline & 547 & 1094 & 1641 & 2188 & 2735 & 3282 & 3829 & 4376 & 4923 & 5470 & 6017 & 6564 & 7111 & 7658 & 8205 & 8752 & 9299 & 9846 \\
\hline $\mathrm{Cm}$ & 1 & [ 5 & 31 & 50 & 51 & 47 & 33 & 21 & 12 & 6 & 2 & 1 & 0 & 0 & 0 & 0 & 0 & 0 \\
\hline $\mathrm{Cm}^{\prime}$ & 52 & 48 & 22 & 3 & 2 & 6 & 20 & 32 & 41 & 47 & 51 & 52 & 53 & 53 & 53 & 53 & 53 & 53 \\
\hline & 547 & 1094 & 1641 & 2188 & 2735 & 3282 & 3829 & 4376 & 4923 & 5470 & 6017 & 6564 & 7111 & 7658 & 8205 & 8752 & 9299 & 9846 \\
\hline$\overline{P r}$ & 0 & 2 & [ 18 & 46 & 52 & 52 & 47 & 40 & 19 & 5 & 2 & 2 & 0 & 0 & 0 & 0 & 0 & 0 \\
\hline $\mathbf{P r}^{\prime}$ & 53 & 51 & 35 & 7 & 1 & 1 & 6 & 13 & 34 & 48 & 51 & 51 & 53 & 53 & 53 & 53 & 53 & 53 \\
\hline & 547 & 1094 & 1641 & 2188 & 2735 & 3282 & 3829 & 4376 & 4923 & 5470 & 6017 & 6564 & 7111 & 7658 & 8205 & 8752 & 9299 & 9846 \\
\hline$\overline{\mathbf{L i}}$ & 0 & 0 & 19 & 47 & 51 & 46 & 31 & 19 & 8 & 1 & 1 & 0 & 0 & 0 & 0 & 0 & 0 & 0 \\
\hline $\mathrm{Li}^{\prime}$ & 53 & 53 & 34 & 6 & 2 & 7 & 22 & 34 & 45 & 52 & 52 & 53 & 53 & 53 & 53 & 53 & 53 & 53 \\
\hline
\end{tabular}


Table 3. Contingency tables based on the presence/absence of all possible two species combinations of C. maxillosus (Cm) adults, P.regina larvae (Pr) and L. illustris larvae (Li). The absence of a species in a given category is indicated with an apostrophe following the species name abbreviation (ex. Pr' $=P$. regina not observed). Column values are the start of each time interval as measured in accumulated degree hours above $0^{\circ} \mathrm{C}$. The grey, bracketed area is the confidence interval about a PMI estimation, at the $95 \%$ confidence level for each scenario of presence/absence.

\begin{tabular}{|c|c|c|c|c|c|c|c|c|c|c|c|c|c|c|c|c|c|c|}
\hline & 547 & 1094 & 1641 & 2188 & 2735 & 3282 & 3829 & 4376 & 4923 & 5470 & 6017 & 6564 & 7111 & 7658 & 8205 & 8752 & 9299 & 9846 \\
\hline $\mathrm{Cm}^{\mathrm{Pr}}$ & 1 & [ 5 & 20 & $\begin{array}{ll}5 & ]\end{array}$ & 0 & 1 & {$\left[\begin{array}{lll} & 2 & ]\end{array}\right]$} & 1 & [ 6 & 5 & $2]$ & 1 & 0 & 0 & 0 & 0 & 0 & 0 \\
\hline $\mathrm{Cm}^{\prime} \mathrm{Pr}$ & 0 & [ 2 & $\begin{array}{ll}7 & ]\end{array}$ & 1 & 1 & {$\left[\begin{array}{ll}6 \\
{[}\end{array}\right.$} & 16 & 20 & 13 & 4 & 2 & $2]$ & 0 & 0 & 0 & 0 & 0 & 0 \\
\hline $\mathrm{Cm} \mathrm{Pr}$ & 0 & 0 & [ 11 & 45 & 51 & 46 & 31 & 20 & $6]$ & 1 & 0 & 0 & 0 & 0 & 0 & 0 & 0 & 0 \\
\hline $\mathrm{Cm}^{\prime} \mathrm{Pr}^{\prime}$ & 52 & 46 & 15 & $2]$ & 1 & 0 & [ 4 & 12 & 28 & 43 & 49 & 50 & 53 & 53 & 53 & 53 & 53 & 53 \\
\hline & 547 & 1094 & 1641 & 2188 & 2735 & 3282 & 3829 & 4376 & 4923 & 5470 & 6017 & 6564 & 7111 & 7658 & 8205 & 8752 & 9299 & 9846 \\
\hline$\overline{C m ~ L i '}$ & 1 & 5 & 20 & 5 & 2 & 7 & 12 & 11 & 9 & 6 & $2]$ & 1 & 0 & 0 & 0 & 0 & 0 & 0 \\
\hline Cm' Li & 0 & 0 & [ 8 & 2 & 2 & 6 & 10 & 9 & 5 ] & 1 & 1 & 0 & 0 & 0 & 0 & 0 & 0 & 0 \\
\hline Cm Li & 0 & 0 & [ 11 & 45 & 49 & 40 & 21 & 10 & 3 ] & 0 & 0 & 0 & 0 & 0 & 0 & 0 & 0 & 0 \\
\hline Cm' Li' & 52 & 48 & 14 ] & 1 & 0 & 0 & [ 10 & 23 & 36 & 46 & 50 & 52 & 53 & 53 & 53 & 53 & 53 & 53 \\
\hline & 547 & 1094 & 1641 & 2188 & 2735 & 3282 & 3829 & 4376 & 4923 & 5470 & 6017 & 6564 & 7111 & 7658 & 8205 & 8752 & 9299 & 9846 \\
\hline$\overline{P r} \mathrm{Li}^{\prime}$ & 0 & [ 2 & 6 & 5 & 2 & 6 & 17 & 23 & 13 & 5 & 2 & 2 ] & 0 & 0 & 0 & 0 & 0 & 0 \\
\hline Pr' Li & 0 & 0 & {$[7$} & 6 ] & 1 & 0 & 1 & [ 2 & 2 ] & 1 & 1 & 0 & 0 & 0 & 0 & 0 & 0 & 0 \\
\hline Pr Li & 0 & 0 & [ 12 & 41 & 50 & 46 & 30 & 17 & 6 ] & 0 & 0 & 0 & 0 & 0 & 0 & 0 & 0 & 0 \\
\hline Pr' Li' & 53 & 51 & $28]$ & 1 & 0 & 1 & [ 5 & 11 & 32 & 47 & 50 & 51 & 53 & 53 & 53 & 53 & 53 & 53 \\
\hline
\end{tabular}


Table S1. List of beetle species collected from 53 pig corpses and reference used for identification

\begin{tabular}{|c|c|c|c|}
\hline Family & Subfamily & Species & Identification Reference \\
\hline \multirow[t]{7}{*}{ Carabidae } & Harpalinae & Amara familiaris ${ }^{\mathrm{d}}$ & Lindroth [1] \\
\hline & & Amara littoralis ${ }^{\mathrm{d}}$ & Lindroth [1] \\
\hline & & Apristus subsulcatus ${ }^{\mathrm{j}}$ & Lindroth [1] \\
\hline & & Chlaenius tricolor & Lindroth [1] \\
\hline & & Harpalus indianus ${ }^{\mathrm{j}}$ & Lindroth [1] \\
\hline & & Lebia analis ${ }^{\mathrm{j}}$ & Lindroth [1] \\
\hline & & Stenolophus ochropezus ${ }^{\mathrm{j}}$ & Lindroth [1] \\
\hline \multirow[t]{3}{*}{ Trogidae } & Troginae & Omorgus suberosus & Vaurie [2] \\
\hline & & Trox unistriatus & Vaurie [2] \\
\hline & & Trox spinulosus & Vaurie [2] \\
\hline Geotrupidae & Geotrupinae & Geotrupes splendidus & Howden [3] \\
\hline \multirow[t]{5}{*}{ Scarabaeidae } & Scarabaeinae & Onthophagus hecate & Howden \& Cartwright [4] \\
\hline & & Onthophagus orpheus & Howden \& Cartwright [4] \\
\hline & & Onthophagus pennsylvanicus & Howden \& Cartwright [4] \\
\hline & Aphodiinae & Dialytes truncatus ${ }^{\mathrm{e}}$ & Gordon \& Skelley [5] \\
\hline & Melolonthinae & Macrodactylus angustatus & Horn [6], Katovich [7] \\
\hline \multirow[t]{6}{*}{ Silphidae } & Silphinae & Necrodes surinamensis ${ }^{\mathrm{k}}$ & Ratcliffe [8], Ratcliffe [9] \\
\hline & & Necrophila americana ${ }^{\mathrm{k}}$ & Ratcliffe [9] \\
\hline & & Oiceoptoma noveboracense ${ }^{\mathrm{k}}$ & Ratcliffe [9] \\
\hline & Necrophilinae & Nicrophorus marginatus & Ratcliffe [9] \\
\hline & & Nicrophorus orbicollis & Ratcliffe [9] \\
\hline & & Nicrophorus tomentosus & Ratcliffe [9] \\
\hline \multirow[t]{19}{*}{ Staphylinidae } & Staphylininae & Bisnius blandus ${ }^{\mathrm{b}}$ & Smetana [10] \\
\hline & & Creophilus maxillosus ${ }^{\mathrm{b}, \mathrm{k}}$ & Brunke et al. [11], Kasule [135] \\
\hline & & Ontholestes cingulatus ${ }^{\mathrm{b}}$ & Brunke et al. [11] \\
\hline & & Philonthus $^{\mathrm{k}}$ caeruleipennis $^{\mathrm{b}}$ & Smetana [10], Kasule [135] \\
\hline & & Philonthus ${ }^{\mathrm{k}}$ cruentatus ${ }^{\mathrm{b}}$ & Smetana [10], Kasule [135] \\
\hline & & Philonthus ${ }^{\mathrm{k}}$ politus ${ }^{\mathrm{b}}$ & Smetana [10], Kasule [135] \\
\hline & & Philonthus ${ }^{\mathrm{k}}$ rectangulus ${ }^{\mathrm{b}}$ & Smetana [10], Kasule [135] \\
\hline & & Philonthus ${ }^{\mathrm{k}}$ sericans ${ }^{\mathrm{b}}$ & Smetana [10], Kasule [135] \\
\hline & & Philonthus ${ }^{\mathrm{k}}$ varians ${ }^{\mathrm{b}}$ & Smetana [10], Kasule [135] \\
\hline & & Platydracus fossator $^{\mathrm{b}}$ & Brunke et al. [11] \\
\hline & Oxytelinae & Anotylus sp. & Arnett \& Thomas [12] \\
\hline & & Oxytelus sp. & Arnett \& Thomas [12] \\
\hline & Paederinae & Belonuchus rufipennis ${ }^{\mathrm{b}}$ & Expert Identification \\
\hline & & Lathrobium sp. ${ }^{\mathrm{b}}$ & Arnett \& Thomas [12] \\
\hline & & Rugilus sp. ${ }^{\mathrm{b}}$ & Arnett \& Thomas [12] \\
\hline & Aleocharinae & Aleochara sp. ${ }^{\mathrm{b}}$ & Arnett \& Thomas [12] \\
\hline & & Aleochara sp. ${ }^{\mathrm{b}}$ & Arnett \& Thomas [12] \\
\hline & & Atheta sp. ${ }^{\mathrm{b}}$ & Arnett \& Thomas [12] \\
\hline & & Falagria sp. ${ }^{\mathrm{b}}$ & Hoebeke [13] \\
\hline \multirow[t]{2}{*}{ Leiodidae } & Chlovinae & Prionochaeta opaca & Arnett \& Thomas [12] \\
\hline & & Sciodrepoides terminans & Hatch [14] \\
\hline
\end{tabular}


Table S1. continued

\begin{tabular}{|c|c|c|c|}
\hline Family & Subfamily & Species & Reference \\
\hline \multirow[t]{3}{*}{ Hydrophilidae } & Sphaeridiinae & Cercyon praetextatus & Smetana [15] \\
\hline & & Cryptopleurum subtile & Downie \& Arnett [16] \\
\hline & & Sphaeridium bipustulatum & Downie \& Arnett [16] \\
\hline \multirow[t]{9}{*}{ Histeridae $^{\mathrm{k}}$} & Dendrophilinae & Carcinops pumilio ${ }^{\text {a }}$ & Bousquet \& LaPlante [17], Chu [110] \\
\hline & Histerinae & Atholus sedecimstriatus ${ }^{\text {a }}$ & Bousquet \& LaPlante [17], Chu [110] \\
\hline & & Hister abbreviatus ${ }^{\text {a }}$ & Bousquet \& LaPlante [17], Chu [110] \\
\hline & & Hister depurator ${ }^{\mathrm{a}}$ & Bousquet \& LaPlante [17], Chu [110] \\
\hline & & Hister servus ${ }^{\text {a }}$ & Expert Identification, Chu [110] \\
\hline & & Margarinotus hudsonicus ${ }^{\text {a }}$ & Bousquet \& LaPlante [17], Chu [110] \\
\hline & Saprininae & Geomysaprinus moniliatus ${ }^{\text {a }}$ & Bousquet \& LaPlante [17], Chu [110] \\
\hline & & Euspilotus assimilis a & Bousquet \& LaPlante [17], Chu [110] \\
\hline & & Saprinus lugens ${ }^{\text {a }}$ & Bousquet \& LaPlante [17], Chu [110] \\
\hline \multirow[t]{4}{*}{ Curculionidae } & Ceutorhynchinae & Curculio orthorhynchus & Gibson $[18]$ \\
\hline & Entiminae & Calomycterus setarius & Arnett et al. [19] \\
\hline & & Cyrtepistomus castaneus & Arnett et al. [19] \\
\hline & & Otiorhynchus ovatus & Bright \& Bouchard [20] \\
\hline Cerambycidae & Lamiinae & Oplosia nubile & Arnett et al. [19] \\
\hline \multirow[t]{3}{*}{ Chrysomelidae } & Criocerinae & Oulema sayi & Richard [21] \\
\hline & Eulopinae & Paria quadrinotata & Wilcox [22] \\
\hline & Galerucinae & Phyllotreta robusta ${ }^{\mathrm{j}}$ & Howard [23] \\
\hline Meloidae & Meloinae & Epicauta funebris $^{\mathrm{j}}$ & Werner [24] \\
\hline Tenebrionidae & Tenebrioninae & Uloma punctulata & Horn $[25]$ \\
\hline \multirow[t]{3}{*}{ Cleridae } & Korynetinae & Necrobia ${ }^{\mathrm{k}}$ ruficolis & Kim \& Jung [26], Boving \& Champlain [136] \\
\hline & & Necrobia ${ }^{\mathrm{k}}$ rufipes & Kim \& Jung [26], Boving \& Champlain [136] \\
\hline & & Necrobia ${ }^{\mathrm{k}}$ violacea & Kim \& Jung [26], Boving \& Champlain [136] \\
\hline \multirow[t]{6}{*}{ Nitidulidae } & Carpophilinae & Epuraea obtusicollis & Parsons [27] \\
\hline & Cryptarchinae & Glischrochilus fasciatus & Parsons [27] \\
\hline & & Glischrochilus quadrisignatus & Parsons [27] \\
\hline & Nitidulinae & Omosita colon & Parsons [27] \\
\hline & & Pallodes pallidus & Parsons [27] \\
\hline & & Stelidota octomaculata & Parsons [27] \\
\hline Monotomidae & Monotominae & Monotoma picipes ${ }^{\mathrm{j}}$ & Bousquet \& Laplante [28] \\
\hline Coccinellidae & Coccinellinae & Harmonia axyridis & Gordon \& Vandenberg [29] \\
\hline \multirow[t]{3}{*}{ Dermestidae } & Dermestinae & Dermestes ${ }^{\mathrm{k}}$ ater & Downie \& Arnett [16], Rees [137] \\
\hline & & Dermestes ${ }^{\mathrm{k}}$ caninus & Downie \& Arnett [16], Rees [137] \\
\hline & & Dermestes $^{\mathrm{k}}$ maculatus & Downie \& Arnett [16], Rees [137] \\
\hline Buprestidae & Agrilinae & Agrilus sp. ${ }^{\mathrm{j}}$ & Arnett et al. [19] \\
\hline Cantharidae & Chauliognathinae & Chauliognathus marginatus ${ }^{\mathrm{j}}$ & Fender [30] \\
\hline \multirow[t]{2}{*}{ Elateridae } & Elaterinae & Melanotus gradatus ${ }^{\mathrm{j}}$ & Quate \& Thompson [31] \\
\hline & & Parallelostethus attenuatus ${ }^{\mathrm{j}}$ & Arnett et al. [19] \\
\hline
\end{tabular}


Table S2. List of fly species collected from 53 pig corpses and reference used for identification

\begin{tabular}{|c|c|c|c|}
\hline Family & Subfamily & Species & Reference \\
\hline \multirow[t]{2}{*}{ Chironomidae } & Chironominae & Chironomus sp. & Oliver [32] \\
\hline & & Polypedilum sp. ${ }^{\mathrm{j}}$ & Oliver [32] \\
\hline \multirow[t]{3}{*}{ Culicidae } & Culicinae & Aedes cinereus & Siverly [33] \\
\hline & & Aedes triseriatus & Siverly [33] \\
\hline & & Aedes vexans & Siverly [33] \\
\hline Cecidomyiidae & Cecidomyiinae & Dasineura sp. ${ }^{\mathrm{j}}$ & Gagne [34] \\
\hline \multirow[t]{2}{*}{ Sciaridae } & Sciarinae & Schwenkfeldina dolens ${ }^{\mathrm{j}}$ & Steffan [35] \\
\hline & Cratyninae & Epidapus sp. ${ }^{\mathrm{j}}$ & Steffan [35] \\
\hline Mycetophilidae & Mycomyinae & Mycomya sp. ${ }^{j}$ & Vockeroth [36] \\
\hline Keroplatidae & Macrocerinae & Macrocera sp. ${ }^{\mathrm{j}}$ & Vockeroth [36] \\
\hline Rhagionidae & Chrysopilinae & Chrysopilus quadrates & Hardy [37] \\
\hline Tabanidae & Chrysopsinae & Chrysops univittatus & Thomas \& Marshall [38] \\
\hline Empididae & Empidinae & Empis clausa & Coquillett [39] \& Melander [40] \\
\hline \multirow[t]{4}{*}{ Hybotidae } & Hybotinae & Syndyas lustricola & Teskey \& Chillcott [41] \\
\hline & Tachydromiinae & Crossopalpus septentrionalis & Melander [42] \\
\hline & & Platypalpus flammifer & Chillcott [43] \\
\hline & & Platypalpus sp. ${ }^{\mathrm{j}}$ & Steyskal \& Knutson [44] \\
\hline \multirow[t]{7}{*}{ Dolichopodidae } & Sciapodinae & Condylostylus furcatus & Curran $[45]$ \\
\hline & & Condylostylus patibulatus & Curran [45] \\
\hline & & Condylostylus siphon & Curran [45] \\
\hline & Dolichopodinae & Dolichopus scapularis & Van Duzee \& Curran [46] \\
\hline & Medeterinae & Medetera aberrans & Bickel [47] \\
\hline & & Medetera apicalis & Bickel [47] \\
\hline & & Medetera veles & Bickel [47] \\
\hline \multirow[t]{7}{*}{ Phoridae } & Metopininae & Megaselia scalaris & Peterson [48] \\
\hline & & Megaselia morphoseries-1 & Peterson [48] \\
\hline & & Megaselia morphoseries-2 & Peterson [48] \\
\hline & & Megaselia morphoseries-3 & Peterson [48] \\
\hline & & Megaselia morphoseries-4 & Peterson [48] \\
\hline & Phorinae & Dohrniphora incisuralis & Peterson [48] \\
\hline & & Dohrniphora mississippiensis ${ }^{\mathrm{j}}$ & Peterson [48] \\
\hline \multirow[t]{2}{*}{ Syrphidae } & Syrphinae & Toxomerus marginatus & Vockeroth [49] \\
\hline & & Toxomerus politus & Vockeroth [49] \\
\hline \multirow[t]{2}{*}{ Ulidiidae } & Ulidiinae & Euxesta notata & Curran $[50]$ \\
\hline & & Euxesta stigmatias & Curran $[50]$ \\
\hline Platystomatidae & Platystomatinae & Rivellia quadrifasciata & Namba [51] \\
\hline \multirow[t]{3}{*}{ Piophilidae $^{\mathrm{k}}$} & Piophilinae & Prochyliza xanthostoma & McAlpine [52], Smith [138] \\
\hline & & Stearibia nigriceps & McAlpine [53], Smith [138] \\
\hline & & Protopiophila latipes & McAlpine [53], Smith [138] \\
\hline \multirow[t]{5}{*}{ Lauxaniidae } & Homoneurinae & Homoneura philadelphica & Shewell [54] \\
\hline & Lauxaniinae & Camptoprosopella $\mathrm{sp}^{\mathrm{j}}$ & Shewell [55] \\
\hline & & Melanomyza sp. & Shewell [55] \\
\hline & & Minettia lupulina & Malloch \& McAtee [56], Shewell [54] \\
\hline & & Minettia magna & Malloch \& McAtee [56] \\
\hline
\end{tabular}


Table S2. Continued

\begin{tabular}{|c|c|c|c|}
\hline Family & Subfamily & Species & Reference \\
\hline \multirow[t]{3}{*}{ Sepsidae $^{k}$} & Sepsinae & Meroplius stercorarius & Steyskal [57], Smith [138] \\
\hline & & Sepsis punctum & Ozerov [58], Smith [138] \\
\hline & & Sepsis neocynipsea & Ozerov [58], Smith [138] \\
\hline \multirow[t]{10}{*}{ Chloropidae } & Oscinellinae & Apallates particeps $^{\mathrm{c}}$ & Sabrosky [59] \\
\hline & & Apallates sp. (undescribed) ${ }^{\mathrm{c}, \mathrm{j}}$ & Expert Identification \\
\hline & & Conioscinella triorbiculata $^{\mathrm{c}}$ & Sabrosky [60] \\
\hline & & Hippelates nobilis ${ }^{\mathrm{c}}$ & Sabrosky [59] \\
\hline & & Hippelates plebejus ${ }^{\mathrm{c}}$ & Sabrosky [59] \\
\hline & & Liohippelates bishoppi $^{\mathrm{c}}$ & Sabrosky [59] \\
\hline & & Liohippelates pallipes $^{\mathrm{c}}$ & Sabrosky [59] \\
\hline & & Olcella provocans ${ }^{\mathrm{c}}$ & Sabrosky [61] \\
\hline & & Rhopalopterum carbonarium $^{\mathrm{c}}$ & Expert Identification \\
\hline & & Tricimba trisulcata ${ }^{\mathrm{c}, \mathrm{j}}$ & Sabrosky [62] \\
\hline \multirow[t]{7}{*}{ Sphaeroceridae } & Copromyzinae & Lotophila atra $^{\mathrm{j}}$ & Marshall \& Richards [63] \\
\hline & Limosininae & Coproica ferruginata ${ }^{\mathrm{f}}$ & Richards [64] \\
\hline & & Leptocera caenosa ${ }^{\mathrm{f}}$ & Buck \& Marshall [65] \\
\hline & & Leptocera erythrocera ${ }^{\mathrm{f}}$ & Buck \& Marshall [65] \\
\hline & & Spelobia bifrons ${ }^{\mathrm{f}}$ & Marshall [66] \\
\hline & & Spelobia clunipes ${ }^{\mathrm{f}}$ & Marshall [66] \\
\hline & Sphaerocerinae & Ischiolepta pusilla ${ }^{\mathrm{f}}$ & Han \& Kim [67] \\
\hline \multirow[t]{7}{*}{ Drosophilidae } & Steganinae & Leucophenga morphoseries-1 & Wheeler [68] \\
\hline & & Leucophenga morphoseries-2 & Wheeler [68] \\
\hline & Drosophilinae & Drosophila morphoseries -1 & Wheeler [68] \\
\hline & & Drosophila morphoseries-2 & Wheeler [68] \\
\hline & & Drosophila morphoseries-3 & Wheeler [68] \\
\hline & & Drosophila morphoseries-4 & Wheeler [68] \\
\hline & & Scaptomyza sp. ${ }^{j}$ & Wheeler [68] \\
\hline Diastatidae & Diastatinae & Diastata sp. & McAlpine [69] \\
\hline \multirow[t]{5}{*}{ Anthomyiidae } & Anthomyiinae & Anthomyia oculifera & Huckett $[70]$ \\
\hline & & Anthomyia procellaris & Huckett [70] \\
\hline & & Hylemyza partita & Huckett [71] \\
\hline & Pegomyinae & Emmesomyia socialis & Steyskal [72] \\
\hline & & Pegomya sp. ${ }^{\mathrm{j}}$ & Huckett [71] \\
\hline \multirow[t]{2}{*}{ Fanniidae } & Fanniinae & Fannia canicularis $^{\mathrm{k}}$ & Chillcott [73] \\
\hline & & Fannia scalaris ${ }^{\mathrm{k}}$ & Chillcott [73] \\
\hline
\end{tabular}


Table S2. Continued

\begin{tabular}{|c|c|c|c|}
\hline Family & Subfamily & Species & Reference \\
\hline \multirow[t]{14}{*}{ Muscidae } & \multirow[t]{7}{*}{ Azeliinae } & Hydrotaea $^{k}$ dentipes & Huckett [74], Skidmore [78] \\
\hline & & Ophyra ${ }^{k}$ aenescens & Huckett [74], Skidmore [78] \\
\hline & & Ophyra ${ }^{k}$ leucostoma & Huckett [74], Skidmore [78] \\
\hline & & Muscina ${ }^{k}$ assimilis & Snyder [75], Skidmore [78] \\
\hline & & Muscina ${ }^{k}$ levida & Snyder [75], Skidmore [78] \\
\hline & & Muscina $^{k}$ pascuorum & Snyder [75], Skidmore [78] \\
\hline & & Muscina ${ }^{k}$ stabulans & Snyder [75], Skidmore [78] \\
\hline & Coenosiinae & Neodexiopsis ovate & Snyder [76], Skidmore [78] \\
\hline & \multirow[t]{4}{*}{ Muscinae } & Eudasyphora cyanicolor & Cuny [77] \\
\hline & & Morellia micans & Skidmore [78] \\
\hline & & Musca domestica & Sabrosky [79] \\
\hline & & Stomoxys calcitrans & Huckett \& Vockeroth [80] \\
\hline & Mydaeinae & Myospila meditabunda & Huckett \& Vockeroth [80] \\
\hline & Phaoniinae & Phaonia fuscana ${ }^{\mathrm{j}}$ & Malloch [81] \\
\hline \multirow[t]{5}{*}{ Sarcophagidae $^{\mathrm{k}}$} & & Morphoseries-1 & GE Shewell [82], Smith [138] \\
\hline & & Morphoseries-2 & GE Shewell [82], Smith [138] \\
\hline & & Morphoseries-3 & GE Shewell [82], Smith [138] \\
\hline & & Morphoseries-4 & GE Shewell [82], Smith [138] \\
\hline & & Morphoseries-5 & GE Shewell [82], Smith [138] \\
\hline \multirow[t]{5}{*}{ Tachinidae } & Exoristinae & Winthemia sp. ${ }^{\mathrm{j}}$ & Wood [83] \\
\hline & Tachininae & Epalpus signifier & Wood [83], O’Hara \& Wood [84] \\
\hline & & Genea brevirostris ${ }^{\mathrm{j}}$ & James [85] \\
\hline & & Gnadochaeta $^{\mathrm{j}}$ & Wood [83] \\
\hline & & Siphona intrudens & O’Hara [86] \\
\hline \multirow{8}{*}{ Calliphoridae } & \multirow{2}{*}{ Calliphorinae } & Calliphora vicina & Whitworth [87] \\
\hline & & Calliphora vomitoria & Whitworth [87] \\
\hline & \multirow[t]{2}{*}{ Chrysomyinae } & Phormia regina ${ }^{\mathrm{k}}$ & Whitworth [87], Wells et al. [139] \\
\hline & & Cochliomyia macellaria ${ }^{k}$ & Whitworth [87], Wells et al. [139] \\
\hline & \multirow[t]{3}{*}{ Luciliinae } & Lucilia coeruleiviridis $^{k}$ & Whitworth [87], Liu \& Greenberg [140] \\
\hline & & Lucilia illustris $^{k}$ & Whitworth [87], Liu \& Greenberg [140] \\
\hline & & Lucilia sericata $^{k}$ & Whitworth [87], Liu \& Greenberg [140] \\
\hline & Polleniinae & Pollenia rudis ${ }^{\mathrm{j}}$ & Whitworth [87] \\
\hline
\end{tabular}


Table S3. List of non-fly and non-beetle species collected from 53 pig corpses and reference used for identification

\begin{tabular}{|c|c|c|c|c|}
\hline Order & Family & Subfamily & Species & Reference \\
\hline Collembola & Entomobryidae & Lepidocyrtinae & Lepidocyrtus curvicollis & Arnetti [88] Scott [89] \\
\hline Orthoptera & Gryllidae & Oecanthinae & Neoxabea bipunctata ${ }^{\mathrm{j}}$ & Walker [90] \\
\hline \multirow[t]{2}{*}{ Psocodea } & \multirow[t]{2}{*}{ Psocidae } & Amphigerontiinae & Blastopsocus lithinus & Moeford [91] \\
\hline & & Psocinae & Cerastipsocus venosus ${ }^{\mathrm{j}}$ & Moeford [91] \\
\hline \multirow[t]{22}{*}{ Hemiptera } & Aphididae & Aphidinae & Aphis sp. ${ }^{\mathrm{j}}$ & Wilson [92] \\
\hline & \multirow[t]{7}{*}{ Cicadellidae } & \multirow[t]{6}{*}{ Deltocephalinae } & Amblysellus curtisii ${ }^{\mathrm{j}}$ & Delong \& Hamilton [93] \\
\hline & & & Latalus sayii $^{\mathrm{j}}$ & Beirne [94] \\
\hline & & & Osbornellus auronitens & Beamer [95] \\
\hline & & & Paraphlepsius $\mathrm{sp}^{\mathrm{j}}$ & Oman [96] \\
\hline & & & Scaphoideus sp. ${ }^{\mathrm{j}}$ & Oman [96] \\
\hline & & & Texananus sp. ${ }^{j}$ & Oman [96] \\
\hline & & Typhlocybinae & Alebra sp. & Oman [96] \\
\hline & \multirow[t]{2}{*}{ Membracidae } & \multirow[t]{2}{*}{ Smiliinae } & Vanduzea sp. ${ }^{\mathrm{j}}$ & Dennis [97] \\
\hline & & & 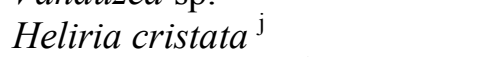 & Dennis [97] \\
\hline & \multirow[t]{2}{*}{ Flatidae } & \multirow[t]{2}{*}{ Flatinae } & Metcalfa pruinosa ${ }^{\mathrm{j}}$ & Dozie [98] \\
\hline & & & Ormenoides venusta & Dozie [98] \\
\hline & Cydnidae & Cydninae & Pangaeus bilineatus & Froeschner [99] \\
\hline & Thyreocoridae & Thyreocorinae & Galgupha nitiduloides & Hart [100] \\
\hline & Pentatomidae & Pentatominae & Cosmopepla lintneriana $^{\mathrm{j}}$ & McPherson [101] \\
\hline & Berytidae & Metacanthinae & Jalysus sp. ${ }^{\mathrm{j}}$ & Henry [102] \\
\hline & \multirow{2}{*}{ Rhyparochromidae } & \multirow{2}{*}{ Rhyparochrominae } & Myodocha serripes ${ }^{\mathrm{j}}$ & Peredo [103] \\
\hline & & & Scolopostethus thomsoni & Slater \& Brailovsky [104] \\
\hline & \multirow{3}{*}{ Miridae } & Bryocorinae & Pycnoderes quadrimaculatus & Blatchley [105] \\
\hline & & Cylapinae & Fulvius imbecilis $\mathrm{j}$ & Henry et al. [106] \\
\hline & & Orthotylinae & Halticus bractatus & Henry [107] \\
\hline & Tingidae & Tinginae & Corythucha arcuata & Gibson [108] \\
\hline \multirow{18}{*}{$\begin{array}{l}\text { Neuroptera } \\
\text { Hymenoptera }\end{array}$} & Chrysopidae & \multirow[t]{2}{*}{ Chrysopinae } & \multirow[t]{2}{*}{ Leucochrysa sp. } & Strange [109] \\
\hline & Tenthredinidae ${ }^{1}$ & & & Chu [110] \\
\hline & \multirow[t]{12}{*}{ Formicidae } & \multirow[t]{8}{*}{ Formicinae } & Camponotus americanus & Wheeler [111] \\
\hline & & & Camponotus novaeboracensis & Wheeler [111] \\
\hline & & & Camponotus pennsylvanicus & Wheeler [111] \\
\hline & & & Formica fusca grp. & Creighton [112] \\
\hline & & & Formica pallidefulva & Trager et al. [113] \\
\hline & & & Lasius niger & Wilson [114] \\
\hline & & & Lasius umbratus & Wilson [114] \\
\hline & & & Prenolepis impairs & Fisher \& Cover [115] \\
\hline & & \multirow{4}{*}{ Myrmicinae } & Aphaenogaster fulva & Creighton [112] \\
\hline & & & Aphaenogaster tennesseensis & Creighton [112] \\
\hline & & & Myrmica americana & Weber [116] \\
\hline & & & Myrmica punctiventris & Weber [116] \\
\hline & Megachilidae & Megachilinae & Megachile sp. & Mitchell [117] \\
\hline & \multirow[t]{3}{*}{ Halictidae } & \multirow[t]{3}{*}{ Halictinae } & Augochloropsis sumptosa & Campbell [118] \\
\hline & & & Lasioglossum (Dialictus) sp.-1 & Gibbs [119] \\
\hline & & & Lasioglossum (Dialictus) sp.-2 & Gibbs [119] \\
\hline
\end{tabular}


Table S3. Continued

\begin{tabular}{|c|c|c|c|c|}
\hline Order & Family & Subfamily & Species & Reference \\
\hline \multirow[t]{16}{*}{ Hymenoptera } & Braconidae & Alysiinae & Aphaereta pallipes & Wharton [120] \\
\hline & & Cheloninae & Ascogaster sp. ${ }^{j}$ & Shaw [121] \\
\hline & & Helconinae & Diospilus sp. ${ }^{\mathrm{j}}$ & Sharkey [122] \\
\hline & & Microgastrinae & Apanteles sp. & Whitfield [123] \\
\hline & & & Microgaster sp. & Whitfield [123] \\
\hline & & & Microplitis sp. ${ }^{\mathrm{j}}$ & Whitfield [123] \\
\hline & Ichneumonidae & Mesochorinae & Mesochorus sp. ${ }^{\mathrm{j}}$ & Wahl [124] \\
\hline & Cynipidae & Cynipinae & Morphoseries- 1 & Ritchie [125] \\
\hline & Figitidae & Eucoilinae & Morphoseries- 1 & Ritchie [125] \\
\hline & & & Morphoseries-2 & Ritchie [125] \\
\hline & Diapriidae & Diapriinae & Basalys sp. ${ }^{\mathrm{j}}$ & Masner \& Garcia [126] \\
\hline & Proctotrupidae & Proctotrupinae & Brachyserphus sp. ${ }^{\mathrm{j}}$ & Masner [127] \\
\hline & Eulophidae & Entedoninae & Chrysocharis sp. ${ }^{\mathrm{j}}$ & Hansson [128] \\
\hline & & Eulophinae & Hyssopus rhyacionae $\mathrm{j}$ & Schauff [129] \\
\hline & Pteromalidae & Pteromalinae & Nasonia vitripennis ${ }^{\mathrm{j}}$ & Darling \& Werren [130] \\
\hline & Torymidae & Toryminae & Torymus sp. & $\begin{array}{l}\text { Vere Graham \& Gijswijt } \\
\text { [131] }\end{array}$ \\
\hline \multirow[t]{12}{*}{ Lepidoptera } & Arctiidae & Arctiinae & Estigmene sp. ${ }^{\mathrm{j}, 1}$ & Wagner [132] \\
\hline & Geometridae & Ennominae & Lomographa sp. ${ }^{\mathrm{j}, 1}$ & Wagner [132] \\
\hline & & & Plagodis sp. & Wagner [132] \\
\hline & & & Individual ${ }^{\mathrm{j}, \mathrm{i}}$ & Wagner [132] \\
\hline & Lycaenidae & Polyommatinae & Celastrina sp. & Belth [133] \\
\hline & Noctuidae & Acontiinae & Individual $\mathrm{j}, 1$ & Wagner [132] \\
\hline & & Catocalinae & Catacola sp. ${ }^{\mathrm{j}, 1}$ & Wagner [132] \\
\hline & & & Phoberia sp. ${ }^{\mathrm{j}, 1}$ & Wagner [132] \\
\hline & & Plusiinae & Zale sp. ${ }^{\mathrm{j}, 1}$ & Wagner [132] \\
\hline & Nymphalidae & Heliconiinae & Boloria sp. ${ }^{\mathrm{j}, 1}$ & Belth [133] \\
\hline & Tineidae & Tineinae & Tinea sp. & Dietz [134] \\
\hline & & & Tineola sp. ${ }^{\mathrm{j}}$ & Dietz [134] \\
\hline
\end{tabular}


Table S4. Reoccurrence frequency (Reoccurrence Carcasses/\# of Pigs (from table 1)) for each carrion species that was observed on a high enough proportion of carcasses $(>45 / 53)$ for placing confidence limits on an estimation of postmortem interval.

\begin{tabular}{lccc} 
& Reoccurrence & Reoccurrence \\
Species & Cl day & Carcasses & Proportion (\%) \\
\hline Euspilotus assimilis(A) & Yes & 23 & 43.4 \\
Necrophila americana(A) & Yes & 14 & 28.6 \\
Creophilus maxillosus(L) & Yes & 27 & 54.0 \\
Philonthus politus(A) & Yes & 29 & 60.4 \\
Philonthus sericans(A) & Yes & 37 & 75.5 \\
Philonthus sp.(L) & Yes & 30 & 61.2 \\
Omosita colon(A) & Yes & 40 & 76.9 \\
Prochyliza xanthostoma(A) & Yes & 26 & 49.0 \\
Stearibia nigriceps(A) & Yes & 16 & 32.0 \\
Meroplius stercorarius(A) & Yes & 38 & 71.7 \\
Sepsis punctum(A) & Yes & 22 & 47.8 \\
Liohippelates bishoppi(A) & Yes & 27 & 51.9 \\
Ophyra sp.(L) & Yes & 21 & 43.8 \\
Fannia scalaris(A) & Yes & 37 & 69.8 \\
Cochliomyia macellaria(A) & Yes & 16 & 32.0 \\
Phormia regina(A) & Yes & 27 & 50.9 \\
Necrodes surinamensis(A) & No & 5 & 11.1 \\
Necrophila americana(L) & No & 11 & 22.9 \\
Creophilus maxillosus(A) & No & 4 & 7.5 \\
Necrobia ruficollis(A) & No & 9 & 20.0 \\
Fannia scalaris(L) & No & 12 & 23.5 \\
Cochliomyia macellaria $(\mathrm{L})$ & No & 6 & 13.0 \\
Phormia regina(L) & No & 1 & 1.9 \\
Lucilia illustris(L) & No & 14 & 26.4 \\
\hline
\end{tabular}




\section{Acknowledgements}

We would like to thank multiple taxonomic experts for identification of selected insect species.

Superscript letters apply to footnotes in the supplementary materials.

${ }^{a}$ Dr. Michael Caterino, Department of Invertebrate Zoology, Santa Barbara Museum of Natural History, 2559 Puesta Del Sol, Santa Barbara, California 93105 USA,

${ }^{b}$ Dr. Alfred Newton, Division of Insects, Field Museum of Natural History, 1400 South Lake

Shore Drive, Chicago, Illinois 60605, USA,

${ }^{\mathrm{c}}$ Dr. Terry A. Wheeler, Department of Natural Resources, McGill University, Macdonald campus, Ste-Anne-de-Bellevue, QC, H9X 3V9, Canada,

${ }^{\mathrm{d}}$ Dr. James Liebherr, Department of Entomology, Cornell University Insect Collection, 2144

John and Anna Comstock Hall, Ithaca, New York 14853 USA,

${ }^{\mathrm{e}}$ Dr. Paul Skelley, Florida State Collection of Arthropods, The Doyle Connor Building, 1911 SW $34^{\text {th }}$ Street, Gainesville, Florida 32608 USA,

${ }^{\mathrm{f}}$ Dr. Stephen Marshall, University of Guelph Insect Collections and Systematics Laboratory, 1216 Edmund C. Bovey Building, University of Guelph, ON N1G 2W1, Canada. 


\section{References}

[1] C.H. Lindroth, The ground-beetles (Carabidae, excl. Cicindeliinae) of Canada and Alaska, parts 1-6, Opusc. Entomol. Supplementa, 1969, 1192 pp.

[2] P. Vaurie, A revision of the genus Trox in North America (Coleoptera, Scarabaeidae), Bull. Am. Mus. Nat. Hist. 106 (1955) 1-90.

[3] H.F. Howden, Biology and taxonomy of North American beetles of the subfamily Geotrupinae, with revisions of the genera Bolbocerosoma, Eucanthus, Geotrupes, and Peltotrupes (Scarabaeidae), Proc. U. S. Nat. Mus. 104 (1950) 151-341.

[4] H.F. Howden, O.L. Cartwright, Scarab beetles of the genus Onthophagus Latreille north of Mexico (Coleoptera: Scarabaeidae), Proc. U. S. Nat. Mus. 114 (1963) 1-135.

[5] R.D. Gordon, P.E. Skelley, A monograph of the Aphodiini inhabiting the United States and Canada (Coleoptera: Scarabaeidae: Aphodiinae), Mem. Am. Entomol. Soc. 79 (2007) 580pp.

[6] G.H. Horn, Revision of the United States species of Ochodaeus and other genera of Scarabaeidae, Trans. Am. Entomol. Soc. 5 (1876) 177-197.

[7] K. Katovich, A generic-level phylogenetic review of the Macrodactylini (Coleoptera: Scarabaeidae: Melolonthinae), Insecta Mundi 23 (2008) 1-78.

[8] B.C. Ratcliffe, The natural history of Necrodes surinamensis (Fabr.) (Coleoptera: Silphidae), Trans. Am. Entomol. Soc. 98 (1972) 359-410.

[9] B.C. Ratcliffe, The carrion beetles (Coleoptera: Silphidae) of Nebraska, Bull. Univ. Nebr. State Mus. 13 (1996) 1-100. 
[10] A. Smetana, Rove beetles of the subtribe Philonthina of America north of Mexico (Coleoptera: Staphylinidae) classification, phylogeny and taxonomic revision, Associated Publishers, Gainesville, FL, 1995, 946 pp.

[11] A. Brunke, A. Newton, J. Klimaszewski, C. Majka, S. Marshall, Staphylinidae of eastern Canada and adjacent United States. Key to subfamilies; Staphylininae: tribes and subtribes, and species of Staphylinina, Can. J. Arthropod Identif. 12 (2011) 1-110.

[12] R.H. Arnett Jr., M.C. Thomas, American Beetles Volume I: Archostemata, Myxophaga, Adephaga, Polyphaga: Staphyliniformia, CRC Press LLC, Boca Raton, FL, 2001, 464 pp.

[13] E.R. Hoebeke, A revision of the rove beetle tribe Falagriini of America north of Mexico (Coleoptera: Staphylinidae: Aleocharinae), J. N. Y. Entomol. Soc. 93 (1985) 913-1018.

[14] H.M. Hatch, Studies on the Leptoderidae (Catopidae) with descriptions of new species, J. N. Y. Entomol. Soc. 41 (1933) 187-236, 238-239.

[15] A. Smetana, Revision of the subfamily Sphaeridiinae of America north of Mexico (Coleoptera: Hydrophilidae), Mem. Entomol. Soc. Can. 110 (1978) 1-292.

[16] N.M. Downie, R.H. Arnett Jr., The Beetles of Northeastern North America Volumes 1 and 2, Sandhill Crane Press, Gainesville, FL, 1996, 1721 pp.

[17] Y. Bousquet, S. Laplante, The Insects and Arachnids of Canada Part 24. Coleoptera Histeridae, NRC Research Press, Ottawa, Ontario, 2006, 485 pp.

[18] L.P. Gibson, Monograph of the genus Curculio in the New World (Coleoptera: Curculionidae) Part I. United States and Canada, Misc. Publ. Entomol. Soc. Am. 6 (1969) 239285. 
[19] R.H. Arnett Jr., M.C. Thomas, P.E. Skelley, J.H. Frank (Eds.), American Beetles Volume II: Polyphaga: Scarabaeoidea through Curculionoidea, CRC Press, Boca Raton, FL, 2002, 880 pp.

[20] D.E. Bright, P. Bouchard, Insects and Arachnids of Canada Part 25. Coleoptera, Curculionidae, Entiminae, NRC Research Press, Ottawa, Ontario, 2008, 327 pp.

[21] E.W. Richard, A revision of the subfamily Criocerinae (Chrysomelidae) of America north of Mexico, U. S. Dep. Agric. Tech. Bull. No. 1805 (1993) 158pp.

[22] J.A. Wilcox, A revision of the North American species of Paria Lec. (Coleoptera: Chrysomelidae), N. Y. State Mus. and Sci. Svc. Bull. 365 (1957) 1-45.

[23] S.E. Howard, Revision of the genus Phyllotreta Chevrolat of America north of Mexico Part I. The maculate species (Coleoptera: Chrysomelidae, Alticinae), Fieldiana Zool. 28 (1985) 1-168.

[24] F.G. Werner, A revision of the genus Epicauta in America north of Mexico (Coleoptera, Meloidae), Bull. Mus. Comp. Zool. 95 (1945) 421-517.

[25] G.H. Horn, Revision of the Tenebrionidae of America north of Mexico, Trans. Am. Philos. Soc. 14 (1870) 253-404.

[26] J. Kim, B.H. Jung, Taxonomic review of the Cleridae (Coleoptera) in Korea (Part 3): Korynetinae, Tarsosteninae and Tillinae, Entomol. Res. 36 (2006) 245-252.

[27] C.T. Parsons, A revision of Nearctic Nitidulidae (Coleoptera), Bull. Mus. Comp. Zool. 92 (1943) 121-278.

[28] Y. Bousquet, S. Laplante, Taxonomic revision of the Canadian species of the genus Monotoma Herbst (Coleoptera: Monotomidae), Proc. Entomol. Soc. Ont. 130 (1999) 67-96. 
[29] R.D. Gordon, N. Vandenberg, Field guide to recently introduced species of Coccinellidae (Coleoptera) in North America, with a revised key to North American genera of Coccinellini, Proc. Entomol. Soc. Wash. 93 (1991) 845-867.

[30] F.M. Fender, The Chauliognathini of America north of Mexico (Coleoptera-Cantharidae) Part 1\&2, Northwest Sci. 38 (1964) 52-64, 95-106.

[31] L.W. Quate, S.E. Thompson, Revision of click beetles of genus Melanotus in America north of Mexico (Coleoptera: Elateridae), Proc. U. S. Nat. Mus. 121 (1967) 1-83.

[32] D.R. Oliver, Chironomidae, in: J.F. McAlpine, B.V. Peterson, G.E. Shewell, H.J. Teskey, J.R. Vockeroth, D.M. Wood (Eds.), Manual of Nearctic Diptera Volume 1, Agriculture Canada Monograph 27, 1981, 423-458.

[33] R.E. Siverly, Mosquitoes of Indiana, State Board of Health, Indianapolis, IN, 1972, 126 pp.

[34] R.J. Gagne, Cecidomyiidae, in: J.F. McAlpine, B.V. Peterson, G.E. Shewell, H.J. Teskey, J.R. Vockeroth, D.M. Wood (Eds.), Manual of Nearctic Diptera Volume 1, Agriculture Canada Monograph 27, 1981, 257-292.

[35] W.A. Steffan, Sciaridae, in: J.F. McAlpine, B.V. Peterson, G.E. Shewell, H.J. Teskey, J.R. Vockeroth, D.M. Wood (Eds.), Manual of Nearctic Diptera Volume 1, Agriculture Canada Monograph 27, 1981, 247-256.

[36] J.R. Vockeroth, Mycetophilidae, in: J.F. McAlpine, B.V. Peterson, G.E. Shewell, H.J. Teskey, J.R. Vockeroth, D.M. Wood (Eds.), Manual of Nearctic Diptera Volume 1, Agriculture Canada Monograph 27, 1981, 223-246.

[37] D.E. Hardy, The American Chrysopilus (Rhagionidae-Diptera), Am. Midl. Nat. 41 (1949) 143-167. 
[38] A.W. Thomas, S.A. Marshall, Tabanidae of Canada east of the Rocky Mountains 1: a photographic key to the species of Chrysopsinae and Pangoniinae, Can. J. Arthropod Identif. 8 (2009) 1-172.

[39] D.W. Coquillett, Revision of the North American Empididae-a family of two-winged insects, Proc. U. S. Nat. Mus. 18 (1895) 387-440.

[40] A.L. Melander, Synopsis of Coptophilibia with descriptions of new American and Oriental species (Diptera, Empididae), Pan-Pac. Entomol. 22 (1946) 105-117.

[41] H.J. Teskey, J.G. Chillcott, A revision of the Nearctic species of Syndyas Loew (Diptera: Empididae), Can. Entomol. 109 (1977) 1445-1455.

[42] A.L. Melander, The dipterous genus Drapetis (Family Empididae), Ann. Entomol. Soc. Am. 11 (1918) 183-221.

[43] J.G. Chillcott, A revision of the Platypalpus juvenis complex in North America (Diptera: Empididae), Can. Entomol. 94 (1962) 113-143.

[44] G.C. Steyskal, L.V. Knutson, Empididae, in: J.F. McAlpine, B.V. Peterson, G.E. Shewell, H.J. Teskey, J.R. Vockeroth, D.M. Wood (Eds.), Manual of Nearctic Diptera Volume 1, Agriculture Canada Monograph 27, 1981, 607-624.

[45] C.H. Curran, American Diptera, Bull. Am. Mus. Nat. Hist. 80 (1942) 51-84.

[46] M.C. Van Duzee, C.H. Curran, Key to the females of Nearctic Dolichopus Latreille (Diptera), Am. Mus. Novit. 684 (1934) 1-17.

[47] D.J. Bickel, A revision of the Nearctic Medetera (Diptera, Dolichopodidae), U.S. Dep. Agric. Tech. Bull. 1692 (1985) 1-109. 
[48] B.V. Peterson, Phoridae, in: J.F. McAlpine, B.V. Peterson, G.E. Shewell, H.J. Teskey, J.R. Vockeroth, D.M. Wood (Eds.), Manual of Nearctic Diptera Volume 2, Agriculture Canada Monograph 28, 1987, 689-712.

[49] J.R. Vockeroth, The Flower Flies of the Subfamily Syrphinae of Canada, Alaska, and Greenland, Diptera: Syrphidae, The Insects and Arachnids of Canada Part 18, Agriculture Canada, Ottawa, Ontario, 1992, 456 pp.

[50] C.H. Curran, New American Diptera, Am. Mus. Novit. 812 (1935) 1-24.

[51] R. Namba, A revision of the flies of the genus Rivellia (Otitidae, Diptera) of America north of Mexico, Proc. U. S. Nat. Mus. 106 (1956) 21-84.

[52] J.F. McAlpine, A revised classification of the Piophilidae including 'Neottiophilidae' and the 'Thyreophoridae' (Diptera: Schizophora), Mem. Entomol. Soc. Can. 103 (1977) 1-66.

[53] J.F. McAlpine, Piophilidae, in: J.F. McAlpine, B.V. Peterson, G.E. Shewell, H.J. Teskey, J.R. Vockeroth, D.M. Wood (Eds.), Manual of Nearctic Diptera Volume 2, Agriculture Canada Monograph 28, 1987, 845-852.

[54] G.E. Shewell, The Lauxaniidae (Diptera) of southern Quebec and adjacent regions, Can. Entomol. 70 (1938) 102-108; 133-142.

[55] G.E. Shewell, Lauxaniidae, in: J.F. McAlpine, B.V. Peterson, G.E. Shewell, H.J. Teskey, J.R. Vockeroth, D.M. Wood (Eds.), Manual of Nearctic Diptera Volume 2, Agriculture Canada Monograph 28, 1987, 951-964.

[56] J.R. Malloch, W.L. McAtee, Keys to flies of the families Lonchaeidae, Pallopteridae, and Sapromyzidae of the eastern United States, with a list of the species of the District of Columbia region, Proc. U. S. Nat. Mus. 65 (1924) 1-26. 
[57] G.C. Steyskal, Sepsidae, in: J.F. McAlpine, B.V. Peterson, G.E. Shewell, H.J. Teskey, J.R. Vockeroth, D.M. Wood (Eds.), Manual of Nearctic Diptera Volume 2, Agriculture Canada Monograph 28, 1987, 945-950.

[58] A.L. Ozerov, Revision of the Nearctic species of the genus Sepsis Fallen, 1810 (Diptera, Sepsidae), Russ. Entomol. J. 9 (2000) 161-176.

[59] C.W. Sabrosky, The Hippelates flies or eye gnats: preliminary notes, Can. Entomol. 73 (1941) 23-27.

[60] C.W. Sabrosky, Twelve new North American species of Oscinella (Diptera: Chloropidae), Can. Entomol 72 (1940) 214-230.

[61] C.W. Sabrosky, A synopsis of the Nearctic species of Oscinella and Madiza, based on a study of the types (Diptera, Chloropidae), Ann. Entomol. Soc. Am. 29 (1936) 707-728.

[62] C.W. Sabrosky, Taxonomic notes on the dipterous family Chloropidae, J. N. Y. Entomol. Soc. 46 (1938) 417-434.

[63] S.A. Marshall, O.W. Richards, Sphaeroceridae, in: J.F. McAlpine, B.V. Peterson, G.E. Shewell, H.J. Teskey, J.R. Vockeroth, D.M. Wood (Eds.), Manual of Nearctic Diptera Volume 2, Agriculture Canada Monograph 28, 1987, 993-1006.

[64] O.W. Richards, On two North American species of Leptocera Oliv., subgenus Coproica Rond., with a review of the subgenus (Dipt., Sphaeroceridae), Ann. Mag. Nat. Hist. 13 (1960) 199-256.

[65] M. Buck, S.A. Marshall, Revision of the New World Leptocera Olivier (Diptera, Sphaeroceridae), Zootaxa 2039 (2009) 1-139. 
[66] S.A. Marshall, A revision of the genus Spelobia Spuler (Diptera: Sphaeroceridae) in North America and Mexico, Trans. Am. Entomol. Soc. 111 (1985) 1-101.

[67] H.-Y. Han, K.C. Kim, Systematics of Ischiolepta Lioy (Diptera: Sphaeroceridae), Ann. Entomol. Soc. Am. 83 (1990) 409-443.

[68] M.R. Wheeler, Drosophilidae, in: J.F. McAlpine, B.V. Peterson, G.E. Shewell, H.J. Teskey, J.R. Vockeroth, D.M. Wood (Eds.), Manual of Nearctic Diptera Volume 2, Agriculture Canada Monograph 28, 1987, 1011-1018.

[69] J.F. McAlpine, Diastatidae, in: J.F. McAlpine, B.V. Peterson, G.E. Shewell, H.J. Teskey, J.R. Vockeroth, D.M. Wood (Eds.), Manual of Nearctic Diptera Volume 2, Agriculture Canada Monograph 28, 1987, 1019-1022.

[70] H.C. Huckett, The Anthomyiidae of California exclusive of the subfamily Scatophaginae (Diptera), Bull. Calif. Insect Surv. 12 (1971) 1-121.

[71] H.C. Huckett, Anthomyiidae, in: J.F. McAlpine, B.V. Peterson, G.E. Shewell, H.J. Teskey, J.R. Vockeroth, D.M. Wood (Eds.), Manual of Nearctic Diptera Volume 2, Agriculture Canada Monograph 28, 1987, 1099-1114.

[72] G.C. Steyskal, The genus Emmesomyia Malloch in North America (Diptera, Anthomyiidae), U. S. Dept. Coop. Econ. Insect Rep. 23 (1973) 331-332.

[73] J.G. Chillcott, A revision of the Nearctic species of Fanniinae (Diptera: Muscidae), Mem. Entomol. Soc. Can. $92 . S 14$ (1960) 5-295.

[74] H.C. Huckett, A review of the North American species belonging to the genus Hydrotaea Robineau-Desvoidy (Diptera: Muscidae), Ann. Entomol. Soc. Am. 47 (1954) 316-342. 
[75] F.M. Snyder, Notes and descriptions of Muscina and Dendrophaonia (Diptera: Muscidae), Ann. Entomol. Soc. Am. 48 (1956) 445-452.

[76] F.M. Snyder, A review of the New World Neodexiopsis (Diptera, Muscidae), the Ovata group, Am. Mus. Novit. 1892 (1958) 1-27.

[77] R. Cuny, Revision of the Eudasyphora Townsend (Diptera: Muscidae), and reflections on its evolution, Can. Ent. 112 (1980) 345-373.

[78] P. Skidmore, The biology of the Muscidae of the world, Ser. Entomol. 29 (1985) 1-550.

[79] C.W. Sabrosky, Recognition of species of Musca, U. S. Dept. Coop. Econ. Insect Rep. 9 (1959) 988.

[80] H.C. Huckett, J.R. Vockeroth, Muscidae, in: J.F. McAlpine, B.V. Peterson, G.E. Shewell, H.J. Teskey, J.R. Vockeroth, D.M. Wood (Eds.), Manual of Nearctic Diptera Volume 2, Agriculture Canada Monograph 28, 1987, 1115-1132.

[81] J.R. Malloch, Flies of the anthomyiid genus Phaonia Robineau-Desvoidy and related genera known to occur in North America, Trans. Am. Entomol. Soc. 48 (1923) 221-282.

[82] G.E. Shewell, Sarcophagidae, in: J.F. McAlpine, B.V. Peterson, G.E. Shewell, H.J. Teskey, J.R. Vockeroth, D.M. Wood (Eds.), Manual of Nearctic Diptera Volume 2, Agriculture Canada Monograph 28, 1987, 1159-1186.

[83] D.M. Wood, Tachinidae, in: J.F. McAlpine, B.V. Peterson, G.E. Shewell, H.J. Teskey, J.R. Vockeroth, D.M. Wood (Eds.), Manual of Nearctic Diptera Volume 2, Agriculture Canada Monograph 28, 1987, 1193-1270.

[84] J.E. O'Hara, D.M. Wood, Catalogue of the Tachinidae (Diptera) of America north of Mexico, Mem. Entomol. Int. 18 (2004) 1-410. 
[85] M.T. James, A review of the larvaevorid flies of the tribe Leskiini with the setulose first vein (R1 ), Proc. U. S. Nat. Mus. 97 (1947) 91-115.

[86] J.E. O’Hara, Classification, phylogeny and zoogeography of the North American species of Siphona Meigen (Diptera: Tachinidae), Quaest. Entomol. 18 (1982) 261-380.

[87] T. Whitworth, Keys to the genera and species of blow flies (Diptera: Calliphoridae) of America north of Mexico, Proc. Entomol. Soc. Wash. 108 (2006) 689-725.

[88] P.M. Arnetti, A taxonomic key to the collembolan in four seral stages leading to the beechmaple climax, Proc. Ind. Acad. Sci. (1970) 234-237.

[89] H.G. Scott, Collembola, pictorial keys to the Nearctic genera, Ann. Entomol. Soc. Am. 54 (1961) 104-113.

[90] T.J. Walker, The taxonomy and calling songs of United States tree crickets (Orthoptera: Gryllidae: Oecanthinae). I. The genus Neoxabea and the niveus and varicornis groups of the genus Oecanthus, Ann. Entomol. Soc. Am. 55 (1962) 303-322.

[91] E.L. Moeford, North American Psocoptera, Sand Hill Crane Press, Gainesville, FL, 1993, $455 \mathrm{pp}$.

[92] H.F. Wilson, Key to the genera of the subfamily Aphidinae and notes on synonymy, Ann. Entomol. Soc. Am. 3 (1910) 314-325.

[93] D.M. Delong, K.G.A. Hamilton, The genus Amblysellus (Homoptera: Cicadellidae): a key to the known species, with descriptions of 8 new species, Can. Entomol. 106 (1974) 841-849.

[94] B.P. Beirne, Canadian species of Latalus (Homoptera: Cicadellidae), Can. Entomol. 86 (1953) 123-127. 
[95] R.H. Beamer, A review of the genus Osbornellus in the United States and Canada (Homoptera-Cicadellidae), J. Kans. Entomol. Soc. 10 (1937) 89-112.

[96] P.W. Oman, The Nearctic leafhoppers (Homoptera: Cicadellidae) a generic classification and checklist, Mem. Entomol. Soc. Wash. 3 (1949) 1-253.

[97] C.J. Dennis, The Membracidae of Wisconsin, Trans. Wisc. Acad. Sci. Arts Lett. 41 (1952) 129-152.

[98] H.L. Dozie, The Fulgoridae or plant-hoppers of Mississippi including those of possible occurrence: a taxonomic, biological, ecological and economic study, Miss. Agric. Exp. Sta. Tech. Bull. 14 (1926) 1-152.

[99] R.C. Froeschner, Cydnidae of the Western Hemisphere, Proc. U. S. Nat. Mus. 111 (1960) $337-680$.

[100] C.A. Hart, The Pentatomidae of Illinois with keys to the Nearctic genera, Bull. Ill. Nat. Hist. Sur. 13 (1922) 157-223.

[101] J.E. McPherson, The Pentatomidae (Hemiptera) of northeastern North America: with emphasis on the fauna of Illinois, Southern Illinois University Press, Carbondale, IL, 1982, 240 pp.

[102] T.J. Henry, Monograph of the stilt bugs, or Berytidae (Heteroptera) of the Western Hemisphere, Mem. Entomol. Soc. Wash. 19 (1997) 1-149.

[103] L.C. Peredo, Two new species of Myodocha (Lygaeoidea: Rhyparochromidae: Myodochini) with a key to species, Ann. Entomol. Soc. Am. 98 (2005) 458-469. 
[104] J.A. Slater, H. Brailovsky, A new species of Drymus Fieber from Mexico, with a key to species and a checklist of Western Hemisphere Drymini (Hemiptera: Lygaeidae), Proc. Entomol. Soc. Wash. 99 (1997) 37-41.

[105] W.S. Blatchley, Some new Miridae from the eastern United States, Entomol. News 37 (1946) 163-169.

[106] T.J. Henry, R.L. Hoffman, A. Wolski, First North American record of the Old World cylapine Fulvius subnitens Popplus (Hemiptera: Heteroptera: Miridae) from Virginia, with descriptions and a key to the United States species of Fulvius, Proc. Entomol. Soc. Wash. 113 (2011) 127-136.

[107] T.J. Henry, The garden leafhopper genus Halticus (Hemiptera: Miridae): resurrection of an old name and key to species of the Western Hemisphere, Proc. Entomol. Soc. Wash. 85 (1983) 607-611.

[108] E.H. Gibson, The genus Corythucha Stal (Tingidae: Heteroptera), Trans. Am. Entomol. Soc. 44 (1918) 69-104.

[109] L.A. Strange, The green lacewings of Florida (Neuroptera: Chrysopidae).1. Genera, Entomol. Cir. No. 400 Div. Plant Ind., Fla. Dept. Agric. \& Consumer Ser., 2000, 4 pp.

[110] H.F. Chu, How to Know the Immature Insects, M.C. Brown Company Publishers, Dubuque, IA, 1949, 244 pp.

[111] W.M. Wheeler, The North American ants of the genus Camponotus Mayr, Ann. N. Y. Acad. Sci. 20 (1910) 205-354.

[112] W.S. Creighton, The ants of North America, Bull. Mus. Comp. Zool. 104 (1950) 1-585. 
[113] J.C. Trager, J.A. MacGown, M.D. Trager, Revision of the Nearctic endemic Formica pallidefulva group (Hymenoptera: Formicidae: Formicinae), in: R.R. Snelling, P.S. Ward, B.J. Fisher (Eds.), Advances in Ant Systematics, Mem. Am. Entomol. Inst. 80, 2007, pp. 610-636.

[114] E.O. Wilson, A monographic revision of the ant genus Lasius, Bull. Mus. Comp. Zool. 113 (1955) 1-204.

[115] B.L. Fisher, S.P. Cover, Ants of North America: A Guide to Genera, University of California Press, Berkley, CA, 2007, 194 pp.

[116] N.A. Weber, A revision of the North American ants of the genus Myrmica Latreille with a synopsis of the Palearctic species, Ann. Entomol. Soc. Am. 40 (1947) 437-474.

[117] T.B. Mitchell, The bees of the eastern United States. II, N.C. Agric. Exp. Stn. Tech. Bull. 152 (1962) 1-557.

[118] G.E. Campbell, A comparative morphological study and generic revision of the augochlorine bees (Hymenoptera: Halictidae), Univ. Kans. Sci. Bull. 48 (1969) 325-524.

[119] J. Gibbs, Revision of the metallic species of Lasioglossum (Dialictus) in Canada (Hymenoptera, Halictidae, Halictini), Zootaxa 2591 (2010) 1-382.

[120] R.A. Wharton, New World Aphaereta species (Hymenoptera: Braconidae) with a discussion of terminology used in the tribe Alysiini, Ann. Entomol. Soc. Am. 70 (1977) 782-803.

[121] S.R. Shaw, Subfamily Cheloninae, in: R.A. Wharton, P.M. Marsh, M.J. Sharkey (Eds.), Manual of the New World Genera of the Family Braconidae (Hymenoptera), Special Publ. Int. Soc. Hym. 1, 1997, pp. 192-201. 
[122] M.J. Sharkey, Subfamily Helconinae, in: R.A. Wharton, P.M. Marsh, M.J. Sharkey (Eds.), Manual of the New World Genera of the Family Braconidae (Hymenoptera), Special Publ. Int. Soc. Hym. 1, 1997, pp. 260-272.

[123] J.B. Whitfield, Subfamily Microgastrinae, in: R.A. Wharton, P.M. Marsh, M.J. Sharkey (Eds.), Manual of the New World Genera of the Family Braconidae (Hymenoptera), Special Publ. Int. Soc. Hym. 1, 1997, pp. 333-364.

[124] D.B. Wahl, Cladistics of the genera of Mesochorinae (Hymenoptera: Ichneumonidae), Syst. Entomol. 18 (1993) 371-387.

[125] A.J. Ritchie, Superfamily Cynipoidea, in: H. Goulet, J.T. Huber (Eds.), Hymenoptera of the World: An Identification Guide to Families, Agriculture Canada, Ottawa, Canada, 1993, pp. 521536.

[126] L. Masner, J.L. Garia, The genera of Diapriinae (Hymenoptera: Diapriidae) in the New World, Bull. Am. Mus. Nat. His. 268 (2002) 1-138.

[127] L. Masner, Proctotrupidae. Key to genera of the world (Hymenoptera Proctotrupoidea), Exploration du Parc National de l'Upemba, Mission GF. De Witte. Bruxelles 60 (1961) 37-45.

[128] C. Hansson, Revised key to the Nearctic species of Chrysocharis Forster (Hymenoptera: Eulophidae), including three new species, J. Hym. Res. 4 (1995) 80-98.

[129] M.E. Schauff, Revision of the Nearctic species of Hyssopus Girault (Hymenoptera: Eulophidae), J. N. Y. Entomol. Soc. 93 (1985) 1096-1108.

[130] D.C. Darling, J.H. Werren, Biosystematics of Nasonia (Hymenoptera, Pteromalidae): two new species reared from birds' nests in North America, Ann. Entomol. Soc. Am. 83 (1990) 352370. 
[131] M.W.R. de Vere Graham, M.J. Gijswijt, Revision of the European species of Torymus Dalman (Hymenoptera: Torymidae), Zool. Verh. Leiden 317 (1998) 1-202.

[132] D.L. Wagner, Caterpillars of Eastern North America: A Procedural Guide to Identification and Natural History, Princeton University Press, NJ, 2005, 514 pp.

[133] J.E. Belth, Butterflies of Indiana: A Field Guide, Indiana University Press, Bloomington, IN, 2013, 323 pp.

[134] W.G. Dietz, Revision of the genera and species of the tineid subfamilies Amydriinae and Tineinae inhabiting North America, Trans. Am. Entomol. Soc. 31 (1905) 1-96.

[135] F.K. Kasule, The larvae of Paederinae and Staphylininae (Coleoptera: Staphylinidae) with keys to the known British genera, Trans. R. Entomol. Soc. Lond. 122 (1970) 49-80.

[136] A.G. Boving, A.B. Champlain, Larvae of North American beetles of the family Cleridae, Proc. U. S. Nat. Mus. 57 (1920) 575-649.

[137] B.E. Rees, Classification of the Dermestidae (larder, hide, and carpet beetles) based on larval characters, with a key to the North American genera, U. S. Dept. of Agriculture Misc. Publ. No. 511 (1943) 1-18.

[138] K.G.V. Smith, A Manual of Forensic Entomology, Cornell University Press, Ithaca, NY, 1986, $205 \mathrm{pp}$.

[139] J.D. Wells, J.H. Byrd, T.I. Tantawi, Key to third-instar Chrysomyinae (Diptera:

Calliphoridae) form carrion in the continental United States, J. Med. Entomol. 36 (1999) 638-641.

[140] D. Liu, B. Greenberg, Immature stages of some flies of forensic importance, Ann. Entomol. Soc. Am. 82 (1989) 80-93. 


\title{
Chapter 5: Precision and Accuracy of Succession Based Postmortem Interval Estimates Using a Physiological and an Absolute Time Measure
}

\begin{abstract}
Although insect development and activity are temperature dependent, carrion insect succession has been historically recorded in absolute time. Recent studies have suggested the utility of accumulated degree hours (ADH), a physiological time measure, for improved prediction of succession events across carcasses exposed to variable temperature histories. The generation of a succession training dataset large enough to statistically support succession interval (SI) estimates most likely requires pooling of data developed at unequal temperature histories, suggesting utility of a physiological time measure. Preliminary support and identification of useful species for $\mathrm{ADH}$ - described succession can be gained through observations of a comparative increase of insect occurrence overlap and decrease of relative presence period. These characteristics should result in more precise (determined by a decreased SI width) and accurate SI estimations. The presence/absence of eight, previously determined forensically important, species collected from 53 pigs exposed over three years with varying temperature histories were used to determine both ADH and absolute time measured: (1) occurrence overlap, (2) relative presence period, (3) SI width and (4) accuracy of statistically supported SI estimates (determined using the approach of LaMotte and Wells (2000)). Two different ADH ranges were used to determine SI width and accuracy, in order to explore any effect of binning. Comparatively, the use of ADH increased occurrence overlap and decreased SI width, but did not affect relative presence period or SI accuracy. Equivalent accuracy of a more precise SI indicates utility of ADH in succession models, but limitations of ADH use are highlighted.
\end{abstract}




\section{Introduction}

Ambient temperatures affect insect development and activity levels. Because of this relationship, it is common to describe insect development and phenology with a model that measures time in heat units as opposed to absolute time (Damos and Savopoulou-Soultani 2012). Physiological models are commonly used in agriculture to predict emergence times/critical life stages of target pests (Stevenson et al. 2008, Nowatzki et al. 2002). For similar reasons, a physiological time measure is attractive for modeling postmortem decay, because rarely do temperatures at a crime scene mimic experimental conditions.

Current forensic studies aimed at estimating the postmortem interval (PMI) commonly use a thermal accumulation model (Vass et al. 2002, Megyesi et al. 2005, Simmons et al. 2010, Michaud and Moreau 2011), expressing physiological time as accumulated degree hours or days (ADH/ADD). This model utilizes an assumed positive linear relationship between temperature and development rate at intermediate temperatures and has the advantage of being calculable from any temperature profile (Higley and Haskell 2010). Given a curve representing temperature history (i.e. temperature versus time), the area underneath the curve and above a lower developmental threshold (base temperature) for a specific period of time, equals the amount of $\mathrm{ADH}$ experienced. This area can be approximated by summing the average temperatures for a specified period of time (e.g. hourly) above a base temperature ( $\Sigma$ temperature recorded- base temperature). Forensic entomologists use $\mathrm{ADH}$ to describe the development of forensically relevant flies (e.g. Williams 1984, Anderson 2000, Nabity et al. 2006) and beetles (e.g. Richardson and Goff 2001, Midgley and Villet 2009, Velasquez and Viloria 2009). The minimum 
time elapsed since death can be determined by comparing attributes (e.g. length, weight) of maggots collected from the corpse to experimentally generated development data for the same maggot species under similar conditions (Williams 1984).

Support for the use of ADH to calculate specimen age comes from both successful use in case reports (Lord et al. 1986a, Lord et al. 1986b, Oliveira-Costa and Mello-Patiu 2004) and a validation study (VanLaerhoven 2008). Noted advantages to using a linear model, as opposed to some other positive function, (for examples of nonlinear models see table 1 of Kontodimas et al. (2004)) include comparative simplicity of concept and calculation, and examples of comparable performance for agriculturally important insect species (Higley and Haskell 2010). Even though the relationship between development rate and temperature is curvilinear at temperature extremes (i.e. high and low temperatures), to my knowledge there has not been a comparison of predictive performance of linear and nonlinear development models for any forensic insect. While the use of $\mathrm{ADH}$ to describe forensic insect development is widespread, the assumption that development is a linear function of temperature has seldom been tested (Nabity et al. 2006).

If development is linear, individuals of a species should reach a developmental landmark (e.g. pupariation) at the same ADH value (thermal constant) regardless of temperature history (as long as fluctuations stayed within the linear temperature range). In other words, a zero-relationship between thermal constants and rearing temperature distinguishes data appropriate for a linear model (Arnold 1959). This assumption could be preliminarily investigated for any experiment, rearing the same species at more than one temperature, by testing for significant differences in thermal constants across temperature treatments. 
A second, time-dependent process that is used to estimate time since death compares the set of insect species/life stages in the corpse to a model of postmortem insect succession (Wells and LaMotte 2010). Succession encompasses the time elapsed both pre- and post- colonization, enabling the estimation of both a minimum and maximum times since death (assuming the victim died where she or he was found). Commonly, succession data are recorded as an occurrence matrix, displaying presence or absence of species/life stages for each known value of a succession interval (SI). Insects collected on a corpse with an unknown SI are compared to a succession model generated under similar conditions. Model SI values with the same species composition as collected from the corpse are included in a PMI estimation (Schoenly et al. 1996). Since forensic insect succession is an ecological process that involves both insect activity and development, it is not surprising that there is support for a positive relationship between succession rate and temperature (Archer 2003, Archer and Elgar 2003, Michaud and Moreau 2009, Michaud and Moreau 2011) though historically succession patterns have been described in absolute time (i.e. days) (Anderson and VanLaerhoven 1996, Tabor et al. 2004, Voss 2008).

Intuitively, a succession pattern would be harder to model, as compared to development, because it involves multiple species, most likely with both different base temperatures and development rates. In addition, for some species (e.g. Ontholestes cingulatus) a model that incorporates ADH does not increase the predictability of occurrence on carcasses (Michaeud and Moreau 2009). The greater complexity of a succession pattern as compared to a single-species growth curve suggests that something other than a simple landmark must be used to determine the appropriateness of an ADH model. While the synchronization of development can be shown by a small number of developmental milestones, synchronization of two or more succession data sets should be evaluated according to some more complicated measure of overlap. Complete overlap 
of two succession datasets results from synchronous arrival and departure of a species from both corpses. An increase in single species succession pattern overlap on multiple carcasses when measured in $\mathrm{ADH}$ as compared to absolute time can be used to preliminarily assess a species future use in a succession model described in physiological time.

Establishing the exact form of the relationship of succession rate and temperature is beyond the scope of this paper. Instead, I will evaluate the performance of carrion insect species for SI prediction using an ADH model. Previous authors have identified predictability and narrow presence period as the most important measurable features of a carrion insect species that leads to a precise PMI estimation (Matuszewski et al. 2010). Given a practical measure of physiological time, a candidate species should display an increase in temporal overlap across carcasses indicating predictability. This increase in temporal overlap should result in a decreased SI width, and a decreased SI width equals a more precise PMI estimate (Schoenly et al. 1996).

In addition to being common (Chapter 4) and nonreoccurring (Schoenly 1992), a species that demonstrates both an increase in temporal overlap among carcasses and decrease in relative presence period in each carcass, when measured in ADH, exhibits utility for succession models that incorporate temperature. The implementation of a physiological time scale into a succession model is not straightforward because temperature history is a continuous variable and succession data are typically recorded in discrete ranges representing columns in an occurrence matrix. For multiple species of forensic importance, our objectives are to: (1) document statistically supported SI widths (made possible by the approach of LaMotte and Wells (2000)) resulting from different column values (both days and $\mathrm{ADH}$ ranges) to give an initial evaluation of the practical 
implications of pooling $\mathrm{ADH}$ in a succession model, (2) determine the relationship of the relative presence period and occurrence overlap to statistically supported SI widths and (3) assess the predictive performance (accuracy) of SI widths resulting from different column values.

\section{Materials and Methods}

\section{Temperature Comparison Among Years}

Daily insect collections from 53 domestic pig carcasses were made during the summer months (June-August) of three consecutive years (2008-2010). Because of limited pig availability, few of the pigs shared exactly the same exposure period, therefore few had the same ambient temperature history. Those pigs sharing the exact same exposure period were considered to be in the same batch. See Chapter 4 Materials and Methods for details concerning experimental methods and the study site. Temperature was measured hourly throughout the entire experimental period with a HOBO Pro series weatherproof data logger (Onset Cape Cod, Maine). The data logger was secured to a tree, at chest level $(\sim 1.22 \mathrm{~m})$, in full shade. The amount of ADH ( $\Sigma$ temperature recorded-base temperature) in each 24 hour period starting at the time of pig placement was calculated using three different commonly used base temperatures $\left(0,6,10{ }^{\circ} \mathrm{C}\right)$ (VanLaerhoven 2008). Possible differences in total heat input to each carcass were investigated by comparing the average $\mathrm{ADH}$ per day experienced by each batch of pigs using a one-way analysis of variance (ANOVA) in the statistical package JMP version 8.0.1 (SAS Institute Inc, Cary, North Carolina). A separate ANOVA was run using ADH calculations with each of the three base temperatures to determine if significant differences in average $\mathrm{ADH}$ are dependent on 
base temperature. An a posteriori Tukey test for multiple comparisons of means was used to identify which exposure periods significantly differed $(p<0.5)$.

\section{Occurrence Overlap and Relative Presence Period}

The calculated ADH of each daily occurrence for each species previously described as abundant and nonreoccurring (Necrodes surinamensis adults, Necrophila americana larvae, Creophilus maxillosus adults, Necrobia ruficollis adults, Fannia scalaris larvae, Cochliomyia macellaria larvae, Phormia regina larvae, and Lucilia illustris larvae) (Chapter 4) were used to determine occurrence overlap and relative presence period. Both average metrics were calculated twice, once using an absolute (hour) and once using one physiological (ADH) time measure. The proportion of occurrence overlap was calculated for each pairwise comparison on the 53 pigs using one of four equations (Figure 1) depending on the nature of the overlap. Relative presence period was calculated by dividing the length of occurrence of each species by the total length of the sampling period for each pig carcass exposed. This calculation is the same as the previously described relative length of the presence period (Matuszewski et al. 2010).

For both overlap and relative presence period calculations, the comparison of hour and ADH calculations for the same instance was facilitated by scoring each comparison as either a 1 or 0 . A score of 1 indicates the calculation using hours is greater, while a score of 0 indicates the calculation using $\mathrm{ADH}$ is greater. Average scores provide a numerical means to describe trends in the data not apparent from average relative presence period or overlap calculations. An average comparison score $>0.5$, indicates absolute time calculations were more often higher. Conversely, 
an average comparison score $<0.5$, indicates physiological time calculations were more often higher.

\section{Comparison of SI Widths Using Hours and ADH}

Separate, single-species, contingency tables (as described by LaMotte and Wells (2000)) were created from occurrence matrices of the eight identified species. For six of the eight species, $(N$. surinamensis, C. maxillosus, $N$. ruficollis, C. macellaria, $P$. regina, and L. illustris larvae) three statistically-supported SI widths, were calculated using three separate contingency tables, each with different column values: (1) absolute time in days, (2) ADH ranges representing the average daily $\mathrm{ADH}(547 \mathrm{ADH})$, and (3) $\mathrm{ADH}$ ranges representing the minimum $\mathrm{ADH}$ experienced in a 24-hour period (428 ADH) (Appendix 1). Two different ADH ranges were used to explore a possible effect of binning. Because a fourteen day collection period did not encompass the entire SI for two species (N. americana and F. scalaris), the time elapsed before the first SI value ( $\left.\mathrm{SI}_{\min }\right)$ was calculated in the same manner as SI width. A longer time to $\mathrm{SI}_{\min }$ presumably shortens the SI width. The SI values calculated were based on the scenario of presence of the studied species at $\alpha=0.05$ (any day with more than four carcasses observed to have the species present was rejected from the PMI estimation) (See table 3 of LaMotte and Wells (2000)).

To facilitate the comparison of all three measurements, the SI widths calculated from absolute time column values were converted to ADH by multiplying the number of days included in the width or pre-SI $\mathrm{S}_{\min }$ interval by the average $\mathrm{ADH}$ experienced over the entire experimental period. In changing column values of occurrence matrices, periodically zeros were created due to non- 
collection as opposed to an observed absence. If this non-collection zero occurred between two observations of presence, a presence was recorded in the cell with no experimental observation. Otherwise, cells with no experimental observation were recorded as absences.

Succession Interval (SI) Performance

The same 24 contingency tables created for determining SI widths (three contingency tables, each with different column values, for each of eight species) were also used to assess the performance of SIs. In the same manner, two additional sets of contingency tables were created solely from either 2009 ( $\mathrm{n}=20$ pig corpses) or 2010 ( $\mathrm{n}=31$ pig corpses) corpse collections for each of eight species. Observations were made for three general situations: a corpse collection compared to a SI established by a contingency table resulting from training data with either a (1) dissimilar, (2) similar, or (3) varied (both similar and dissimilar) temperature history. Each SI was calculated based on the scenario of presence of the studied species at $\alpha=0.05$. See table 3 of LaMotte and Wells (2000) for all maximum observed frequency values $(x)$ of species presence for which a specified time period since death can be rejected from a PMI estimation given a desired confidence level and number of categories (e.g. for the presence/absence of one species the number of categories is two). The frequency with which each single observation of presence as well as the entire relative presence period of an experimental corpse was encompassed (i.e. smaller than or equal to) by the SI was recorded. 


\section{Dissimilar Temperature History Comparisons}

The performance of dissimilar temperature comparisons was evaluated by determining the number of times the entire presence period and each single observation of presence on experimental carcasses exposed in 2009 were encompassed by the 2010 training data SI (20 comparisons) and vice versa (31 comparisons).

\section{Similar Temperature History Comparisons}

The performance of similar temperature comparisons was evaluated by removing a random subset of corpses from the training data used to create a contingency table for a particular year (three of 20 removed from 2009 and five of 31 removed from 2010). The removal of three and five corpses, respectively, from the 2009 and 2010 contingency tables was chosen in order to remove a similar proportion of corpses in each year, while maintaining a training dataset capable of determining a SI. These subsets of corpses were compared to the reduced dataset from which they were removed to determine the frequency of entire presence period and single occurrence observations encompassed by the reduced dataset SI. This procedure was performed ten times and the average was recorded.

\section{Varied Temperature History Comparisons}

A contingency table including data collected from all three years contains experimental corpses with varied temperature histories. Like the similar temperature history comparisons, a random 
subset of corpses from the entire training dataset was removed (eight of 53), removing a similar proportion of carcasses as for 2009 and 2010. These subsets of corpses were compared to the reduced dataset from which they were removed to determine the frequency of entire presence period and single occurrence observations encompassed by the reduced dataset SI. This procedure was performed ten times and the average was recorded.

\section{Results and Discussion}

Temperature Comparison Among Years

There are significant differences in accumulation of heat units per day across exposure periods when calculated with each of the chosen base temperatures, $0^{\circ} \mathrm{C}(\mathrm{F}=11.1326, p<0.001), 6^{\circ} \mathrm{C}$ $(\mathrm{F}=11.6022, p<0.001)$ or $10^{\circ} \mathrm{C}(\mathrm{F}=11.2703, p<0.001)$. Separate Tukey tests for multiple comparisons displayed the same relationship among exposure periods regardless of base temperature used to calculate average ADH. Exposure periods during 2008 and 2010 were significantly warmer than exposure periods in 2009 (Figure 2). These observed differences are important for exploring the effect of using a physiological time measure and can be used to interpret occurrence overlap, relative presence period, SI width and performance results. A base temperature of $0^{\circ} \mathrm{C}$ was used for all subsequent $\mathrm{ADH}$ calculations. 


\section{Occurrence Overlap and Relative Presence Period}

For seven out of eight species, occurrence overlap was greater when measured in ADH as compared to hours (Table 1). Both an increase in ADH-measured average occurrence overlap and low unlike temperature comparison values, indicate utility of $\mathrm{ADH}$ for describing insect succession for most of the studied species. Average occurrence overlap comparisons of corpses experiencing like-temperatures are centered on 0.5 (Table 1), indicating equal likelihood that occurrence overlap will be higher when calculated with either ADH or hours for corpses experiencing very similar temperature histories.

Relative presence periods were very similar whether calculated using hours or $\mathrm{ADH}$, the average difference between measurements is less than 0.01 (Table 2). The similarity of measurements can be, at least partially, attributed to the inconsistent effect of time measure on relative presence period across years. Compared to absolute time, ADH-measured relative presence periods were more often wider in cooler years, and more often narrower in warmer years, leading to very similar overall relative presence period averages (Table 2). Average occurrence overlap does indicate a temperature effect on succession but the minimal increase in occurrence overlap (average increase is $3.43 \%$ for the seven affected species) and inconsistent effect of temperature on relative presence period suggests that this effect is not linear and/or there is an inherent difference in succession between a cold and warm year.

One species, Necrophila americana (all instars), did not exhibit the same response in occurrence overlap to temperature as observed in the seven other species studied, instead ADH measured 
overlap decreased by one percent (Table 1). The tendency toward comparatively narrower ADHmeasured relative presence period during warm periods and wider ADH-measured relative presence period during cooler periods was not observed for two species, F. scalaris and $N$. americana (Table 2). These observations may be explained by the length of the collection period (14 days). After the first summer of exposures, (two pig corpses) a two week collection period was chosen because no carrion insects were observed after that time. During collections in subsequent summers, this collection period length did not include the entire SI for two species ( $N$. americana and $F$. scalaris). Recording the last day of presence as the last day of collection (when possibly it was several days later) could superficially increase absolute time-measured overlap because all corpses were exposed for very similar amounts of time but differed in ADH experienced.

\section{Comparison of SI Widths Using Hours and ADH}

SI width was narrower calculated in ADH compared to absolute time. For four of six species SI width was narrowest with minimum ADH column values (Table 3). For the remaining two species, both the $\mathrm{SI}_{\min }$ was always longest with minimum $\mathrm{ADH}$ column values, indicating a possible shortening of SI width (Table 3). Using ADH, and presumably other physiological time measures, decreases SI width for succession data collected across years with varying temperature histories, resulting in more precise SI estimations. 
Relationship of Overlap and Presence Period to SI Width

Insect species with smaller relative presence periods commonly have lower overlap measurements (Tables 1 and 2). Both metrics are used for assessing the relative usefulness of carrion species (Matuszewski 2011), but they can give contradictory indications. Species with smaller relative presence periods are attractive for use in estimating a precise SI but low overlap across corpses can result in a wider statistically supported SI than the average relative presence period indicates. As an example, $N$. surinamensis has the shortest average relative presence period, but this does not equate to the narrowest PMI width (C. macellaria), possibly due to a comparatively lower occurrence overlap. The species with the highest occurrence overlap measurements, consistently have larger relative presence periods and wider SI estimations, suggesting that narrow relative presence period is a better predictor of narrow SI width (Tables 2 and 3). In the evaluation of relative usefulness of carrion insect species, overlap and relative presence period can be used as preliminary indicators, but only after species-specific statistically supported SI widths are created can the relative utility of a species be determined.

Succession Interval (SI) Performance

An ADH-described SI is, on average, more accurate than an SI described in absolute time (Table 4). Further, among ADH-described SIs those binned by average ADH values are more often most accurate (Table 4). This observation is incongruous with the observation of narrowest SI widths when $\mathrm{ADH}$ minimum bins are used, evidence that in some cases, procedures aimed at shortening 
SI widths may result in less accurate SI estimations. The largest disparity between average absolute and physiological SI performance occurred among dissimilar temperature history comparisons, with improved SI accuracy when ADH was used. Although SI performance improved, the average dissimilar comparison performance is substantially lower than both similar and varied temperature history comparisons. In a few cases (e.g. C. macellaria 2009 to 2010 and N. surinamensis 2010 to 2009) dissimilar comparisons led to gross underperformance regardless of the time measure. The underperformance and large fluctuations in accuracy of dissimilar temperature comparison performance makes SI estimation using succession data with experimental temperature history differing from case temperature history inappropriate, whether described in days or ADH.

The performance of physiological and absolute time measures within a similar or varied comparison type, were congruent although consistently, physiological time measures were slightly more accurate than the absolute time measure. These data indicate the practical utility of either training data with: (1) corpses that all experienced like-temperature histories to the case history or (2) corpses that experienced a wide variety of temperature histories that includes the case temperature history. The SIs of the above described training datasets did not display an obvious increase in accuracy given a time measurement type, but ADH-measured SI widths are consistently narrower as compared to absolute time-measured SI widths, and therefore more precise. Although minimum ADH yields a more precise SI, average ADH interval use is advocated because these intervals often increase precision with comparatively higher accuracy. 
Also noted is a possible effect of sample size on SI performance. Prediction intervals derived from contingency tables with larger sample sizes (i.e. $n=31$ as compared to $n=20$ ) were more accurate. The similarity of the varied $(\mathrm{n}=52)$ and 2010 similar $(\mathrm{n}=31)$ temperature comparison indicates that the effect of sample size on SI accuracy may be restricted to sample sizes $\sim \leq 30$ and/or there is an interactive effect of sample size and temperature history on SI performance. The essentially equal performance of similar and varied temperature training datasets supports the practice of combining corpses with different temperature histories into a single training dataset in order to generate larger training datasets. 


\section{References}

Anderson GS. 2000. Minimum and maximum development rates of some forensically important Calliphoridae (Diptera). Journal of Forensic Sciences 45(4): 824-832.

Anderson GS and SL VanLaerhoven. 1996. Initial studies on insect succession on carrion in southwestern British Columbia. Journal of Forensic Sciences 41(4): 617-625.

Archer MS. 2003. Annual variation in arrival and departure times of carrion insects at carcasses: implications for succession studies in forensic entomology. Australian Journal of Zoology 51: 569-576.

Archer MS and MA Elgar. 2003. Yearly activity patterns in southern Victoria (Australia) of seasonally active carrion insects. Forensic Science International 132: 173-176.

Arnold CY. 1959. The determination and significance of the base temperature in a linear heat unit system. Proceedings of the American Society of Horticultural Science 74: 430-445.

Damos P and M Savopoulou-Soultani. 2012. Temperature-driven models for insect development and vital thermal regulations. Psyche: Article ID 123405. 13 pp.

Higley LG and NH Haskell. 2010. Insect Development and Forensic Entomology in: The Utility of Arthropods in Legal Investigations, $2^{\text {nd }}$ edition. JH Byrd and JL Castner eds. CRC Press, Boca Raton, FL, USA, pp. 389-403.

Kontodimas DC, PA Eliopoulos, GJ Stathas and LP Economou. 2004. Comparative temperaturedependent development of Nephus includes (Kirsch) and Nephus bisignatus (Boheman) (Coleoptera:Coccinellidae) preying on Planococcus citri (Risso) (Homoptera: Pseudococcidae): Evaluation of a linear and various nonlinear models using specific criteria. Physiological Ecology 33(1): $1-11$. 
LaMotte LR and JD Wells. 2000. $p$-values for postmortem intervals from arthropod succession data. Journal of Agricultural, Biological, and Environmental Statistics 5(1): 58-68.

Lord WD, EP Catts, DA Scarbor and DB Hadfield. 1986a. The green blow fly, Lucilia illustris (Meigen), as an indicator of human post-mortem interval: a case of homicide from Fort Lewis, Washington. Bulletin of the Society for Vector Ecology 11(2): 271-275.

Lord WD, RW Johnson and F Johnson. 1986b. The blue bottle fly, Calliphora vicina (=erythrocephala) as an indicator of human post-mortem interval: a case of homicide from suburban Washington D.C. Bulletin of the Society for Vector Ecology 11(2): 276-280.

Matuszewski S. 2011. Estimating the pre-appearance interval from temperature in Necrodes littoralis L. (Coleoptera: Silphidae). Forensic Science International 212: 180-188.

Matuszewski S, D Bajerlein, S Konwerski and K Szpila. 2010. Insect succession and carrion decomposition in selected forests of Central Europe. Part 2: Composition and residency patterns of carrion fauna. Forensic Science International 195: 42-51.

Megyesi MS, SP Nawrocki and NH Haskell. 2005. Using accumulated degree days to estimate the postmortem interval from decomposed human remains. Journal of Forensic Sciences 50(3): 618-626.

Michaud JP and G Moreau. 2009. Predicting the visitation of carcasses by carrion-related insects under different rates of degree-day accumulation. Forensic Science International 185: 78-83.

Michaud JP and G Moreau. 2011. A statistical approach based on accumulated degree-days to predict decomposition-related processes in forensic studies. Journal of Forensic Sciences 56(1): 229-232. 
Midgley JM and MH Villet. 2009. Development of Thanatophilus micans (Fabricius 1974) (Coleoptera:Silphidae) at constant temperatures. International Journal of Legal Medicine 123: 285-292.

Nabity PD, LG Higley and TM Heng-Moss. 2006. Effects of temperature on development of Phormia regina (Diptera: Calliphoridae) and use of developmental data in determining time intervals in forensic entomology. Journal of Medical Entomology 43(6): 1276-1286.

Nowatzki TM, JJ Tollefso and DD Calvin. 2002. Development and validation of models for predicting the seasonal emergence of corn rootworm (Coleoptera: Chrysomelidae) beetles in Iowa. Environmental Entomology 31: 864-873.

Oliveira-Costa J and CA de Mello-Patiu. 2004. Application of forensic entomology to estimate of the postmortem interval (PMI) in homicide investigations by the Rio de Janeiro Police Department in Brazil. Aggrawal's Internet Journal of Forensic Medicine and Toxicology 5(1): 4044.

Richardson MS and ML Goff. 2001. Effects of temperature and intraspecific interaction on the development of Dermestes maculatus (Coleoptera: Dermestidae). Journal of Medical Entomology 38(3): 347-351.

Schoenly KG. 1992. A statistical analysis of successional patterns in carrion-arthropod assemblages: Implications for forensic entomology and determination of the postmortem interval. Journal of Forensic Sciences 37 (6): 1489-1513.

Schoenly KG, GM Lee, JD Wells and WD Lord. 1996. Quantifying statistical uncertainty in succession based entomological estimates of the postmortem interval in death scene investigations: a simulation study. American Entomologist 42(2): 106-112. 
Simmons T, RE Adlam and C Moffatt. 2010. Debugging decomposition data- comparative taphonomic studies and the influence of insects and carcass size on decomposition rate. Journal of Forensic Sciences 55(1): 8-13.

Stevenson DE, GJ Michels, JB Bible, JA Jackman and MK Harris. 2008. Physiological time model for predicting adult emergence of western corn rootworm (Coleoptera: Chrysolmelidae) in the Texas High Plains. Journal of Economic Entomology 101(5): 1584-1593.

Tabor KL, CC Brewster and RD Fell. 2004. Analysis of the successional patterns of insects on carrion in southwest Virginia. Journal of Medical Entomology 41(4): 785-795.

VanLaerhoven SL. 2008. Blind validation of postmortem interval estimates using developmental rates of blow flies. Forensic Science International 180: 76- 80.

Vass AA, S-A Baishick, G Sega, J Caton, JT Skeen, JC Love and JA Systelien. 2002.

Decomposition chemistry of human remains: a new methodology for determining the postmortem interval. Journal of Forensic Sciences 47(3): 542-553.

Velasquez Y and AL Viloria. 2009. Effects of temperature on the development of the neotropical carrion beetle Oxelytrum discicolle (Brulle, 1840) (Coleoptera: Silphidae). Forensic Science International 185: 107-109.

Voss SC, SL Forbes and IR Dadour. 2008. Decomposition and insect succession on cadavers inside a vehicle environment. Forensic Science, Medicine, and Pathology 4: 22-32.

Williams H. 1984. A model for the aging of fly larvae in forensic entomology. Forensic Science International 25(3): 191-199.

Wells JD and LR LaMotte. 2010. Estimating the postmortem interval in: Forensic Entomology: The Utility of Arthropods in Legal Investigations, $2^{\text {nd }}$ edition. JH Byrd and JL Castner eds. CRC Press, Boca Raton, FL, USA, pp. 367-384. 


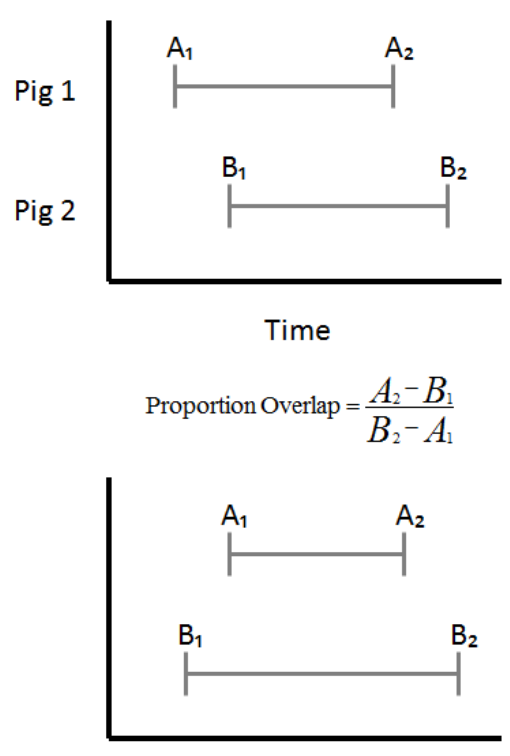

Proportion Overlap $=\frac{A_{2}-A_{1}}{B_{2}-B_{1}}$
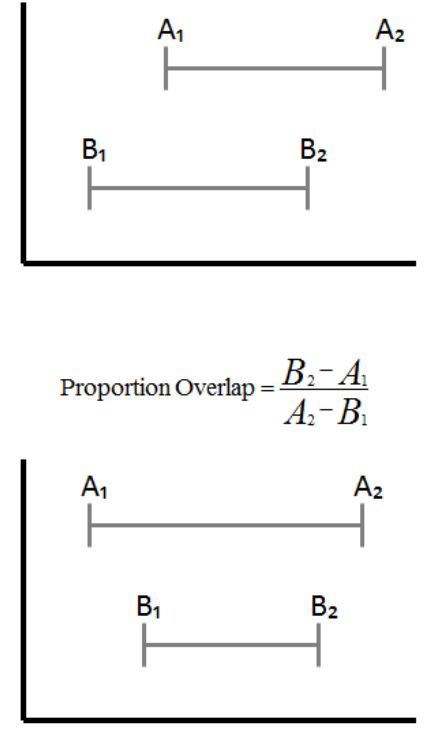

Proportion Overlap $=\frac{B_{2}-B_{1}}{A_{2}-A_{1}}$

Figure 1. Graphical representations and associated equations of four hypothetical types of occurrence overlap 
Average Daily ADH For Each Exposure Period

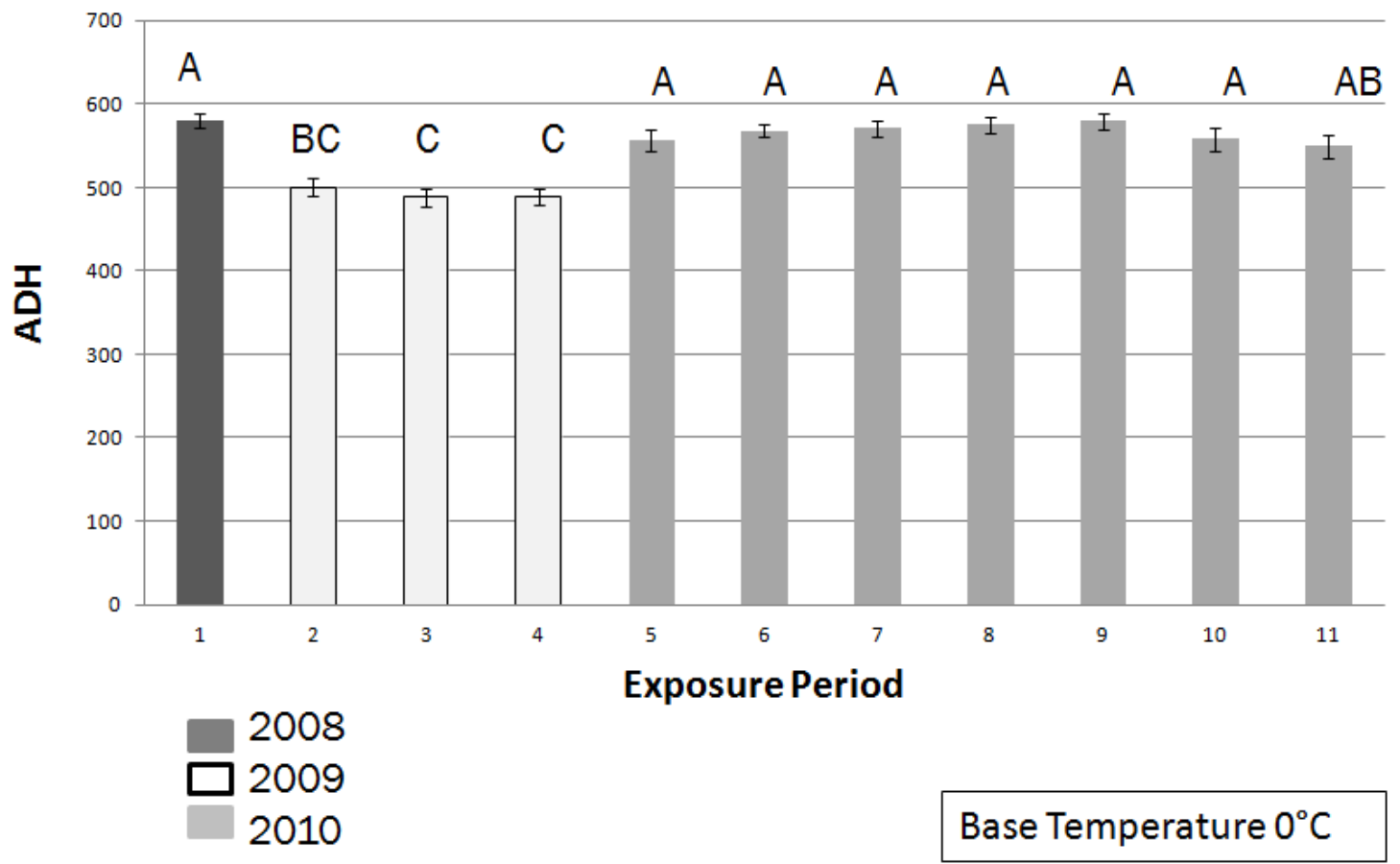

Figure 2. Average Daily ADH for exposure periods, each experienced by a different batch of pigs. All daily $\mathrm{ADH}$ values were calculated using a $0^{\circ} \mathrm{C}$ base temperature. Differing shading of bars indicates pigs exposed in different years. Exposure periods sharing the same letter do not significantly differ in temperature accumulation rates and therefore represent batches with similar temperature histories. Exposure periods with differing letters significantly differ in temperature accumulation rates. 
Table 1. Average occurrence overlap for absolute (hours) and physiological (ADH) time measures. Like temperature comparisons (i.e. \% overlap hrs vs. \%overlap ADH for within year and 2008 compared to 2010) and unlike temperature comparisons (i.e. 2009 compared to 2008 and 2010) range from one to zero. Values $>0.5$ indicate $\%$ overlap hours is more often greater; values $<0.5$ indicate $\%$ overlap $\mathrm{ADH}$ is more often greater.

\begin{tabular}{|c|c|c|c|c|c|}
\hline & & \% Overlap & \% Overlap & Like Temp & Unlike Temp \\
\hline Species & Life Stage & Hrs & ADH & Comparison & Comparison \\
\hline N. surinamensis & Adult & 0.22 & 0.24 & 0.52 & 0.09 \\
\hline N. americana & Larvae (all instars) & 0.48 & 0.47 & 0.61 & 0.63 \\
\hline C. maxillosus & Adult & 0.47 & 0.52 & 0.46 & 0.07 \\
\hline N.ruficollis & Adult & 0.21 & 0.24 & 0.46 & 0.17 \\
\hline F. scalaris & 3rd instar larvae & 0.33 & 0.38 & 0.47 & 0.29 \\
\hline C. macellaria & 3rd instar larvae & 0.30 & 0.31 & 0.63 & 0.37 \\
\hline L. illustris & 3rd instar larvae & 0.51 & 0.54 & 0.54 & 0.22 \\
\hline P. regina & 3rd instar larvae & 0.57 & 0.62 & 0.50 & 0.14 \\
\hline
\end{tabular}


Table 2. Average relative presence period for absolute (hrs) and physiological (ADH) time measures. Column 2008\&2010 represents the comparison of relative presence period measured in hours and ADH for each pairwise comparison in warm years. Column 2009 represents the comparison of relative presence period measured in hours and $\mathrm{ADH}$ for each pairwise comparison in the cool year. Values $>0.5$ indicate $\%$ overlap hours is more often greater; values $<0.5$ indicate $\%$ overlap $\mathrm{ADH}$ is more often greater.

\begin{tabular}{|c|c|c|c|c|c|}
\hline \multirow[b]{2}{*}{ Species } & \multicolumn{4}{|c|}{ Relative Presence Relative Presence } & \multirow[b]{2}{*}{2009} \\
\hline & Life Stage & Period Hrs & Period ADH & $2008 \& 2010$ & \\
\hline N. surinamensis & Adult & 0.1325 & 0.1321 & 0.74 & 0.39 \\
\hline N. americana & Larva (all instars) & 0.3524 & 0.3525 & 0.30 & 0.56 \\
\hline C. maxillosus & Adult & 0.1921 & 0.1932 & 0.64 & 0.35 \\
\hline N. ruficollis & Adult & 0.2144 & 0.2155 & 0.57 & 0.39 \\
\hline F. scalaris & Larva (all instars) & 0.2739 & 0.2747 & 0.27 & 0.39 \\
\hline C. macellaria & Larva (3rd instars) & 0.1691 & 0.1677 & 0.82 & 0.50 \\
\hline L. illustris & Larva (3rd instars) & 0.2495 & 0.2484 & 0.80 & 0.22 \\
\hline$P$. regina & Larva (3rd instars) & 0.3227 & 0.3221 & 0.79 & 0.24 \\
\hline
\end{tabular}


Table 3. Statistically supported SI widths calculated using one of three time measurement categories as column values in a contingency table; (1) days converted (\# of days contained in SI width x average ADH experienced over the entire experimental period), (2) ADH mean (average ADH experienced over the entire experimental period and (3) ADH narrow (shortest ADH amount experienced in any 24 hour period over the entire experimental period)

\begin{tabular}{|c|c|c|c|c|c|c|c|c|}
\hline & $\begin{array}{l}\text { Creophilus } \\
\text { maxillosus }\end{array}$ & $\begin{array}{l}\text { Necrobia } \\
\text { ruficollis }\end{array}$ & $\begin{array}{c}\text { Necrodes } \\
\text { surinamensis }\end{array}$ & $\begin{array}{l}\text { Necrophila } \\
\text { americana* }\end{array}$ & $\begin{array}{l}\text { Fannia } \\
\text { scalaris* }\end{array}$ & $\begin{array}{c}\text { Cochliomyia } \\
\text { macellaria }\end{array}$ & $\begin{array}{c}\text { Phormia } \\
\text { regina }\end{array}$ & $\begin{array}{l}\text { Lucilia } \\
\text { illustris }\end{array}$ \\
\hline Days & 10 & 8 & 6 & 5 & 4 & 6 & 9 & 8 \\
\hline \multicolumn{9}{|l|}{ Days } \\
\hline Converted & 5470 & 4376 & 3282 & 2735 & 2188 & 3282 & 4923 & 4376 \\
\hline ADH Mean & 4923 & 4376 & 3282 & 3282 & 2735 & 2735 & 4376 & 3829 \\
\hline ADH Narrow & 4708 & 3852 & 2996 & 3424 & 2996 & 2996 & 4280 & 3852 \\
\hline
\end{tabular}

(*)Denote species with occurrences on the last day of collection, therefore all 4 associated values represent $\mathrm{SI}_{\min }$. 
Table 4. The accuracy of succession intervals measured by the percentage of instances the SI contains either the entire presence period (E) or each single observation within a presence period (S) of an experimental pig used for comparison, at $\alpha=0.05$.

Comparisons belong to one of three categories: (1) dissimilar temperature comparisons (2009 to 2010 and 2010 to 2009), (2) similar temperature comparisons (2009 to 2009 and 2010 to 2010) and (3) varied temperature comparisons (2008-10 to 2008-10)

\begin{tabular}{|c|c|c|c|c|c|c|c|c|c|c|c|c|c|c|c|c|}
\hline \multirow[b]{2}{*}{ Species } & & \multicolumn{3}{|c|}{2009 to 2010} & \multicolumn{3}{|c|}{2010 to 2009} & \multicolumn{3}{|c|}{2009 to 2009} & \multicolumn{3}{|c|}{2010 to 2010} & \multicolumn{3}{|c|}{$2008-10$ to $2008-2010$} \\
\hline & & Day & Min & $\overline{\text { Avg }}$ & Day & Min & Avg & Day & Min & $\overline{\text { Avg }}$ & Day & Min & Avg & Day & $\mathrm{in}$ & $\mathrm{vg}$ \\
\hline \multirow[t]{2}{*}{ N. surinamensis } & $\mathrm{E}$ & 3.55 & 3.55 & 96.77 & 45.00 & 45.00 & 70.00 & 86.67 & 86.67 & 86.67 & 86.00 & & & 3 & & .00 \\
\hline & $\mathrm{S}$ & 4.64 & .64 & 96.43 & 4.29 & & & 93.73 & & 96.08 & 88.67 & & & & & \\
\hline \multirow[t]{2}{*}{ N. americana } & $\mathrm{E}$ & 6.77 & & & 00 & & & 90.00 & & & & & & & & \\
\hline & $\mathrm{S}$ & 0 & & & 1 & & & & & & 4 & & & & & \\
\hline \multirow[t]{2}{*}{ C. maxillosus } & $\mathrm{E}$ & & & 96 & .00 & & & & & & & & & & & \\
\hline & $\mathrm{S}$ & 100.0 & 0 & 99. & 0.90 & 0 & 33 & 97.00 & & 99.02 & 7 & & 9 & & & 20 \\
\hline \multirow[t]{2}{*}{ N. ruficollis } & $\mathrm{E}$ & & & 9 & .00 & & & & & 7 & & & & & & \\
\hline & $S$ & & & 98 & 4.69 & & 37 & & & 92.52 & & & & & & \\
\hline \multirow[t]{2}{*}{ F. scalaris } & $\Gamma$ & 74.19 & & 77. & 00.0 & & & & & 90 & 96 & & & & & \\
\hline & $\mathrm{S}$ & 2.03 & & 9 & 0.0 & & 77 & 2 & & 78 & 26 & & 4 & & & 42 \\
\hline \multirow[t]{2}{*}{ C. macellaria } & $\mathrm{E}$ & 5 & 4 & 38. & 0.00 & & & 90.00 & & 88 & 98.00 & & 8.00 & & & 0 \\
\hline & S & 58 & & 7 & 57 & & 0 & 0 & & 0 & 23 & & 23 & & & 95 \\
\hline \multirow[t]{2}{*}{ L. illustris } & F & 100.0 & 0.0 & 100.0 & 45.00 & & 65.00 & 76.67 & 76 & 93.33 & 100.0 & & .0 & & & .75 \\
\hline & $\mathrm{S}$ & & & & 3.01 & & & & & 98.91 & & & & & & 77 \\
\hline \multirow[t]{2}{*}{ P. regina } & $\mathrm{E}$ & 74.19 & 74.19 & 93.54 & 40.00 & 0 & 00 & 73.34 & 90.00 & 80.00 & 90.00 & & 90.00 & 88.75 & & .25 \\
\hline & $\mathrm{S}$ & 4.26 & 34 & 98.45 & 82.02 & 93 & 4.56 & 91.96 & 96. & 92.99 & 98.06 & & 0 & 96.68 & 90 & 02 \\
\hline \multirow[t]{2}{*}{ Average } & $\mathrm{E}$ & 03 & 7 & 3 & .50 & 0 & 3 & 4 & & 5.91 & 93.00 & & . & & & \\
\hline & $\mathrm{S}$ & .68 & 35 & .47 & 9.00 & 0.25 & 91.01 & 94.84 & 94 & 5.56 & 96.87 & & & 97.09 & 96.50 & 1 \\
\hline
\end{tabular}


Table S1. Contingency tables for all abundant and nonreoccurring insect species, each created with a different column value: (a) 1 day, (b) $428 \mathrm{ADH}$; the minimum ADH experienced in a 24 hour period over the entire experimental period and (c) $547 \mathrm{ADH}$; the average $\mathrm{ADH}$ for the entire experimental period. For tables (a) and (b) the column heading is the upper cut-off of the ADH range; the lower cut-off is 0.01 greater than the previous column heading.

Necrodes surinamensis (adult)

a.

\begin{tabular}{|c|c|c|c|c|c|c|c|c|c|c|c|c|c|c|}
\hline & 1 & 2 & 3 & 4 & 5 & 6 & 7 & 8 & 9 & 10 & 11 & 12 & 13 & 14 \\
\hline $\mathbf{P}$ & 1 & 3 & 22 & 31 & 27 & 13 & 11 & $\begin{array}{ll}6 & 1\end{array}$ & 2 & 1 & 1 & 0 & 0 & 0 \\
\hline A & 52 & 50 & 31 & 22 & 26 & 40 & 42 & 47 & 51 & 52 & 52 & 53 & 53 & 53 \\
\hline
\end{tabular}

b.

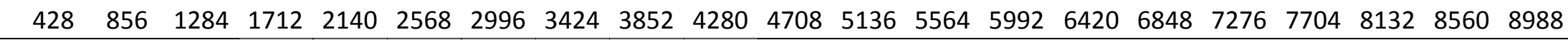

\begin{tabular}{|c|c|c|c|c|c|c|c|c|c|c|c|c|c|c|c|c|c|c|c|c|c|}
\hline$P$ & 0 & 1 & 3 & {$[14$} & 23 & 36 & 23 & 12 & 12 & 61 & 3 & 2 & 1 & 0 & 0 & 0 & 0 & 0 & 0 & 0 & 0 \\
\hline A & 53 & 52 & 50 & 39 & 30 & 17 & 30 & 41 & 41 & 47 & 50 & 51 & 52 & 53 & 53 & 53 & 53 & 53 & 53 & 53 & 53 \\
\hline
\end{tabular}

c.

\begin{tabular}{|c|c|c|c|c|c|c|c|c|c|c|c|c|c|c|c|c|c|c|}
\hline & 47 & 1094 & 1641 & 2188 & 2735 & 3282 & 3829 & 4376 & 4923 & 5470 & 6017 & 6564 & 7111 & 7658 & 8205 & 8752 & 9299 & 9849 \\
\hline $\mathbf{P}$ & 1 & 1 & 9 & 24 & 35 & 19 & 13 & & 2 & 1 & 0 & 0 & 0 & 0 & 0 & 0 & 0 & 0 \\
\hline A & 52 & 52 & 44 & 9 & 18 & 34 & 40 & 46 & 51 & 52 & 53 & 53 & 53 & 53 & 53 & 53 & 53 & 53 \\
\hline
\end{tabular}


Table S1. Continued

Necrophila americana (larva)

a.

\begin{tabular}{|c|c|c|c|c|c|c|c|c|c|c|c|c|c|c|}
\hline & 1 & 2 & 3 & 4 & 5 & 6 & 7 & 8 & 9 & 10 & 11 & 12 & 13 & 14 \\
\hline $\mathbf{P}$ & 0 & 0 & 0 & 2 & 1 & 8 & 19 & 28 & 32 & 36 & 40 & 37 & 33 & 35 \\
\hline A & 53 & 53 & 53 & 51 & 52 & 45 & 34 & 25 & 21 & 17 & 13 & 16 & 20 & 18 \\
\hline
\end{tabular}

b.

$\begin{array}{lllllllllllllllllllll}428 & 856 & 1284 & 1712 & 2140 & 2568 & 2996 & 3424 & 3852 & 4280 & 4708 & 5136 & 5564 & 5992 & 6420 & 6848 & 7276 & 7704 & 8132 & 8560 & 8988\end{array}$

\begin{tabular}{|c|c|c|c|c|c|c|c|c|c|c|c|c|c|c|c|c|c|c|c|c|c|}
\hline $\mathbf{P}$ & 0 & 0 & 0 & 0 & 1 & 1 & 2 & 3 & [ 10 & 20 & 31 & 31 & 40 & 39 & 38 & 37 & 31 & 26 & 19 & 1 & 0 \\
\hline A & 53 & 53 & 53 & 53 & 52 & 52 & 51 & 50 & 43 & 33 & 22 & 22 & 13 & 14 & 15 & 16 & 22 & 27 & 34 & 52 & 53 \\
\hline
\end{tabular}

c.

$\begin{array}{llllllllllllllllll}547 & 1094 & 1641 & 2188 & 2735 & 3282 & 3829 & 4376 & 4923 & 5470 & 6017 & 6564 & 7111 & 7658 & 8205 & 8752 & 9299 & 9849\end{array}$

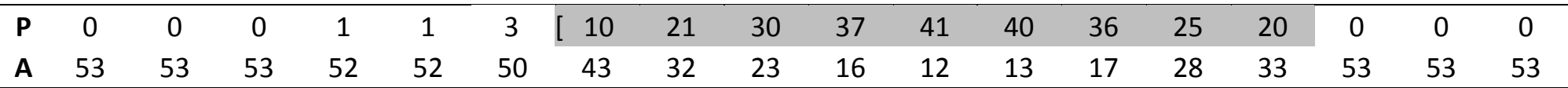


Table S1. Continued

Creophilus maxillosus (adult)

a.

\begin{tabular}{|c|c|c|c|c|c|c|c|c|c|c|c|c|c|c|}
\hline & 1 & 2 & 3 & 4 & 5 & 6 & 7 & 8 & 9 & 10 & 11 & 12 & 13 & 14 \\
\hline $\mathbf{P}$ & 3 & [ 23 & 40 & 49 & 48 & 35 & 24 & 17 & 11 & 6 & $5]$ & 1 & 0 & 0 \\
\hline A & 50 & 30 & 13 & 4 & 5 & 18 & 29 & 36 & 42 & 47 & 48 & 52 & 53 & 53 \\
\hline
\end{tabular}

b.

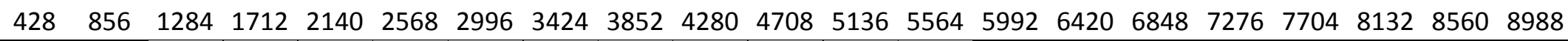

\begin{tabular}{cccccccccccccccccccccccc}
\hline $\mathbf{P}$ & 0 & 4 & {[} & 25 & 37 & 49 & 51 & 51 & 39 & 27 & 20 & 12 & 8 & 5 & 1 & 1 & 0 & 0 & 0 & 0 & 0 & 0 \\
$\mathbf{A}$ & 53 & 49 & 28 & 16 & 4 & 2 & 2 & 14 & 26 & 33 & 41 & 45 & 48 & 52 & 52 & 53 & 53 & 53 & 53 & 53 & 53 \\
\hline
\end{tabular}

c.

$\begin{array}{llllllllllllllllll}547 & 1094 & 1641 & 2188 & 2735 & 3282 & 3829 & 4376 & 4923 & 5470 & 6017 & 6564 & 7111 & 7658 & 8205 & 8752 & 9299 & 9849\end{array}$

\begin{tabular}{|c|c|c|c|c|c|c|c|c|c|c|c|c|c|c|c|c|c|c|}
\hline $\mathbf{P}$ & 1 & [ 5 & 31 & 50 & 51 & 47 & 33 & 21 & 12 & $6]$ & 2 & 1 & 0 & 0 & 0 & 0 & 0 & 0 \\
\hline A & 52 & 48 & 22 & 3 & 2 & 6 & 20 & 32 & 41 & 47 & 51 & 52 & 53 & 53 & 53 & 53 & 53 & 53 \\
\hline
\end{tabular}


Table S1. Continued

Necrobia ruficollis (adult)

a.

\begin{tabular}{|c|c|c|c|c|c|c|c|c|c|c|c|c|c|c|}
\hline & 1 & 2 & 3 & 4 & 5 & 6 & 7 & 8 & 9 & 10 & 11 & 12 & 13 & 14 \\
\hline $\mathbf{P}$ & 0 & 0 & 4 & 17 & 23 & 26 & 23 & 17 & 13 & 10 & 81 & 3 & 2 & 1 \\
\hline A & 53 & 53 & 49 & 36 & 30 & 27 & 30 & 36 & 40 & 43 & 45 & 50 & 51 & 52 \\
\hline
\end{tabular}

b.

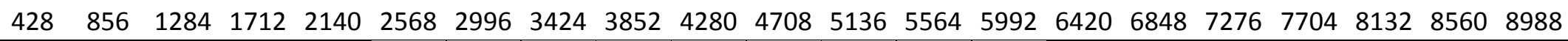

\begin{tabular}{|c|c|c|c|c|c|c|c|c|c|c|c|c|c|c|c|c|c|c|c|c|c|}
\hline $\mathbf{P}$ & 0 & 0 & 0 & 1 & 4 & [ 17 & 27 & 25 & 27 & 22 & 16 & 11 & 9 & 7 ] & 4 & 1 & 1 & 0 & 0 & 0 & 0 \\
\hline A & 53 & 53 & 53 & 52 & 49 & 36 & 26 & 28 & 26 & 31 & 37 & 42 & 44 & 46 & 49 & 52 & 52 & 53 & 53 & 53 & 53 \\
\hline
\end{tabular}

c.

$\begin{array}{lllllllllllllllllll}547 & 1094 & 1641 & 2188 & 2735 & 3282 & 3829 & 4376 & 4923 & 5470 & 6017 & 6564 & 7111 & 7658 & 8205 & 8752 & 9299 & 9849\end{array}$

\begin{tabular}{|c|c|c|c|c|c|c|c|c|c|c|c|c|c|c|c|c|c|c|}
\hline $\mathbf{P}$ & 0 & 0 & 0 & [ 8 & 21 & 27 & 28 & 22 & 17 & 11 & 9 & 4 & 1 & 1 & 0 & 0 & 0 & 0 \\
\hline A & 53 & 53 & 53 & 45 & 32 & 26 & 25 & 31 & 36 & 42 & 44 & 49 & 52 & 52 & 53 & 53 & 53 & 53 \\
\hline
\end{tabular}


Table S1. Continued

Fannia scalaris $\left(3^{\text {rd }}\right.$ instar larva)

a.

\begin{tabular}{|c|c|c|c|c|c|c|c|c|c|c|c|c|c|c|}
\hline & 1 & 2 & 3 & 4 & 5 & 6 & 7 & 8 & 9 & 10 & 11 & 12 & 13 & 14 \\
\hline $\mathbf{P}$ & 0 & 0 & 0 & 0 & [ 5 & 7 & 20 & 28 & 30 & 39 & 34 & 28 & 20 & 12 \\
\hline A & 53 & 53 & 53 & 53 & 48 & 46 & 33 & 25 & 23 & 14 & 19 & 25 & 33 & 41 \\
\hline
\end{tabular}

b.

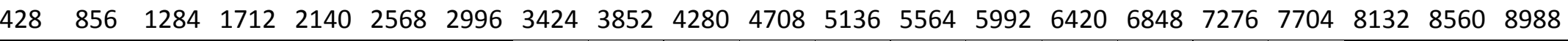

\begin{tabular}{cccccccccccccccccccccccc}
\hline $\mathbf{P}$ & 0 & 0 & 0 & 0 & 0 & 0 & 4 & {[} & 7 & 10 & 22 & 29 & 33 & 37 & 43 & 32 & 24 & 18 & 7 & 1 & 1 & 0 \\
$\mathbf{A}$ & 53 & 53 & 53 & 53 & 53 & 53 & 49 & 46 & 43 & 31 & 24 & 20 & 16 & 10 & 21 & 29 & 35 & 46 & 52 & 52 & 53 \\
\hline
\end{tabular}

c.

$\begin{array}{llllllllllllllllll}547 & 1094 & 1641 & 2188 & 2735 & 3282 & 3829 & 4376 & 4923 & 5470 & 6017 & 6564 & 7111 & 7658 & 8205 & 8752 & 9299 & 9849\end{array}$

\begin{tabular}{|c|c|c|c|c|c|c|c|c|c|c|c|c|c|c|c|c|c|c|}
\hline$P$ & 0 & 0 & 0 & 0 & 1 & [ 5 & 9 & 22 & 32 & 38 & 44 & 33 & 23 & 13 & 2 & 0 & 0 & 0 \\
\hline A & 53 & 53 & 53 & 53 & 52 & 48 & 44 & 31 & 21 & 15 & 9 & 20 & 30 & 40 & 51 & 53 & 53 & 53 \\
\hline
\end{tabular}


Table S1. Continued

Cochliomyia macellaria $\left(3^{\text {rd }}\right.$ instar larva $)$

a.

\begin{tabular}{|c|c|c|c|c|c|c|c|c|c|c|c|c|c|c|}
\hline & 1 & 2 & 3 & 4 & 5 & 6 & 7 & 8 & 9 & 10 & 11 & 12 & 13 & 14 \\
\hline $\mathbf{P}$ & 0 & 0 & 17 & 30 & 31 & 21 & 18 & 8 & 0 & 0 & 0 & 0 & 0 & 0 \\
\hline A & 53 & 53 & 36 & 23 & 22 & 32 & 35 & 45 & 53 & 53 & 53 & 53 & 53 & 53 \\
\hline
\end{tabular}

b.

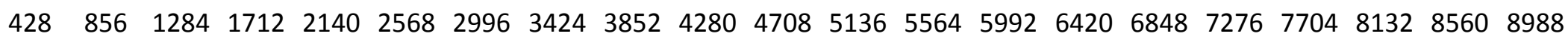

\begin{tabular}{cccccccccccccccccccccc}
\hline $\mathbf{P}$ & 0 & 0 & 0 & {[} & 9 & 18 & 33 & 30 & 22 & 20 & 14 & 3 & 0 & 0 & 0 & 0 & 0 & 0 & 0 & 0 & 0 \\
$\mathbf{A}$ & 53 & 53 & 53 & 44 & 35 & 20 & 23 & 31 & 33 & 39 & 50 & 53 & 53 & 53 & 53 & 53 & 53 & 53 & 53 & 53 & 53 \\
\hline
\end{tabular}

c.

$\begin{array}{lllllllllllllllllll}547 & 1094 & 1641 & 2188 & 2735 & 3282 & 3829 & 4376 & 4923 & 5470 & 6017 & 6564 & 7111 & 7658 & 8205 & 8752 & 9299 & 9846\end{array}$

\begin{tabular}{|c|c|c|c|c|c|c|c|c|c|c|c|c|c|c|c|c|c|c|}
\hline $\mathbf{P}$ & 0 & 0 & 3 & 20 & 35 & 30 & 23 & $14]$ & 1 & 0 & 0 & 0 & 0 & 0 & 0 & 0 & 0 & 0 \\
\hline A & 53 & 53 & 50 & 33 & 18 & 23 & 30 & 39 & 52 & 53 & 53 & 53 & 53 & 53 & 53 & 53 & 53 & 53 \\
\hline
\end{tabular}


Table S1. Continued

Phormia regina $\left(3^{\text {rd }}\right.$ instar larva)

a.

\begin{tabular}{ccccccccccccccc} 
& 1 & 2 & 3 & 4 & 5 & 6 & 7 & 8 & 9 & 10 & 11 & 12 & 13 & 14 \\
\hline $\mathbf{P}$ & 1 & {[} & 42 & 49 & 52 & 50 & 44 & 25 & 12 & $6]$ & 3 & 2 & 1 & 0 \\
$\mathbf{A}$ & 52 & 44 & 11 & 4 & 1 & 3 & 9 & 28 & 41 & 47 & 50 & 51 & 52 & 53 \\
\hline
\end{tabular}

b.

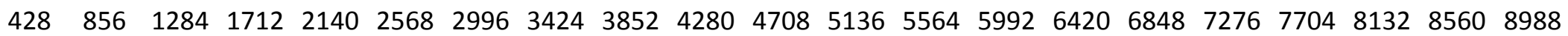

\begin{tabular}{cccccccccccccccccccccc}
\hline $\mathbf{P}$ & 0 & 1 & {[} & 9 & 27 & 45 & 52 & 53 & 48 & 45 & 37 & 22 & 7 & 3 & 2 & 2 & 1 & 0 & 0 & 0 & 0 \\
$\mathbf{A}$ & 53 & 52 & 44 & 26 & 8 & 1 & 0 & 5 & 8 & 16 & 31 & 46 & 50 & 51 & 51 & 52 & 53 & 53 & 53 & 53 & 53 \\
\hline
\end{tabular}

c.

\begin{tabular}{ccccccccccccccccccc} 
& 547 & 1094 & 1641 & 2188 & 2735 & 3282 & 3829 & 4376 & 4923 & 5470 & 6017 & 6564 & 7111 & 7658 & 8205 & 8752 & 9299 & 9849 \\
\hline $\mathbf{P}$ & 0 & 2 & {[} & 18 & 46 & 52 & 52 & 47 & 40 & 19 & 5 & 2 & 2 & 0 & 0 & 0 & 0 & 0 \\
$\mathbf{A}$ & 53 & 51 & 35 & 7 & 1 & 1 & 6 & 13 & 34 & 48 & 51 & 51 & 53 & 53 & 53 & 53 & 53 & 53 \\
\hline
\end{tabular}


Table S1. Continued

Lucilia illustris ( $3^{\text {rd }}$ instar larva)

a.

\begin{tabular}{|c|c|c|c|c|c|c|c|c|c|c|c|c|c|c|}
\hline & 1 & 2 & 3 & 4 & 5 & 6 & 7 & 8 & 9 & 10 & 11 & 12 & 13 & 14 \\
\hline $\mathbf{P}$ & 0 & 8 & 43 & 43 & 49 & 30 & 26 & 10 & 7 & 1 & 1 & 0 & 0 & 0 \\
\hline A & 53 & 45 & 10 & 10 & 4 & 23 & 27 & 43 & 46 & 52 & 52 & 53 & 53 & 53 \\
\hline
\end{tabular}

b.

\begin{tabular}{cccccccccccccccccccccccc} 
& 428 & 856 & 1284 & 1712 & 2140 & 2568 & 2996 & 3424 & 3852 & 4280 & 4708 & 5136 & 5564 & 5992 & 6420 & 6848 & 7276 & 7704 & 8132 & 8560 & 8988 \\
\hline $\mathbf{P}$ & 0 & 0 & {[} & 8 & 33 & 46 & 45 & 48 & 33 & 28 & 16 & 8 & 2 & 1 & 0 & 0 & 0 & 0 & 0 & 0 & 0 & 0 \\
$\mathbf{A}$ & 53 & 53 & 45 & 20 & 7 & 8 & 5 & 20 & 25 & 37 & 45 & 51 & 52 & 53 & 53 & 53 & 53 & 53 & 53 & 53 & 53 \\
\hline
\end{tabular}

c.

\begin{tabular}{|c|c|c|c|c|c|c|c|c|c|c|c|c|c|c|c|c|c|c|}
\hline & 547 & 1094 & 1641 & 2188 & 2735 & 3282 & 3829 & 4376 & 4923 & 5470 & 6017 & 6564 & 7111 & 7658 & 8205 & 8752 & 9299 & 9846 \\
\hline P & 0 & 0 & 19 & 47 & 51 & 46 & 31 & 19 & 8 & 0 & 1 & 0 & 0 & 0 & 0 & 0 & 0 & 0 \\
\hline & 53 & 53 & 34 & 6 & 2 & 7 & 22 & 34 & 45 & 53 & 52 & 53 & 53 & 53 & 53 & 53 & 53 & 53 \\
\hline
\end{tabular}




\section{Chapter 6: Summary and Conclusions}

In response to Daubert v. Merrell Dow Pharmaceuticals (1993) and/or a National Research Council report (2009), forensic entomology investigators have identified failures of current forensic entomology field research methodologies (Tomberlin et al. 2011a, 2011b, 2012, Michaud et al. 2012) including a lack of transparent/uniform data collection/presentation, (Tomberlin et al. 2012) inadequate sample sizes (Michaud et al. 2012) and description of successional variation (Tomberlin et al. 2011a, 2011b, Michaud et al. 2012) resulting in deficient inference strength (Michaud et al. 2012). Oddly, a second tendency of these authors, and others (VanLaerhoven 2010, Fiene et al. 2014), is to advocate an increase in basic ecological research, which will "...eventually produce guidelines that will meet the Daubert criteria (Tomberlin et al. 2011a)" instead of insisting on the timely development and use of forensic succession models that can statistically support PMI estimations.

For 14 years there has been a described novel theoretical model that can place a confidence interval about a succession interval (SI) estimate (LaMotte and Wells 2000), given the development of a succession dataset that is substantially larger than employed in any current study. The sheer amount of work required for this approach (exposure of $>20$, probably $>50$ carcasses) has likely resulted in this models disuse (Matuszewski 2011, 2012). In addition, the effect of many methodological practices necessary for generating a dataset of this magnitude have been, at best, understudied. Using the approach of LaMotte and Wells (2000) this work represents the first successful attempt to generate a succession dataset that can support an SI estimation at a common scientific level of confidence (95\%). Examples of the model are demonstrated with insect species that display requisite (abundant and nonreoccurring) characteristics. Questions 
central to succession data generation and application were characterized, including the effect of: repeated sampling, year, small-scale spatial variation, intercarcass distance, and measurement of time (absolute vs. physiological). This research provides many novel conclusions, but also provides valuable information to the field of forensic entomology in the context of statistical support of preliminary observations and intuitions of previous authors.

When using an insect succession approach, relatively few species are of true forensic utility (eight species of 266 collected). Admittedly, the species identified in this work will not be forensically important for every location, but many have wide ranging distributions and represent promising starting points for future investigators. The identification of a small, manageable, subset of the carrion insect community with exceptional forensic utility is a result valuable for many avenues of future research in forensic entomology. In order to use forensically relevant statistical models, sample sizes in carrion insect studies need to increase, substantially (i.e. at least $5 \mathrm{x}$ the average study). Evidence from this work suggests that researchers may benefit from sample sizes greater than 50 corpses. Focusing collection and identification efforts on a few species, as opposed to the entire carrion community, lessens researcher time and effort, leading to increased replication. The observed independence of intercarcass distance and community at the relatively narrow intercarcass spacing of $>30 \mathrm{~m}$ contributes to optimizing researcher time as well as field space.

Pooling multi-year succession data also facilitates the generation of large succession datasets.

The demonstrated differences in insect communities as a function of both year and characteristically similar mature oak woodlots are of initial concern because the majority of forensic insect succession studies are executed within one year and succession characterization of 
desired areas do not utilize more than one characteristically similar location. It would be exceedingly unlikely for a murder to occur in the same year and study site of a forensic insect succession study. Therefore, for a model to be forensically applicable, it needs to incorporate data collected from multiple characteristically similar sites over multiple years. Although community similarity is a common metric for studying successional variation, future studies could instead benefit from using the SI of forensically important insects as the dependent variable. This forensically targeted, not ecologically driven, approach can lead to results that are more directly applicable to casework.

The observed effect of sampling could possibly be avoided in future studies by collecting only those insects that are forensically useful. Further, many of these species are easily field identified and could be recorded/photographed (Michaud and Moreau 2009) as opposed to collected and preserved. This practice is impossible for most fly larvae, which must be collected for definitive identification. For larvae, a sampling effect may be avoided if relatively low rates of maggot removal ( $\geq 5 \%$ of total present) are used (Michaud and Moreau 2013).

A growing body of published work advocates the use of ADH-modeled succession (or portions of succession) for better prediction of species occurrence (Michaud and Moreau 2009, Matuszewski 2011, 2012, Matuszewski and Szafalowicz 2013). If multi-year succession includes carcasses exposed to significantly different temperature accumulation rates, it is expected that the use of $\mathrm{ADH}$ results in comparatively more precise and accurate SI estimations. Although ADH described succession models did not, generally, increase accuracy of SI estimations, use of ADH 
did result in more precise SI estimations. But, the use of ADH described succession models has limitations.

Extremely poor prediction interval performance was observed when single year training data were used to predict the SI of data from a year with a distinctly different temperature history. This observed underperformance is possibly due to the use of an inappropriate physiological model (i.e. the ADH model is probably not the most accurate description of the relationship of temperature and rate of insect succession) or possibly due to the sensitivity of insect communities and species-specific succession dynamics to non-temperature factors. Future succession models should contain carcasses exposed to similar temperature histories as compared to case temperature histories (either entirely or as part of a training dataset of carcasses with variable temperature histories) and should be described in $\mathrm{ADH}$, although the use of a different physiological model may improve precision and accuracy of SI estimations.

Lastly, although a form of cross validation was performed with the developed training dataset, indicating adequate performance for targeted confidence intervals, external validation is a necessity prior to forensic application. 


\section{References}

Fiene JG, A Sword, SL VanLaerhoven and AM Tarone. 2014. The role of spatial aggregation in forensic entomology. Journal of Medical Entomology 51(1): 1-9.

LaMotte LR and JD Wells. 2000. $p$-values for postmortem intervals from arthropod succession data. Journal of Agricultural, Biological, and Environmental Statistics 5(1): 58-68.

Matuszewski S. 2011. Estimating the pre-appearance interval from temperature in Necrodes littoralis L. (Coleoptera: Silphidae). Forensic Science International 212: 180-188.

Matuszewski S. 2012. Estimating the preappearance interval from temperature in Creophilus maxillosus L. (Coleoptera: Staphylinidae). Journal of Forensic Sciences 57(1): 136-145.

Matuszewski S and M Szafalowicz. 2013. Temperature-dependent appearance of forensically useful beetles on carcasses. Forensic Science International 229: 92-99.

Michaud JP and G Moreau. 2009. Predicting the visitation of carcasses by carrion-related insects under different rates of degree-day accumulation. Forensic Science International 185: 78-83.

Michaud JP, KF Schoenly and G Moreau. 2012. Sampling flies or sampling flaws? Experimental design and inference strength in forensic entomology. Journal of Medical Entomology 49(1): 1 10 .

Michaud JP and G Moreau. 2013. Effect of variable rates of daily sampling of fly larvae on decomposition and carrion insect community assembly: implications for forensic entomology field study protocols. Journal of Medical Entomology 30(4): 890-897.

National Resource Council. 2009. Strengthening forensic science in the United States: a path forward. National Academies Press, Washington, DC, 352 pp. 
Tomberlin JK, R Mohr, ME Benbow, AM Tarone and S VanLaerHoven. 2011a. A roadmap for bridging basic and applied research in forensic entomology. Annual Review of Entomology 56: 401-421.

Tomberlin JK, ME Benbow, AM Tarone and RM Mohr. 2011b. Basic research in evolution and ecology enhances forensics. Trends in Ecology and Evolution 26(2): 53-55.

Tomberlin JK, JH Byrd, JR Wallace and ME Benbow. 2012. Assessment of decomposition studies indicates need for standardized and repeatable research methods in forensic entomology. Journal of Forensic Research. 3:147.doi:10.4172/2157-7145.1000147

VanLaerhoven SL. 2010. Ecological theory and its application in forensic entomology, pp 493518. In Forensic Entomology: The Utility of Arthropods in Legal Investigations, $2^{\text {nd }}$ edition. JH Byrd and JL Castner eds. CRC Press, Boca Raton, FL, USA, 705 pp.

\section{Cases Cited}

Daubert v. Merrell Dow Pharmaceuticals, 509 US 579 (1993) 